University of Louisville

ThinkIR: The University of Louisville's Institutional Repository

Electronic Theses and Dissertations

8-2017

\title{
Diversity for diversity's sake? The relationship between diversity and school-level academic achievement.
}

Richard Aaron Wisman

University of Louisville

Follow this and additional works at: https://ir.library.louisville.edu/etd

Part of the Educational Leadership Commons

\section{Recommended Citation}

Wisman, Richard Aaron, "Diversity for diversity's sake? The relationship between diversity and school-level academic achievement." (2017). Electronic Theses and Dissertations. Paper 2786.

https://doi.org/10.18297/etd/2786

This Doctoral Dissertation is brought to you for free and open access by ThinkIR: The University of Louisville's Institutional Repository. It has been accepted for inclusion in Electronic Theses and Dissertations by an authorized administrator of ThinkIR: The University of Louisville's Institutional Repository. This title appears here courtesy of the author, who has retained all other copyrights. For more information, please contact thinkir@louisville.edu. 


\title{
DIVERSITY FOR DIVERSITY'S SAKE? \\ THE RELATIONSHIP BETWEEN DIVERSITY AND SCHOOL-LEVEL ACADEMIC ACHIEVEMENT
}

\author{
By \\ Richard Aaron Wisman \\ B.S., University of Louisville, 2009 \\ M.A.T., University of the Cumberlands, 2012
}

\begin{abstract}
A Dissertation
Submitted to the Faculty of the

College of Education and Human Development of the University of Louisville In Partial Fulfillment of the Requirements

for the Degree of
\end{abstract}

Doctor of Education

in Education Leadership and Organizational Development

Department of Education Leadership, Evaluation, and Organizational Development University of Louisville

Louisville, KY

August 2017 
Copyright 2017 by Richard Aaron Wisman

All rights reserved 



\title{
DIVERSITY FOR DIVERSITY'S SAKE?
}

THE RELATIONSHIP BETWEEN DIVERSITY AND SCHOOL-LEVEL ACADEMIC ACHIEVEMENT

\author{
By \\ Richard Aaron Wisman \\ B.S., University of Louisville, 2009 \\ M.A.T., University of the Cumberlands, 2012
}

A Dissertation Approved on

June 19, 2017

by the following Dissertation Committee:

Dissertation Director

W. Kyle Ingle

Marco A. Muñoz

Blake Haselton

Deborah Powers 


\title{
DEDICATION
}

This dissertation is dedicated to my wife, children, and mother

\author{
Damian Lea Wisman \\ Ella Monroe Wisman \\ Samuel Aiden Wisman \\ and \\ Selena Broyles Wisman,
}

from whom I have learned much about persistence. 


\section{ACKNOWLEDGMENTS}

Above all else, I would like to acknowledge the love of my wife and children, who continuously supported and encouraged me throughout this doctoral journey. None of this would have been possible without their love and support. Secondly, I must declare the importance of the intensive supports provided by my mentors, Dr. Kyle Ingle and Dr. Marco Muñoz. It would not be possible to over emphasize the importance of their wisdom, support, encouragement, and the clarity, richness, and timeliness of their critical feedback on this dissertation and many other works for which they have served as close mentors. It is to Drs. Ingle and Muñoz that I owe my sense of self-efficacy as an emerging educational researcher. Next, I wish to acknowledge Dr. Deborah Powers for her critical friendship and encouragement; I owe my sense of self-efficacy as an educational leader, largely, to her. Finally, on the support of Dr. Blake Haselton, I am greatly indebted for his insight and expertise in the historical and political context of the present study. 


\title{
ABSTRACT \\ DIVERSITY FOR DIVERSITY'S SAKE? \\ THE RELATIONSHIP BETWEEN DIVERSITY AND SCHOOL-LEVEL ACADEMIC ACHIEVEMENT
}

\author{
Richard Aaron Wisman
}

June 19, 2017

There is contention among researchers about how to best operationalize socioeconomic status (SES). This study seeks to provide an explicit definition of one metric of socioeconomic status, the diversity index (DI) of Jefferson County Public Schools (JCPS) and investigates its efficacy at predicting the aggregate academic achievement of students within a school, relative to other common metrics of SES which are analogous to components of the DI. Another purpose of this study is to investigate possible peer effects of socioeconomic diversity on low SES students. This study utilizes a correlational - multiple regression approach to explore relationships among study variables and to test two competing theories on the relationship between socioeconomic diversity and academic achievement of low SES students. As American educational aims are arguably shifting and its courts seem to be losing interest in mandating desegregation in schools, implications of resegregation must be considered. If not, then arguments for structuring within-school diversity might be misconstrued as doing so for the sake of diversity itself. Implications for practice and future research are discussed. 


\section{TABLE OF CONTENTS}

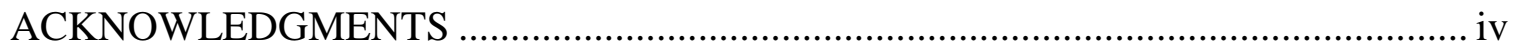

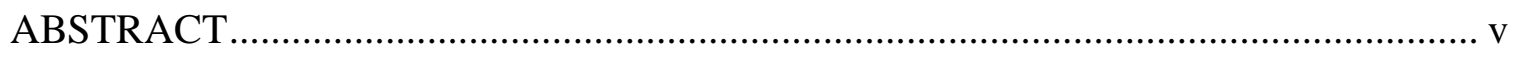

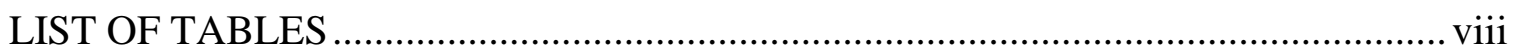

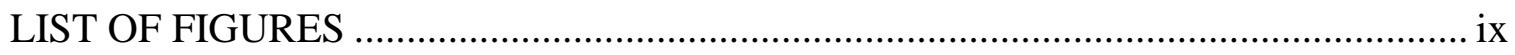

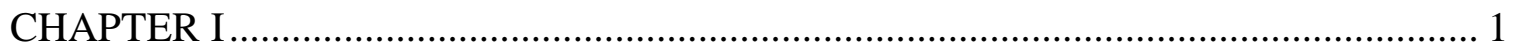

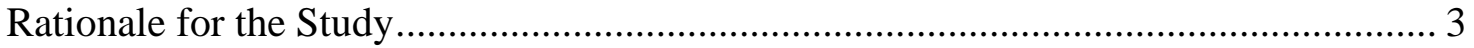

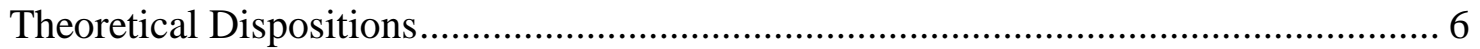

Statement of the Purpose and Research Questions .................................................... 7

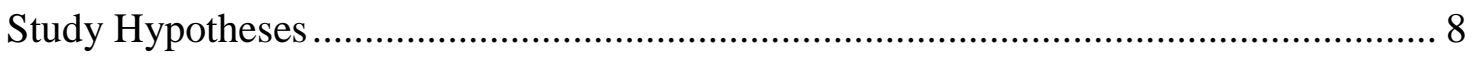

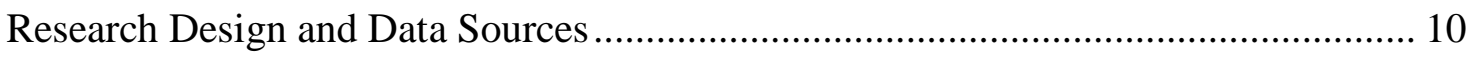

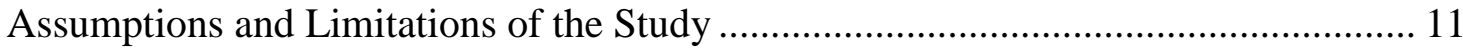

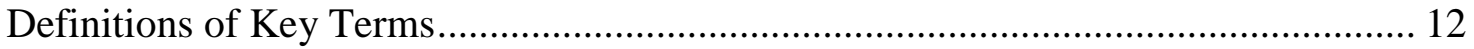

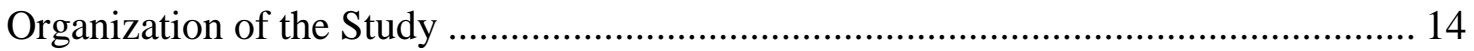

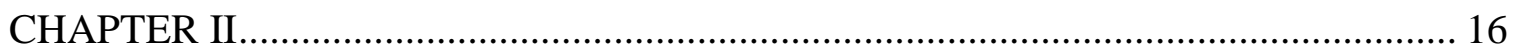

Challenges in Urban Education Environments ...................................................... 19

A Conceptual Framework for Understanding Diversity ........................................ 20

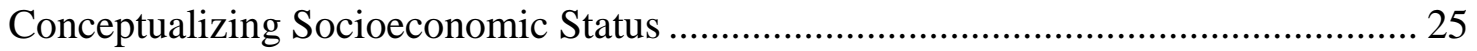

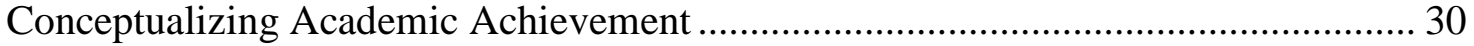

On the Relationship between SES and Achievement............................................. 34

The Theoretical Framework of Lam (2014) .......................................................... 34

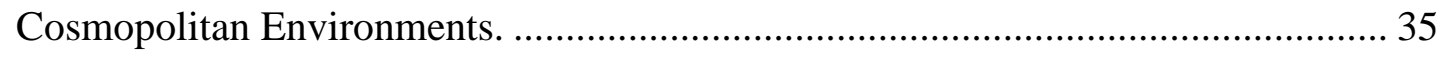

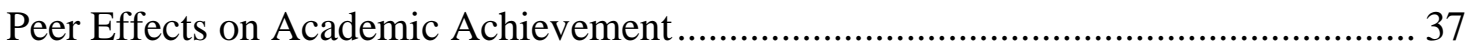

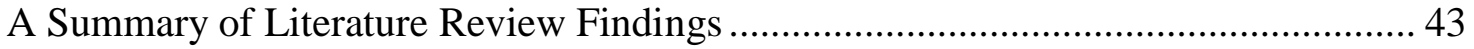

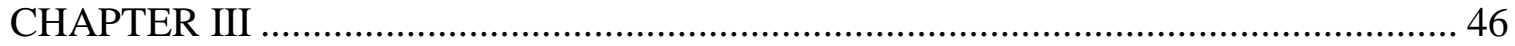

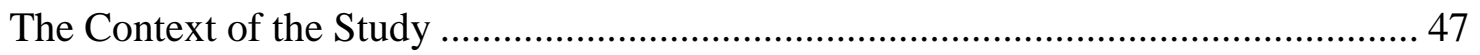


Restatement of the Research Questions ...................................................................... 50

Research Design and Statistical Procedures................................................................ 51

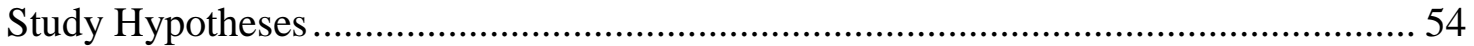

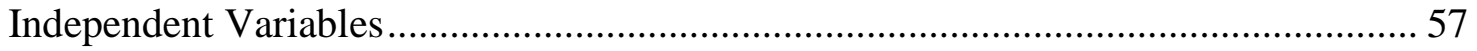

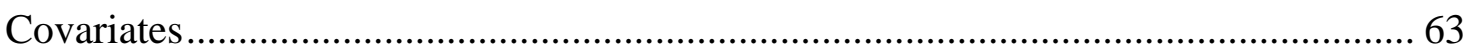

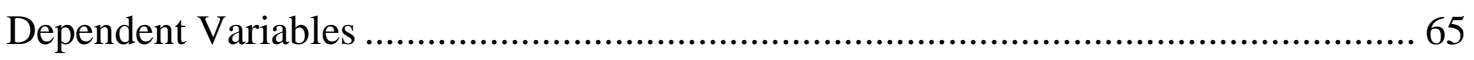

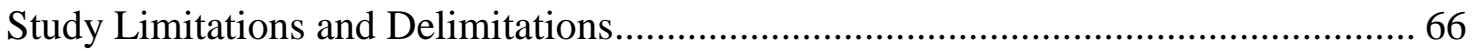

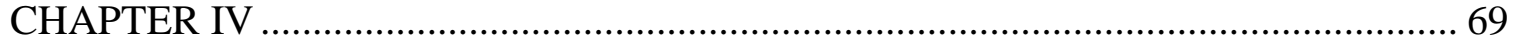

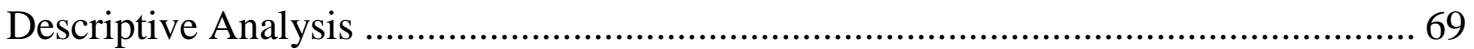

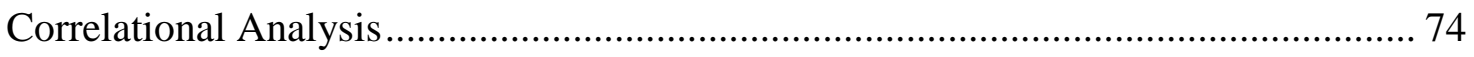

The Relationship between Diversity and School-Level Academic Achievement ........ 80

Research Question 1........................................................................................ 80

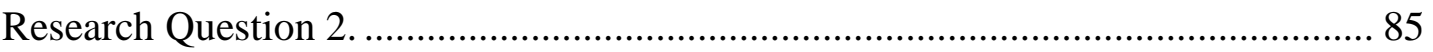

Low SES Students' Achievement Growth across Diversity Contexts ........................ 104

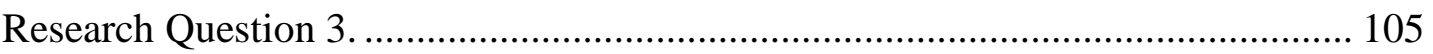

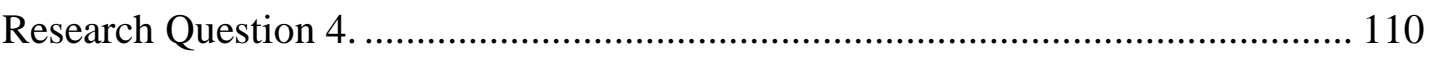

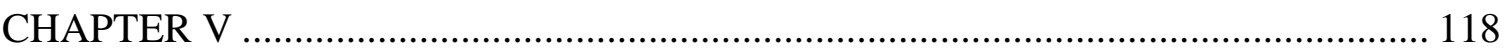

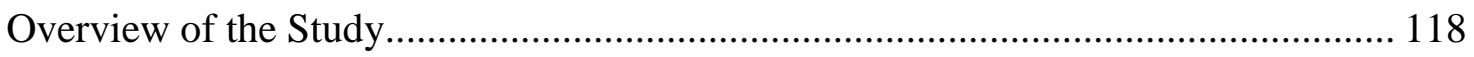

Restatement of the Purpose and Research Questions................................................. 120

Review of the Methodological Approach ........................................................... 122

Key Findings: On the Viability of the DI in Predicting Achievement....................... 122

Situating these Findings in the Literature ............................................................... 125

Key Findings: Conceptions of Diversity in Predicting Low SES Student Growth..... 128

Situating these Findings in the Literature ………................................................ 129

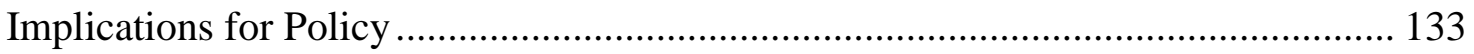

Implications for Future Research ........................................................................ 139

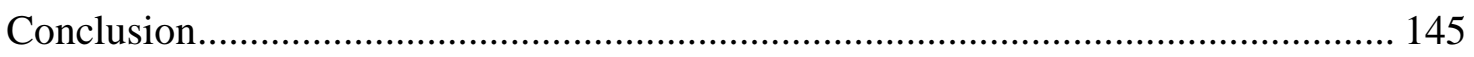

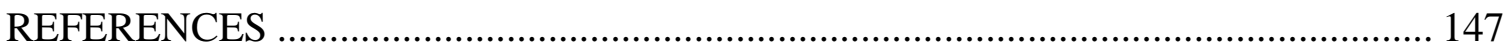

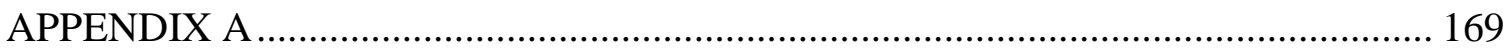

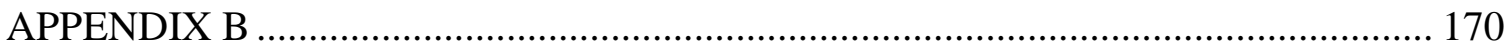

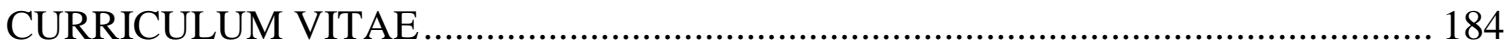




\section{LIST OF TABLES}

PAGE

TABLE 1: CLASSIFICATION CATEGORIES OF THE DI ........................................... 60

TABLE 2: MEANS AND STANDARD DEVIATIONS OF STUDY VARIABLES ..... 72

TABLE 3: PEARSON CORRELATIONS OF PREDICTORS ........................................ 76

TABLE 4: PEARSON CORRELATIONS OF PREDICTORS AND OUTCOMES....... 78

TABLE 5: OLS MODELS: DI AND READING ACHIEVEMENT ................................ 83

TABLE 6: OLS MODELS: DI AND MATH ACHIEVEMENT ……………………....... 85

TABLE 7: OLS MODELS: \% FRL AND READING ACHIEVEMENT ....................... 88

TABLE 8: OLS MODELS: \% MINORITY AND READING ACHIEVEMENT........... 90

TABLE 9: OLS MODELS: FRL X MINORITY AND READING ACHIEVEMENT... 93

TABLE 10: COMPARISON OF OLS MODELS AND READING ACHIEVEMENT.. 94

TABLE 11: OLS MODELS: \% FRL AND MATH ACHIEVEMENT ………………..... 97

TABLE 12: OLS MODELS: \% MINORITY AND MATH ACHIEVEMENT ................ 99

TABLE 13: OLS MODELS FRL X MINORITY AND MATH ACHIEVEMENT ...... 102

TABLE 14: COMPARISON OF OLS MODELS AND MATH ACHIEVEMENT ...... 104

TABLE 15: OLS MODEL: DI AND LOW SES STUDENT READING GROWTH ... 108

TABLE 16: OLS MODELS: DI AND LOW SES STUDENT MATH GROWTH ....... 109

TABLE 17: OLS MODEL: SSH AND LOW SES STUDENT READING GROWTH 112

TABLE 18: OLS MODELS: SSH AND LOW SES STUDENT MATH GROWTH.... 114 


\section{LIST OF FIGURES}

PAGE

FIGURE 1. OLS MODELS ESTIMATED BY RESEARCH QUESTION. 54

FIGURE 2. FACTORS IN ASSIGNING STUDENTS TO A SOCIOECONOMIC

CATEGORY. 58

FIGURE 3. DISTRIBUTIONS OF SCHOOL SOCIOECONOMIC DIVERSITY ........ 73

FIGURE 4. DI PREDICTING READING ACHIEVEMENT. ..................................... 82

FIGURE 5. DI PREDICTING MATH ACHIEVEMENT. ............................................ 84

FIGURE 6. \% FRL PREDICTING READING ACHIEVEMENT …............................ 87

FIGURE 7. \% MINORITY PREDICTING READING ACHIEVEMENT ..................... 89

FIGURE 8. FRL X MINORITY PREDICTING READING ACHIEVEMENT. ........... 92

FIGURE 9. \% FRL PREDICTING MATH ACHIEVEMENT. ...................................... 96

FIGURE 10. \% MINORITY PREDICTING MATH ACHIEVEMENT ......................... 98

FIGURE 11. FRL AND MINORITY PREDICTING MATH ACHIEVEMENT......... 101

FIGURE 12. DI PREDICTING LOW SES STUDENT READING GROWTH.......... 107

FIGURE 13. DI PREDICTING LOW SES MATH GROWTH................................. 108

FIGURE 14. SSH PREDICTING LOW SES READING GROWTH. ........................ 111

FIGURE 15. SSH PREDICTING LOW SES MATH GROWTH................................ 113 


\section{CHAPTER I}

\section{INTRODUCTION}

When we began this [student assignment plan], I think diversity was pretty much at the top... and as we evolved, choice has sort of emerged at the top, but I see something else pushing more at the top too and I see quality pushing up more above diversity.

Linda Duncan, Jefferson County Board of Education, September 13, 2016.

In 2007 the Supreme Court of the United States ruled two voluntary race-related school integration plans, one in Louisville, Kentucky (Meredith v. Jefferson County Board of Education et al., 2007) and another in Seattle, Washington (Parents Involved in Community Schools v. Seattle School District No. 1 et al., 2007) as unconstitutional. These cases questioned the constitutionality of race-based student assignment policies in light of the Equal Protection Clause of the Fourteenth Amendment. As a result of the Supreme Court's ruling, these school districts were required to more narrowly focus the use of an individual's race in student school-assignment decisions and, as Orfield, Frankenberg, and Garces (2008) remark, "By limiting the most common voluntarilyadopted methods for creating racially diverse schools at a time when resegregation is increasing in our nation, the Court's decision will greatly impact the ability of school districts to achieve the educational and social benefits of a diverse learning environment and create conditions for equal learning and opportunity for all students" (p. 97). At a 
time in which American educational aims are arguably shifting (Labaree, 2010), it is important to consider the possible implications of resegregation.

In 2000, Jefferson County Public Schools (JCPS), one of the largest urban school districts in the United States, was declared unitary, meaning the district met the diversity requirements of desegregation mandates and was no longer required to follow the mandated plan established in 1975 to remedy the district's existing, geographically-based school segregation (Phillips, Rodosky, Muñoz, \& Larsen, 2009). While JCPS was no longer required to utilize its student-assignment plan, the district voluntarily continued its use until the Court's 2007 decision in the Meredith case. However, the district maintains a core value that, "The differences of each are assets to the whole" (Jefferson County Public Schools, 2015, p. 2). The district currently utilizes a metric called the diversity index (DI), which uses U.S. Census block data of each student's neighborhood to ensure school "diversity", in a more inclusive sense.

The DI is a measure of diversity that takes into account race, poverty, and adult education attainment of students' neighborhoods and might therefore be considered a measure of socioeconomic status (SES), ensuring a constitutional approach to JCPS's continued commitment to educational equity and its core value of school diversity. In addition to the district's commitment to structuring within-school diversity, JCPS also considers school choice in student assignment decisions. A debate about the relative importance of school diversity and school choice has recently reignited in light of the school choice movement (Labaree, 2010) and as school districts regain significant control in how to turn-around their lowest performing schools. These competing interests of 
student diversity and school choice sit juxtaposed to one another, in part due to pronounced de facto racial and socioeconomic segregation present in the community.

\section{Rationale for the Study}

Socioeconomic status (SES) has long been a variable of keen interest in educational research, most notably because of its relationship to student achievement (Muñoz, Clavijo, \& Koven, 1999; Sirin, 2005; White, 1982). Yet, nearly a century of research on this relationship is not without critique. Harwell and LeBeau (2010) criticize the literature base on the lack of explicit definitions of the metrics of SES used in education research and, especially, the use of student eligibility for free/reduced-price lunch (FRL) as a proxy measure of SES. This study attempts to add to the literature by offering an explicit definition of one metric of SES, the DI, and investigates its efficacy in predicting academic achievement relative to other common predictors analogous to measures included in the DI, such as the percentage of students in a school qualifying for FRL and the racial composition of schools. As Harwell and LeBeau (2010) state, "this process would help to resolve important questions about whether the measurement of student SES should be based on a construct that is unidimensional or multidimensional" (p. 122). Moreover, the APA Task Force on Socioeconomic Status (APA, 2007) recommends that researchers "become better informed about state-of-the-art approaches to conceptualizing and measuring SES and social class" including the "intersection with measures of... race/ethnicity" (p. 26). No scholarly literature could be identified which evaluated the strength of the DI as a predictor of any student outcome variables, in spite of its use in student assignment decisions in the present school district since 2012. 
The context of the present study also provides an opportunity to investigate potential peer-mediating effects of socioeconomic diversity on students of low SES across a spectrum of schools exhibiting a wide range of student diversity in a large urban public school district in the Southeastern United States. While JCPS holds student diversity as a core value (Jefferson County Public Schools, 2015) there exists great heterogeneity in both student demographics and student achievement among schools in the district, providing a unique context for this study. A great deal of research has been conducted on the effects of peers on a range of student outcomes including criminal behavior (Ludwig, Duncan, \& Hirschfield, 2001), substance use (Gaviria \& Raphael, 2001) and body weight (Costa-Font \& Gil, 2003). Peer-effects have gained much attention as moderating variables in predicting academic achievement of students in poverty (Hanushek, Kain, Markman, \& Rivkin, 2003; Kang, 2007; Malecki \& Demaray, 2006; Vandenberghe, 2002). However, there is little research to guide school districts in capitalizing on the potential effects of peer socioeconomic diversity on students of low SES, if any such effects exist.

Studies of international scope, such as those by Kang (2007) and Vandenberghe (2002), have shown peer-effects to be significant moderating variables in predicting academic achievement across developed nations. In 2004, Guryan compared many school districts across the United States using the black exposure index and the dissimilarity index and found that integration reduced drop-out rates of Black students and did not significantly affect White student graduation rates. Hanushek et al. (2003) found a positive effect of peer achievement on achievement growth in Texas schools as measured by the Texas Assessment of Academic Skills (TAAS). Malecki and Demaray 
(2006) found evidence of a positive impact of social support, defined as "one's

perceptions of support behaviors from individuals in [their] social network" (p. 376) on the academic achievement of low SES students based on data from one urban middle school. However, Angrist and Lang (2004) demonstrated the effects of racial integration of schools were only modest and short-lived in Boston's Metropolitan Council for Educational Opportunity (Metco) program, which shipped Black students to surrounding school districts. This study seeks to validate the findings of peer-effects on student achievement from international, state and school-level analyses to one urban public school district and may help to inform student assignment planning in school districts with high geographic stratification of race and other socioeconomic factors.

Jefferson County Public Schools (JCPS) utilizes a managed school-choice Student Assignment Plan (SAP) in an effort to maintain school diversity (Phillips et al., 2009); although the district's definition of diversity has, necessarily, changed since Meredith v. Jefferson County Board of Education et al. (2007). However, the diversity guidelines, based upon the DI, have not been maintained across the school district, and the variation between average school socioeconomic diversity has increased. This trend has resulted in more schools with higher or lower concentrations of students in poverty and students of marginalized races/ethnicities and fewer schools exhibiting moderate levels of diversity (Frankenberg, 2017). The Commonwealth of Kentucky is required by No Child Left Behind (2001) and subsequent federal legislation (the Every Student Succeeds Act of 2015) to identify Persistently Low Achieving (PLA) schools and has done so, under current state statutes, since 2010. Many of the PLA schools in JCPS serve students who tend to be poor and belong to marginalized races/ethnicities. This trend highlights some 
of the apparent challenges of education in urban contexts; high concentrations of poverty and racial/ethnic segregation within schools create unique challenges to education such as teacher preparation, teacher migration and attrition, cultural competency, academic expectations, limited resources, peer effects, etc. (Delpit, 2006; Diem \& Frankenberg, 2013; Ingersoll, 2003; Jones \& Nichols, 2013; Ladson-Billings, 2001; Milner, 2010; Sirin, 2005). As the opportunity gap widens and resegregation continues to impact the potential for educational equity for the poor and marginalized, the question of structuring within-school diversity must be informed by the potential for peer socioeconomic diversity to impact student outcomes. If not, the argument for structuring school diversity might be based on the presumption that diversity is structured solely for the sake of diversity itself.

\section{Theoretical Dispositions}

Several, and sometimes competing, theoretical and conceptual frameworks are adopted for the purpose of grounding this study in the literature and guiding the methodological approach, study hypotheses, and analysis of the results. Attention is given to conceptualizing socioeconomic diversity (Harrison \& Klein, 2007), academic achievement (Labaree, 2010), and the relationship between SES and academic achievement (Blau, Lamb, Stearns, \& Pellerin, 2001; Lam, 2014). The methodological approach selected to address the research questions are grounded in the literature that explores peer effects and hypotheses are informed by the work of Lam (2014) and theories of diversity, or cosmopolitan environments (Blau et al., 2001). These theoretical dispositions are articulated in the literature review, which is found in Chapter 2. 


\section{Statement of the Purpose and Research Questions}

The purpose of this study was to investigate the DI as a predictor of academic achievement relative to analogues of student-level component factors and to investigate potential relationships between socioeconomic diversity on the achievement growth of low SES students. The following research questions are posed:

1. To what extent does the diversity index (DI) predict academic achievement, as measured by the percentage of students within a school scoring proficient or higher on state-mandated reading and math tests, while controlling for other school input and process variables?

2. What is the relative efficacy of the DI in predicting academic achievement to analogous student-level components: (a) the proportion of students receiving free or reduced-price lunch (FRL), (b) the racial/ethnic composition of the school and (c) the interaction between FRL and race/ethnicity, while controlling for other school input and process variables?

3. To what extent does the DI significantly predict academic growth among students of low socioeconomic status (SES), while controlling for other school input and process variables?

4. Does school-level socioeconomic heterogeneity significantly predict academic growth among students of lower socioeconomic status (SES), while controlling for other school input and process variables? 


\section{Study Hypotheses}

\section{Research Question 1:}

$\mathrm{H}_{0}$ : There is no relationship between the DI and the aggregate academic achievement of students within a school.

$\mathrm{H}_{1}$ : There is a positive and statistically significant relationship between the DI and the aggregate academic achievement of students within a school.

\section{Research Question 2a:}

$\mathrm{H}_{0}$ : There is no relationship between the percentage of students receiving FRL services and the aggregate academic achievement of students within a school.

$\mathrm{H}_{1}$ : There is a negative and statistically significant relationship between the percentage of students receiving FRL services and aggregate academic achievement of students within a school.

\section{Research Question 2b:}

$\mathrm{H}_{0}$ : There is no relationship between the percentage of Minority (Black and Latin American) students and the aggregate academic achievement of students within a school.

$\mathrm{H}_{1}$ : There is a negative and statistically significant relationship between the percentage of Minority (Black and Latin American) students and the aggregate academic achievement of students within a school. 


\section{Research Question 2c:}

$\mathrm{H}_{0}$ : There is no relationship between the interaction (product) of students receiving FRL services and the percentage of Minority (Black and Latin American) students and aggregate academic achievement of students within a school.

$\mathrm{H}_{1}$ : There is a negative and statistically significant interaction (product) between the percentage of FRL participants and Minority (Black and Latin American) students and the aggregate academic achievement of students within a school.

\section{Research Question 3:}

$\mathrm{H}_{0}$ : There is no relationship between the DI and the percentage of low SES students within a school making typical or higher academic growth.

$\mathrm{H}_{1}$ : There is a positive and statistically significant relationship between the DI and the percentage of low SES students within a school making typical or higher academic growth.

\section{Research Question 4:}

$\mathrm{H}_{0}$ : School-level socioeconomic heterogeneity is not related to the percentage of low SES students within a school making typical or higher academic growth.

$\mathrm{H}_{1}$ : School-level socioeconomic heterogeneity is positively and significantly related to the percentage of low SES students within a school making typical or higher academic growth. 


\section{Research Design and Data Sources}

The purpose of this study was to explore relationships among variables. These relationships were explored using a correlational - multiple regression approach (Abbott \& McKinney, 2012). The peer effects literature is dominated by the use of multiple regression techniques, as the general purpose is to explore possible relationships between variables attributable to one's peers and one's own academic outcomes, while controlling for other factors known to influence student outcomes. This study estimates a set of ordinary least squares (OLS) regression equations using a cross-section of data from the most recent school year (2015-2016) to address the research questions. Covariates known to be associated with academic achievement, but not correlated to other independent variables were utilized as controls in the present study, as recommended by Kang (2007); a correlation matrix between all study variables and the variance inflation factor (VIF) was monitored to ensure the threat of multicollinearity did not pose problems to any inferences drawn from the sample (Stevens, 1996). The unit of analysis in this study is school-level $(\mathrm{N}=130)$. Special and alternative schools were excluded from the present study, as these schools often serve a special need and DI values are not reported. Data for this study were drawn from public reports made available through the school district's and state education agency's websites. In addition, it was necessary to acquire aggregated data of low SES students for each school included in the present study. 


\section{Assumptions and Limitations of the Study}

All multiple regression models assume that measurement errors are independent and are normally distributed with constant variance (independence). Violations of this assumption can severely inflate the probability of a type I error. A scatterplot of standardized residuals against predicted values was considered to check the assumption of constant variance for each model constructed, as recommended by Stevens (1996). In addition, Cook's distance was monitored in order to identify and remove influential data. One limitation of multiple regression models is that they cannot be used as a basis for arguments of causality, but can simply inform our understanding of relationships between independent and dependent variables.

In addition to the methodological assumptions of the statistical models constructed in the present study, there are some philosophical assumptions worthy of mention here, including some axiological and epistemological assumptions. First, the axiological foundation of this study is to ensure all students are afforded an equitable educational opportunity. If peer socioeconomic diversity positively affects student outcomes, including measures of academic achievement such as those operationalized in this study, then there are implications for SAPs seeking to mitigate the effects of geographic segregation of race and other socioeconomic factors. Second, an important epistemological assumption of this study is that the DI is a valid construct of SES. The

DI is a neighborhood, or collective measure of SES. That is, it is based on students' neighborhood characteristics of U.S. Census block group data, not on individual student characteristics. The extent to which the DI is a valid measure of the average SES of a school is dependent upon the level to which the compositional hypothesis, described by 
Fischer (1976), is true in the U.S. Census block groups of the school district that frames the present study.

There are several key limitations also worthy of mention here. One is the age of the diversity categories of U.S. Census block groups used in assigning students a given socioeconomic category in the construction of the DI. The U.S. Census block group data from which the diversity categories are constructed are more than six years old and demographic shifts occurring across the district since the diversity categories were fixed may pose a limitation, as they may not actually reflect the true SES of the block group. However, it is important to note that this limitation is unavoidable, given the temporal separation of the U.S. Census and this dissertation. Another limitation may arise when attempting to generalize the results of the present study beyond the present school district. Context matters in education and caution should be taken in generalizing the results of this study. However, this study will add to the literature by investigating the possibility that socioeconomic diversity may be an important variable in school-level academic achievement and the academic achievement of low SES students.

\section{Definitions of Key Terms}

The following key terms are defined for the context of the present study:

Academic achievement - The proportion of students within a given school scoring proficient or higher on state-mandated reading and mathematics tests.

Academic growth - The proportion of students within a given school making typical or higher academic growth on state-mandated reading and mathematics tests, as defined by the Kentucky Assessment and Accountability System. 
Compositional hypothesis - Attributed to Fischer (1976), the compositional hypothesis states that certain types of people live in certain areas.

Diversity index - A measure of a school's aggregate socioeconomic status (SES) based upon students' residing Census block group characteristics, such as the median household income, average level of adult education attainment, and the percentage of non-White residence.

Free and reduced-price lunch participants - Students who (a) apply for and (b) qualify for federal assistance through the National School Lunch Program (NSLP, 2013).

Heterogeneity - Refers to a particular conceptualization of unit diversity accounting for the distribution of unit members represented across all categories of the unit composition. Such a conceptualization of diversity may be attributed to Blau (1977) in the social sciences or to Simpson (1949) in ecological studies.

Low socioeconomic status (SES) students - students residing in a Census block group with relatively lower household income and level of adult education attainment and relatively higher concentrations of non-White residence. In this study, low SES students are students classified as category one, according to the socioeconomic combined category (SECC) value used in the construction of the diversity index (DI).

Minority - The present study defines Minority as the percentage of students within a school that identify as one of Kentucky's historically marginalized races/ethnicities, i.e., Black or Latin American students. 
Peer effects - Variables attributable to one's peers which may affect any number of outcome variables. This study explicitly identifies the diversity index (DI) as a variable potentially effecting to the academic achievement of low SES students.

Socioeconomic Diversity - The distribution of social resources among members within a unit of analysis. In the present study, socioeconomic diversity of a school is operationalized by the diversity index (DI) reported by Jefferson County Public Schools (JCPS) in Louisville, Kentucky.

Socioeconomic Status (SES) - Refers to differential expectations of life outcomes based upon characteristics such as income, level of education attainment, gender, age, race/ethnicity, and other socio-political factors.

Student Assignment Plans (SAPs) - Refers to school district plans seeking to strategically distribute students residing within a school district to schools within the district.

\section{Organization of the Study}

This dissertation is organized as follows: Chapter 1 includes the introduction, a rationale for the study, a discussion of the theoretical underpinnings of the study, the study purpose, research questions, hypotheses, assumptions and limitations, and definitions of key terms. Chapter 2 provides a review of some salient literature used to conceptualize diversity, academic achievement, socioeconomic status, and the relationship between peer socioeconomic diversity and academic achievement while making explicit some common methodological approaches utilized in the peer effects literature. Chapter 3 describes the study context, methodological approach and 
procedures to address the research questions, and concludes with assumptions and limitations of the study. In Chapter 4, the results of the analysis are offered - including descriptive, correlational, and regression analyses. Finally, a summary of key findings and implications for policy, practice, and future research are discussed in Chapter 5. 


\section{CHAPTER II}

\section{LITERATURE REVIEW}

It is clear, after decades of educational research, that socioeconomic status (SES) is strongly associated with academic outcomes from the earliest years through the latter years of schooling, such that the higher the student's SES, the more positive the outcomes (Caldwell \& Ginther, 1996; McKown \& Weinstein, 2006; Muñoz et al., 1999; Sirin, 2005; White, 1982). However, much controversy exists about how to best operationalize SES (Bornstein \& Bradley, 2003; Diemer, Mistry, Wadsworth, Lopez, \& Reimers, 2013; Harwell \& LeBeau, 2010; Lucas, Beresford, Chapa, \& Yun, 2010). It seems as though the best one can do is to justify the metric of SES utilized within the context of a study (Harwell \& LeBeau, 2010; Oaks \& Rossi, 2003). While the complete review of measures of SES is well beyond the scope of this dissertation, and is arguably impossible within the scope of any paper (Lucas et al., 2010), the literature reviewed herein seeks to adequately justify the use of one school district's "diversity index" (DI) as a measure of socioeconomic diversity within the context of the present study. For an overview of the variation in conceptualization and operationalization of SES, I recommend Harrington, Marshall, and Müller (2006) and The Report of the APA Task Force on Socioeconomic Status (APA, 2007). This study conceptualizes SES using a socio-psychological analytical framework and operationalizes SES using the DI, a multiple-component measure of SES that captures students' neighborhood characteristics based upon Census 
block group data. The following research questions are posed: To what extent does the DI predict school-level academic achievement, while controlling for school input and process variables? What is the relative efficacy of the diversity index (DI) in predicting academic achievement to analogous student-level components: racial/ethnic composition of the school, the proportion of students qualifying for free or reduced-price lunch (FRL), and the interaction (or, product) of racial/ethnic composition and FRL, while controlling for school input and process variables? To what extend does the diversity index predict aggregated low SES student achievement growth, while controlling for school input and process variables? And, does within-school socioeconomic heterogeneity predict low SES student achievement growth, while controlling for school input and process variables?

In the district in which the present study occurs, a student assignment plan (SAP) incorporates a component of school choice; however, this district also uses the DI to establish parameters to maintain some level of student diversity within schools in a more inclusive sense than solely racial diversity, as mandated by Meredith v. Jefferson County Board of Education et al. (2007). While the school district voluntarily continued to use race as a heavily-weighted component in its SAP after it was declared unitary in 2000, the district was forced to cease the use of individual student race in student assignment decisions (Meredith v. Jefferson County Board of Education et al., 2007). However, race remains a component of the DI. One purpose of this study is to investigate the extent to which the DI predicts student achievement, operationalized by the percentage of students within a school scoring proficient or higher on state-mandated reading and mathematics 
tests, relative to other common measures of SES analogous to the component factors of the DI.

Another purpose of this study is to investigate the potential for socioeconomic diversity in schools to affect the achievement of low SES students. A brief review of some salient literature on peer-effects in academic achievement is offered. While studies of peer effects on academic achievement often utilize SES as a control variable to enhance validity arguments of causality for other factors (Guryan, 2004; Hanushek et al., 2003; Kang, 2007), the literature on the effects of socioeconomic diversity on student achievement among students of low SES at the level of the school district is sparse. This study provides implications for policy in district SAPs seeking to maximize student diversity and achievement in urban school districts with pronounced geographic stratification of SES.

This literature review begins by elucidating some relevant challenges often found in urban education contexts. Next, a framework for understanding diversity in the context of this study is provided. Then, a brief review of some salient literature to situate the conceptualization and operationalization of socioeconomic diversity in this study is presented, including the intersection of socioeconomic status and race. Next, a justification of the use of student test scores as a measure of academic achievement is offered, framed by Labaree's (2010) aims of American education, followed by an explanation of the theoretical frameworks for the relationship between SES and academic achievement from which the study hypotheses are derived. Finally, a review of the literature on peer effects with an emphasis on the hierarchical nesting of study contexts and general methodological approaches utilized in the literature is offered, while offering 
some critiques of prior studies on the effects of peer SES on academic achievement. A summary of key findings in the literature is presented as well.

\section{Challenges in Urban Education Environments}

The context of many urban public school systems presents unique challenges to education. For instance, Goldhaber, Lavery, and Theobald (2015) note the distribution of teachers with greater experience and qualifications disadvantages urban public schools, as high-minority/high-poverty schools tend to employ teachers with less experience and fewer credentials. Isenberg et al. (2013) and Sass, Hannaway, Xu, Figlio, and Feng (2012) demonstrated that teachers with higher value-added scores tend to teach in lowminority/low-poverty school contexts. Ream (2003) identifies reactive mobility, or student movement between schools due to unanticipated family factors, such as poverty, as a potential mediating variable in student achievement. Schools serving high concentrations of students in poverty may face challenges due to greater instances of reactive mobility.

In 1954, the United States Supreme Court ruled that school segregation was inherently unequal; since that ruling, school districts have faced mandates to integrate schools. However, in the past two decades, the Court's role in ensuring the desegregation of schools has waned (Diem \& Frankenberg, 2013). Increasingly, de facto segregation within urban communities has created enclave neighborhoods, or areas of high concentrations of low racial and socioeconomic diversity, resulting in urban communities comprised of a mosaic of enclave neighborhoods. In tandem with these demographic shifts, such as those apparent in the school district that serves as the context for the 
present study, changing political landscapes and school reform efforts are perpetuating the resegregation of urban schools (Diem \& Frankenberg, 2013; Pearce, 1980; SiegelHawley, 2011; Siegel-Hawley \& Frankenberg, 2012). With the advent of the school choice movement (Labaree, 2010) and the fight for neighborhood schools, coupled with the diminished urgency of the court to enforce desegregation efforts, communities may find themselves in difficult situations when attempting to voluntarily integrate schools within diverse communities. Indeed, communities may opt to abandon voluntary integration efforts for the fear of litigation such policies may elicit from the communities they serve, especially those community members with greater political power (Diem \& Frankenberg, 2013).

\section{A Conceptual Framework for Understanding Diversity}

Diversity is deceptive in its apparent simplicity to define. In simplistic terms, diversity may be defined as differences among individuals within a unit. Harrison and Klein (2007), however, offer the following definition: diversity "describe[s] the distribution of differences among the members of a unit with respect to a common attribute" (p. 1200). This definition is reminiscent of the concept of heterogeneity, which is often used synonymously with diversity. Heterogeneity not only accounts for the shear amount of differences (or a simple count of the different forms) present within a unit, but how evenly spread that diversity is. That is, heterogeneity accounts for the relative frequencies of different forms of the common attribute within a unit and not simply the number of differences represented in a group. It is also important to note that a measure of diversity of a unit is never absolute in and of itself; rather, a unit's diversity is relative to other units. That is, units can only be more or less diverse than other units; yet, there 
are some limits to diversity. The number of ways that one can conceptualize and operationalize differences within a group is vast and, as Harrison and Klein (2007) point out, "cumulative findings about the consequences of within-unit differences have been weak, inconsistent, or both" (p. 1199). The reason for the weak or inconsistent findings may be due to a lack of precision in constructing and operationalizing diversity and that, indeed, diversity consists not only of differences but the "substance, pattern, operationalization, and likely consequences of those three things differ remarkably" (Harrison \& Klein, 2007, p. 1200). They also emphasize the importance of aligning the conceptualization and operationalization of diversity constructs and critique the lack of explicit attempts to do so in the literature.

According to Harrison and Klein (2007), a concept of diversity within a unit may be indicative of separation, of variety, or of disparity among members of the unit. The concept of separation, or "differences in position or opinion among unit members" (Harrison \& Klein, 2007, p. 1200) assumes that (a) members of a unit differ along a continuum of the common attribute, (b) units differ in the distribution of their members along the continuum and, (c) the consequences of resulting differences between units occurs because of the presence or lack of group cohesion. For example, groups that are homogenous at one point along the continuum (minimum separation) may feel a strong sense of unity, which may lead to greater feelings of cooperation, trust, and social integration (Locke \& Horowitz, 1990), whereas groups with maximum separation are split equally among opposite ends of the spectrum; here, members may experience low cohesion with other members, inter-group fighting, and poor performance (Tsui, Ashford, St. Clair, \& Xin, 1995). 
Another concept of diversity is one of variety; that is, "differences in kind or categories" (Harrison \& Klein, 2007, p. 1200). One who sees diversity in this way assumes (a) members of a unit differ qualitatively, that is, each may be grouped into some number of categories with respect to the attribute; (b) units can be compared by how their members are equally spread among the categories; and (c) there is no symmetry of diversity, diversity increases as the number of individuals belonging to each category approaches equality. Blau (1977) is credited with coining the term heterogeneity in the social sciences in alignment with the variety concept of diversity. However, as Lau and Murnighan (1998) note, the meaning of this term has evolved into a variety of meanings in the literature. This concept of diversity emerged from the organizational literature pertaining to how organizations process information and solve problems. In the concept of diversity as variety, theorists such as Argote and Ingram (2000), Austin (2003), and Finkelstein and Hambrick (1996) postulate that variety among members of a unit may result in greater productivity and more creative products.

A final concept of diversity indicates disparity, or "differences in concentration of valued social assets or resources... among unit members" (Harrison \& Klein, 2007, p. 1200). With this concept of diversity in mind, theorists and researchers tend to focus on social inequalities, such as socioeconomic disparities, or disparities in resource availability. This construct assumes (a) members within a group differ in the amount of socially valuable resources available, (b) units differ in how resources are distributed among members, and (c) the differences between units in how resources are distributed among unit members lead to predictable outcomes. Minimum disparity occurs when all members possess equal shares of resources. Maximum disparity occurs when one 
member within a unit wields the majority of the resources and other members possess less. Theorists and researchers of disparity often predict inter-group competition and nonconformity with maximum disparity (Bloom, 1999; Pfeffer \& Langton, 1993; Siegel \& Hambrick, 2005).

In conceptualizing diversity, Harrison and Klein's (2007) constructs of diversity are used to frame the context of within-school socioeconomic diversity for the present study in relation to diversity as operationalized herein. It is important to note that the diversity index (DI) does not yield much information with respect to symmetry, as in the case of separation; yet, the distribution of student socioeconomic diversity within a school is likely to be symmetrical across schools. For example, a school with low socioeconomic diversity is likely to be homogenous - serving either a high proportion of low SES students or a high proportion of high SES students. These values correspond to lower or higher (extreme) values of the DI, respectively. A DI value in the middle of its theoretical minimum and maximum values may, however, indicate disparate forms of separation. For example, if all students within a school are of moderate SES, or the distribution of low, moderate, and high SES students is roughly equal, or if the case of maximum separation is true (that is, if students are equally split between low SES and high SES groups), the DI will be unable to differentiate between these forms of separation. While the DI represents the approximate average SES of a school based on discrete categories of student SES, it does not directly conform to the construct of variety either, as the DI is symmetrical and not a true measure of heterogeneity. A school's socioeconomic heterogeneity is greatest when the value of the DI is in the middle of its theoretical distribution. However, as is the case with separation, a maximum variety is 
not necessarily implied by a DI value in the middle of its theoretical distribution. The same is true for the construct of disparity.

The nature of the DI may limit the interpretation of results from this study if ambiguities arise from underlying differences between schools with respect to withinschool socioeconomic heterogeneity, especially if there are stark differences in the distributions of students of low, moderate, and high SES among schools with a DI value near the center of its theoretical minimum and maximum values. It should also be noted that the DI does provide an approximate average SES of the school and therefore an opportunity to explore the possible effects of school socioeconomic diversity on the academic achievement of low SES students by comparing low SES student test scores across a spectrum of socioeconomic contexts operationalized by the DI. However, the DI is a weighted average, thus its value is affected by the relative frequencies of students of low, moderate, or high SES, though it does not explicitly describe the distribution of student SES with a more traditional measure of spread, such as the standard deviation, as Harrison and Klein (2007) suggest. The DI does, however, take the relative proportions of resources available to students by categorizing students' SES. Therefore, I argue that the conceptualization and operationalization of socioeconomic diversity in this study is most closely aligned to Harrison and Klein's (2007) notion of disparity because the present study conceptualizes the average SES of a school as an amalgam of more traditional measures of SES (education attainment and income) with race, which is justified by centuries of racial discrimination in the United States (APA, 2007). Nonetheless, the potential interdependence of disparity with separation and variety is acknowledged. 
Harrison and Klein (2007) join the call for analyses that consider diversity across units within organizations (Jackson, Joshi, \& Erhardt, 2003; Tsui \& Gutek, 1999). This study seeks to do just that, by comparing the achievement outcomes of students across school socioeconomic contexts within a single school district. Furthermore, Harrison and Klein (2007) point to the scant research addressing the consequences of within-unit inequality in power, status, and other resources. This study explicitly defines diversity from a standpoint of disparity, as "socioeconomic diversity" suggests diversity in SES and its intersection with race among students within a school. This study might also be seen through the lens of variety, as the DI operationalizes SES into discrete categories. Although the DI is a continuous and symmetrical variable, students are assigned to a discrete category based on the relative SES of the neighborhood in which a student resides. Moreover, as SES may influence the beliefs and values among students, parents, and peers from a particular socioeconomic background (Benner, Boyle, \& Sadler, 2016;

Hornstra, Van der Veen, Peetsma, \& Volman, 2015; Lam, 2014; Schmidt-Wilson, 2013), this study may also be seen through the lens of separation. Therefore, this study may provide insights into the interaction between disparity, separation, and variety typologies; the call for which is made explicit by Harrison and Klein (2007).

\section{Conceptualizing Socioeconomic Status}

The preponderance of nearly a century of scholarly literature in the field of education suggests a positive and significant relationship between SES and academic outcomes (Battle \& Lewis, 2002; Muñoz et al., 1999; Sirin, 2005, White, 1992). Socioeconomic status has been demonstrated to affect not only expectations of an individual's academic outcomes but, more broadly, expectations of life outcomes. There 
is no lack of scholarly literature on the relation between SES and myriad other outcomes, such as longevity, risk factors for disease, depression, expected lifetime earnings, etc. (Adler \& Rehkopf, 2008; Adler \& Snibbe, 2003; Kessler \& Cleary, 1980; Mather, Banks, Joshy, Bauman, Phongsavan, \& Korda, 2014; Matthews, Gallo, \& Taylor, 2010; McLeod $\&$ Kessler, 1990). Socioeconomic status (SES) refers to differential expectations of life outcomes as a result of an individual's economic situation as well as other factors, such as race/ethnicity, level of parent education, profession, age, gender, and other sociopolitical factors (APA, 2007; Harrington, Marshall, \& Müller, 2006). There is little disagreement in the education literature about whether or not SES plays an important role in academic achievement. What is contestable is agreement on how to best operationalize SES. A review of all measures of SES, even when restricting measures to those employed in the education literature, is too cumbersome for a comprehensive review in any paper (Diemer et al., 2013; Lucas et al., 2010), the purpose of this study is to investigate the predictive power of one measure of SES, the DI, on academic achievement in a single urban public school district in the Southeastern United States. Yet, a brief review of some salient points should be made explicit here in an effort to highlight distinctions in the operationalization of SES, namely to distinguish between micro- and macro-level measures of SES also noted as individual measures of SES (micro-level) and "collective" or "neighborhood" measures (macro-level) and also to distinguish between single and multiple measures of SES; or, measures of SES which operationalize SES with a single variable (the former) or those which combine individual variables into a single, latent variable (the latter). 
Many studies on the relationship between an individual's SES and academic achievement reduce SES to a single, albeit important, variable, such as FRL or parent level of educational attainment. However, many critiques on such an approach can be found. Harwell and LeBeau (2010) critique the use of FRL as a proxy measure of SES for two important reasons: FRL is indirectly dependent on federal poverty guidelines, which are arguably flawed and outdated, and researchers often fail to justify or even acknowledge such a simplification of SES. Nonetheless, a large number of studies use FRL as a proxy for SES. According to Harwell, Maeda, and Lee (2004), 20\% of the studies published in the American Educational Research Journal and Sociology of Education between 1996 and 2004 used FRL as a proxy for SES. Sirin (2005) reviewed a large number of studies on SES and achievement and found that $16 \%$ of studies published between 1990 and 2000 used FRL as a proxy for SES. Although one argument for the use of FRL as a proxy to SES is the economy of data collection, it is possible that over-simplifications of reality may hamper a true understanding of the relationships between variables in nature and may undermine the generalizability of studies across educational contexts, as little is known about the demographics of FRL participants (Harwell \& LeBeau, 2010).

The conceptualization of collective or neighborhood SES is not germane to educational research. Ross and Mirowsky (2008) investigated the effects of neighborhood SES and found that individuals who live in socioeconomically disadvantaged neighborhoods had higher rates of physical impairment than those who live in socioeconomically advantaged neighborhoods, even after controlling for individual SES. To operationalize collective SES, Ross and Mirowsky (2008) utilized 
measures of education level (years of schooling and degrees), employment and work (occupational socioeconomic index), and economic wellbeing (such as household income, wealth, or economic hardship). They caution against the attribution of outcomes based on collective measures of SES without controlling for individual SES as "apparent neighborhood effects" might be due to the possibility that "certain people live in certain areas" (Ross \& Mirowsky, 2008, p. 166). This has been referred to as the "compositional hypothesis" (Araya, Dunstan, Playle, Thomas, Palmer, \& Lewis, 2006; Fischer, 1976). However, whereas Ross and Mirowsky (2008) investigated whether or not neighborhood SES has an impact on an individual's health; the purpose of the present study is to determine the extent to which a school's aggregate level of academic achievement can be explained by the neighborhood compositions of its students. Moreover, a growing body of literature on the relationship between academic achievement and the concentration of poverty within a school has demonstrated that the effects of high concentrations of poverty often extend beyond the effects of an individual's poverty (Banks, 2001; Orfield \& Lee, 2005; Vanderhaar, Muñoz, \& Rodosky, 2006).

Many studies operationalize collective SES using single variables, such as residing in social housing (Martens et al., 2014) or by simply asking principals what percentage of their students were of low SES, average SES, or high SES and then calculating a heterogeneity index similar to the Blau index of racial diversity or Simpson's index (1949) in ecological studies (Menzer \& Torney-Purta, 2012) while others use a combination of multiple and varied factors. Huynh, Borrell, and Chambers (2014), for instance, operationalize neighborhood SES by summing the z-scores of a number of variables within the constructs of education (the proportion of adults 18 and 
over with a high school diploma, the proportion of adults 18 and over with completed college education), wealth/income (the log of the median household income for 1999, the $\log$ of the median value of owner-occupied housing units, and the proportion of the households receiving interest, dividend, or net rental income), and occupation (the proportion of employed persons 16 years of age or older, in executive, managerial, or professional specialty occupations). Such forms of operationalization often contain varied formulaic amalgams of variables available through Census track or block-group data (Johnson, Hsiao, Jani, \& Master, 2011; Peterson et al., 2014). Another common measure of collective SES in the education literature is the percentage of students in a group (classroom, school, school district, etc.) who receive free or reduced-price lunch services (FRL). While it may be apparent that the economy of data collection compels researchers to utilize FRL as a proxy of SES, the least one can do is to justify the metric of SES used within a study (Harwell \& LeBeau, 2010; Oaks \& Rossi, 2003).

Constructs that include multiple components of SES are myriad and are derived from a multitude of theoretical foundations that might be traced back to Max Weber (APA, 2007; Bollen, Glanville, \& Stecklov, 2001; Breen, 2005; Hauser \& Warren, 1997). Many constructs emphasize the importance of specific component factors over others, based on theory, by assigning different weights to each factor while others weigh each factor equally. Diemer et al. (2013), Harwell and LeBeau (2010), Lucas et al (2010), Oaks and Rossi (2003), and Sirin (2005) caution that the component factors chosen for inclusion in an SES metric should be carefully considered within the context of its application. Resource-based measures of SES commonly include measures of income or wealth (Burnett \& Farkas, 2009; Engle \& Black, 2008) or level of parent educational 
attainment (Eshelman \& Rottinghaus, 2015) and the number of variables used to capture these measures is vast (Deimer et al., 2013). Other measures of SES include sociopolitical factors and are said to be prestige-based.

In the school district that frames the context of the present study, the DI is used to establish diversity guidelines for the maintenance of some level of diversity within schools in an attempt to counterbalance the geographic distribution of clusters of high concentrations of people living in poverty, which tend to be persons of minority status (U.S. Census, 2010). In spite of the diversity guidelines, many schools are not heterogeneous with respect to poverty or race. Many of the district's lowest performing schools are the lowest performing schools in the state and also have the highest concentrations of minority students and students living in poverty. Benner and Wang (2014) found that racial/ethnic marginalization in schools had a negative impact on student achievement which was compounded by other SES-related factors. The DI can be considered a multiple-component construct of SES that includes both resource-based (income and parent educational attainment) and sociopolitical factors (race). By first establishing a statistically significant correlation between the DI and academic achievement, it becomes possible to use the DI to investigate potential peer effects of diversity in SES among students of low SES.

\section{Conceptualizing Academic Achievement}

Academic achievement can be conceptualized in many ways. What one considers as academic achievement depends on the goals and aims of education one values. Labaree (2010) suggests three competing aims throughout the history of American 
education and reform: democratic equality, social efficiency, and social mobility. The aim of democratic equality, with the primary purpose of preparing citizens to participate in a capitalist republic, makes paramount the emphasis on access to public education for all and is arguably of great importance given the fact that America is increasingly diverse. Phillips, Rodosky, Muñoz, and Larsen (2008) used the ethnic fragmentation index, or the Absolute Diversity Index (Tam \& Bassett, 2004), and cross-classified models (HCM) to demonstrate that school integration plays a role in determining where students chose to live after matriculating out of high school; more students attending more racially diverse schools chose to live in diverse neighborhoods five years after graduating than students who attended less diverse schools. As the United States looks to education as a primary way to solve social problems (Labaree, 2010), it is important for policy makers and district administrators to consider structuring school diversity, as doing so may allow for the integration of races or social classes in the broader context of society, as Phillips et al. (2008) suggests.

From a social efficiency perspective, the ultimate goal of education is to prepare students to meet the demands of the market economy (Labaree, 2010). Labaree (2010) describes the progression of education from elementary through middle and high school and on into college and graduate studies as being shaped like a pyramid such that access to education is broad, indeed compulsory, in earlier levels of education. As one moves up toward higher and higher levels of education, the likelihood of a student continuing becomes increasingly smaller such that increasingly fewer students continue on to the next ; level of education. Labaree (2010) describes how the hierarchical structure of the job market runs alongside the hierarchical structure of education such that the market 
economy contains more jobs for lower educated workers with successively fewer but higher paying and more prestigious jobs available for those with increasing amounts of education. Students who exit the education system enter the labor queue at whatever level corresponds to their level of educational attainment (high school diploma, associate's degree, etc.). The literature on the effects of peers suggests that socioeconomic and racial diversity may increase levels of educational attainment and test scores for low SES students and students of color (Ewijk \& Sleegers, 2010; Guryan, 2004; Van Dorn et al., 2006; Vandenberghe, 2002). If the achievement gap between poor and minority students and their White and affluent peers is to be mitigated, and if the various hierarchies of the labor queue are to consist of a representative sample of potential workers of diverse races and socioeconomic backgrounds, then the diversity of schools may be a major factor in how education can mitigate the opportunity gap (Milner, 2010).

While the goals of democratic equality and social efficiency portray education as a public good, serving to create citizens for the capitalist republic or to meet the demands of the market economy, the goal of social mobility portrays education as a private good (Labaree, 2010). From the social mobility perspective, education consumers (parents and their children) utilize educational attainment as a means to ensure the maintenance of or to exceed the economic status from one generation to the next by accumulating more education credentials (such as a diploma) which can be exchanged in the market economy for a job. Moreover, students obtain more education credentials or education credentials from more "prestigious" educational institutions to obtain a competitive advantage over their peers, who are also striving to accumulate a larger number of 
credentials from more prestigious institutions. Even within a given institution, students may be tracked according to their perceived academic abilities, resulting in within-school tracking which may further compound issues of student, parent, and teacher expectations. From this perspective, test scores do not mean much, except the fact that higher test scores may provide greater opportunities for students to matriculate into more prestigious institutions. What really matters, from a social mobility perspective, however, is the number and level of perceived prestige of education credentials a student earns such that what is actually learned (knowledge, skills, etc.) becomes secondary to the attainment of a diploma or degree.

In the current era of education reform, dominated by the standards movement and the notion of school choice (Labaree, 2010), the aim of democratic equality - to provide access to education for the purpose of producing capitalist republicans - has been deemphasized in light of the goals of social efficiency and, especially, social mobility. For the goals of social efficiency and mobility, test scores seem to provide an indicator of academic achievement in the modern education reform movement, focused on preparing a work force for the market economy or for parents and their students to gain a competitive advantage for future competition amongst students' peers. Conceptualizing and operationalizing academic achievement using test scores is not uncommon in education literature and is justifiable in the modern reform era of American education. The present study utilizes test scores of state-mandated reading and mathematics tests as a measure of a school's aggregate academic achievement while recognizing the importance of equal access to educational opportunities. 


\section{On the Relationship between SES and Achievement}

In a Weberian sense, classes of society are based on life chances resulting from one's economic situation as well as other factors such as gender, age, and ethnicity. Weberian theories also recognize the struggle for rights and power among groups within society. Bourdieu's (1930/2002) ideas about social reproduction provide a critique on the power of educational institutions to perpetuate class distinctions based on their ability to deceive the individuals they serve into believing in the validity of existing power structures by "accepting the social subordination which is the consequence of failing to perform adequately in authorized assessment situations" (Harrington, Marshall, \& Müller, 2006, p. 567-568). It follows that education institutions play an important role in perpetuating, or not, the reproduction of educational and life outcomes of the students they serve as "students with low SES bear the entire brunt of tracking system[s] in a way that they get poor academic result[s]" (Lam, 2014, p. 326). However, theories of diversity, or cosmopolitan environments (Blau et al., 2001) propose that students of low SES may benefit when diversity approaches evenness, or when the relative proportions of individuals representing different groups approach equality, also known as heterogeneity (Blau, 1977; Simpson, 1949).

The Theoretical Framework of Lam (2014). A socio-psychological analytical framework based on the work of Lam (2014) is utilized for the conceptualization of the relationship between SES and academic achievement in this study. This framework "incorporate[s] micro familial factors into [the] macro factor of the tracking system," strengthening the predictability of outcomes exacerbated by institutionalized inequities

among tracks (Lam, 2014, p. 326). The DI includes micro-familial factors of students, 
approximated by Census-block data of two relatively common component factors of SES (income and level of adult educational attainment) and also includes a component of race. The inclusion of race in constructs of SES is not uncommon and is justified by "the legacy of many generations of discrimination in the United States" which has led to "the disproportionate representation of ethnic minorities in lower SES strata" (APA, 2007, p. 12).

Using a socio-psychological analytical framework, Lam (2014) elucidates the nesting of "micro familial factors into macro factor of the tracking system" (p. 326). In this framework, the nexus of student, family, and teacher expectations of academic achievement, presumably resultant from a student's socioeconomic background, directly impacts actual academic achievement of students within a tracking system. An individual student's socioeconomic background is more distal to academic achievement than variables more proximal to the influence of academic achievement, such as cultural capital, stress reaction and parenting as well as the expectations of those students, their parents, and their teachers. In the present study, it is presumed that the aggregate SES of a particular school (or track) might influence student, parent, and teacher expectations of academic achievement, which then exert a powerful influence on actual academic achievement (Lam, 2014).

Cosmopolitan Environments. Blau, Lamb, Stearns, and Pellerin (2001) invoke the voice of Dewey (1859/1952) in their acknowledgement of the importance of social learning in educational outcomes. Based on the presumption that "student learning depends on what students experience and observe in their daily lives" (p. 121), Blau et al. (2001) investigate the effect of neighborhood racial diversity on students' social studies 
test gains from grade 10 to 12 . They hypothesized that students attending schools in neighborhoods with no pronounced racial inequality, or cosmopolitan environments, would exhibit greater growth on social studies tests than students in neighborhood schools which exhibited greater racial inequality; a hypothesis confirmed by their analysis. That is, as the racial composition of neighborhood schools approached equality, students tended to show greater gains on social studies test scores.

While Blau et al. (2001) more narrowly focused on the potential impact of neighborhood racial diversity on academic growth on social studies tests, the present study seeks to test an extension of this hypothesis: that students attending schools with greater socioeconomic diversity will have greater gains on reading and math tests. Recall that the diversity index (DI) is not solely a measure of socioeconomic status (SES), but is a multiple-component measure of SES that includes race as a component. Lam's theoretical framework on the relationship between SES and academic achievement and Blau et al.'s compositional hypothesis conflict in their attribution of peer socioeconomic and racial diversity on academic outcomes of students. Lam's theoretical framework predicts that students of low SES attending low SES schools will perform worse than low SES students attending high SES schools, whereas Blau et al. might postulate that students of low SES attending schools with higher levels of socioeconomic heterogeneity will perform better than low SES students attending schools with higher or lower concentrations of low SES students. 


\section{Peer Effects on Academic Achievement}

The literature concerning peer effects on academic achievement is growing in light of education reform efforts. The findings are mixed, with some studies demonstrating significant and positive effects of peer achievement on one's own achievement (Carman, \& Zhang, 2012; Guryan, 2004; Kang, 2007; Van Dorn, Bowen, \& Blau, 2006; Vardardottir, 2013) while other studies show no effect (Angrist \& Lang, 2004; Arcidiacono \& Nicholson, 2005). As political landscapes continue to change, especially in light of the replacement of the No Child Left Behind Act of 2001 with the Every Student Succeeds Act of 2015, individual states and local school districts have regained significant flexibility in how to turnaround their lowest performing schools, reigniting debates about school choice and school competition at a time when resegregation is of growing concern. As urban public school districts seek to find ways to improve academic outcomes of marginalized students, a consideration of peer effects on the academic achievement of low SES students can inform district decision-making on policies, such as SAPs.

While student composition within schools undoubtedly weighs heavily on the mind of parents and policy makers alike, Hanushek, Kain, Markman, and Rivkin (2003) point to "difficulties in separating peer effects from other confounding influences" (p. 527). Education production functions and other multivariate analyses have given rise to a mix of results among study contexts. Vandenberghe (2002) investigated the magnitude of peer effects relative to other, more traditional peer-inputs to determine whether peer

effects matter more for students of higher or lower SES in affecting math and science test scores across member countries in the Organization for Economic Co-operation and 
Development (OECD). Vandenberg (2002) demonstrated that low performing students were more sensitive to peer group characteristics, but greater heterogeneity in SES comes at a cost, and Vandenberg (2002) was unable to provide any evidence to guide student grouping. The presence of peer effects has implications for understanding why increasing school choice may lead to inter-school ability grouping and suggests that heterogeneity is an important factor to consider in policy decisions seeking to maximize educational equity and efficiency. Vandenberghe (2002) suggests peer prior-achievement may be more important in predicting a student's academic achievement than SES or other inputs.

In another study investigating peer effects across developed nations, Kang (2007) utilized data from the Third International Mathematics and Science Study (TIMSS), finding a high degree of similarity between participating countries and a strong and positive association between peer achievement and one's own achievement, in spite of variation in ability grouping (also known as tracking). Kang (2007) cautions that research designs attempting to isolate peer effects should control for school-level fixed effects and individual student differences to account for within-school ability grouping, which will otherwise likely contribute to an upward bias of peer interaction effects. The findings from Kang (2007) on positive peer interactions suggest externality, that is, the way in which students are grouped in a classroom or school can impact academic outcomes. The present study attempts to validate the findings of Kang (2007) among schools within a single urban public school district in the Southeastern United States and offers implications for student assignment planning with diversity in mind. 
Positive peer effects were found across student test score distributions in a study of more than 3,000 schools in Texas (Hanushek et al., 2003) utilizing matched panel data of school operations constructed by the UTD Texas School Project. Hanushek et al. (2003) controlled student, school, and school-by-grade fixed effects and determined the variation in peer-group characteristics were attributable to peer effects on math achievement, reporting a 0.1 standard deviation increase in peer average achievement led to a 0.02 increase in individual student achievement. However, Hanushek et al. (2003) explicitly warn of the possibility that the reallocation of students across schools might positively impact the low achieving students assigned to schools with higher-achieving peers, while low achieving students assigned to schools with lower-achieving peers would bear the brunt of the costs attributable to the benefits granted to the former. If this is the case, it may at least be possible to adjust the diversity guidelines of schools within a district in order to maximize educational equity and efficiency.

Van Dorn et al. (2006) used data from the National Education Longitudinal Study, combined with neighborhood Census data (by zip code) and individual student, family, and school characteristics to examine the impacts of racial diversity and consolidated inequality on the likelihood of dropping out of school. The authors hypothesized that greater neighborhood diversity and lower consolidated inequality would be associated with a decreased likelihood of dropping out of school. This hypothesis was based on theories of diversity and cosmopolitan environments similar to Harrison and Klein's (2007) notion of diversity as variety. The sample included 4,079 students attending 418 schools. Racial and ethnic diversity of a neighborhood had a positive effect on school dropout, that is, greater heterogeneity in racial composition of a neighborhood equated to 
a greater chance of dropping out of school, refuting the authors' hypothesis. Like Guryan (2004), Van Dorn et al. (2006) demonstrated that Black students were less likely to drop out when other factors were controlled. To situate the work of Van Dorn et al. (2006) within the present study, it is important to note that only students attending neighborhood schools were considered. In the present study, the district's student assignment plan expends great resources in transporting students out of their zip codes in order to achieve the diversity guidelines established by the district. However, the measure of school diversity in the context of this study is dependent upon the neighborhood characteristics of the students who attend a given school. It should also be pointed out that the present study investigates the impact of socioeconomic diversity on student achievement on standardized test scores not the level of educational attainment, such as a high school diploma. This distinction provides an example of different and competing educational aims, specifically Lebaree's (2010) goals of social efficiency and social mobility. Nevertheless, Van Dorn et al. (2006) call for the study of the possibility that "beneficial effects of diverse environments for ethnic minorities are not realized until the diversity of an area, whether it is the school or neighborhood, approaches equality" (p. 116). The present study does just that, by investigating how socioeconomic diversity affects test scores of low SES students.

Angrist and Lang (2004) studied the impact of a student assignment plan seeking to racially integrate schools by busing Black students from areas of high geographic isolation within the city of Boston to more affluent schools with high concentrations of White students in surrounding school districts as part of the Metropolitan Council for Education Opportunity (Metco) program. The findings suggest that this method of 
school integration provides limited and short-lived positive peer effects among these Black students (most notably, 3rd grade girls), but did not significantly impact White, non-Metco student achievement. While the findings do not significantly support the positive association of peers, it is important to consider that the study is narrowly focused on Black students who are bused far from their neighborhood without considering whether or not the long bus rides affected a sense of school belonging or some other mediating factor, which could have negatively impacted achievement. In contrast, Guryan (2004) demonstrated that racial integration plans of a large number of large, urban public school districts in the 1970s reduced high school dropout rates of Black students. Similarly, Lee and Klugman (2013) found that the concentration of Latino students within a school had a positive effect on the achievement of 1st-grade Latino students of immigrant parents. While the present study considers race as an input variable, the DI reduces the impact of race on school assignment to one of several component factors of SES.

In their meta-analysis of the effects of peer SES on student achievement, Ewijk and Sleegers (2010) identify important trends in the results of the literature they reviewed. They found that studies vary in their attribution of peer-SES to academic achievement based on (a) the way that researchers conceptualize and operationalize SES, (b) the unit of analysis when defining a "group" of students and, (c) the covariates chosen or omitted from the regression models constructed; the peer-effects literature is dominated by multiple regression techniques. More specifically, composite measures of SES, or metrics that include multiple components, tend to result in higher effects attributable to peer SES than studies which use dichotomous variables (such as FRL 
status) or studies whose regression models include several individual average SES variables. It should be noted that in discussion of this trend, Ewijk and Sleegers (2010) fail to discuss the potential of multicollinearity to make the interpretation of results ambiguous. For example, one study that grapples with the interpretation of results is a study by Caldas and Bankston (1997), who found that schools in Louisiana with high concentrations of students in poverty tend to be schools with higher concentrations of Black students. While openly stating that SES and race are highly correlated, Caldas and Bankston (1997) justify their approach by pointing to the fact that race and SES are, indeed, not the same. The present study utilizes a composite measure of SES that combines a component of race with more traditional SES measures. If race is highly correlated with more traditional measures of SES and is used as a covariate, then the combination of race with these more traditional measures of SES will possibly provide a methodological mechanism to mitigate the effects of multicollinearity between race and SES (Stevens, 1996). The inclusion of race with measures of SES is at least theoretically justified by the years of racial inequality in the United States (APA, 2007). However, Hornstra et al. (2015) found a distinction between the two: in classrooms where ethnic diversity was greater, students of low SES tended to achieve higher reading comprehension scores than in classrooms with lower SES peers. The composition of students in the unit of analysis tends to favor studies whose "groups" are smaller than the level of the entire school. Researchers who elect to study individual classrooms typically yield higher effects attributable to peers than studies using cohorts (e.g., grade-levels) or schools. This trend suggests a possible limitation of the present study since intra-school tracking may further confound the results; however, it should be noted that the present 
study seeks to inform student school-assignment in districts with high geographic stratification of SES and cannot control for within-school tracking. Finally, covariates omitted to control for extraneous exogenous or endogenous effects, notably student priorachievement (e.g., Vanderhaar et al., 2006), run the risk of potential omitted variables bias, which can lead to overestimating the effects of peer SES. The present study takes into account prior student achievement by examining measures of student growth and controls for endogenous, school-level process variables while omitting school input variables which are highly correlated to the DI in an effort to mitigate the risk of multicollinearity.

\section{A Summary of Literature Review Findings}

As school districts continue to grapple with the question of whether or not to voluntarily structure within-school diversity, an exploration of all tangible benefits of diversity should be considered. While Brown v. Board of Education of Topeka (1954) made the inherent inequalities of segregation explicit, the Court's purview of the role of government in enforcing desegregation mandates has deteriorated since (Diem \& Frankenberg, 2013). School districts are left to decide whether the costs of structuring within-school diversity outweigh the potential benefits. The promise of achieving diversity in schools warrants further study as research to guide student assignment decisions of urban public school districts with high geographic stratification of SES and race remains limited. Moreover, much is left to be learned about the intersection of race and SES, as well as its impact on academic achievement (APA, 2007). This study fills a gap in the literature by offering an explicit definition of one metric, JCPS's diversity index (DI), to operationalize this intersection and explores its potential use in 
understanding how socioeconomic contexts might predict academic achievement of low SES students both within a school and between schools of an urban public school district with high geographic stratification of SES and race.

The peer effects literature is dominated by the use of regression techniques and have spanned multiple levels of analysis, from classrooms within an individual school to studies of international scope. Myriad specific regression approaches have been employed, from OLS (Caldas \& Bankston, 1997) models to hierarchical linear modeling (Benner et al., 2016, Chen, Chang, Liu, \& He, 2008) and logistic regression (Cherng, Calarco, \& Kao, 2013). Other studies have utilized regression discontinuity approaches (Vardardottir, 2013), meta-analytic approaches (Ewijk \& Sleegers, 2010) and multivariate latent growth curve analysis (Hornstra et al., 2015). Approaches to constructing these models have varied widely and include exploratory (Vanderhaar et al., 2006) and theoretically-based (Carman \& Zhang, 2011) models.

However, there is a scarcity of literature to guide SAPs in school districts seeking to maximize both student diversity and student achievement. One purpose of this study is to provide findings to guide student assignment in urban school districts with high geographic stratification of SES. This study does not question the broader benefits to society of student diversity in learning experiences but more narrowly defines student achievement in terms of test scores, specifically among students of low SES. While peer effects are apparent in certain contexts and with specific methodological designs that incorporate a variety of input variables, the present study utilizes a composite measure of SES explicitly used by the school district under study to maintain school diversity. Findings from this study may serve to inform the district's SAP in an attempt to 
maximize both student diversity and student achievement as defined by mandated achievement tests on students of low SES across a spectrum of school socioeconomic contexts. 


\section{CHAPTER III}

\section{METHODS}

The purpose of the present study was twofold: First, I sought to investigate the relative efficacy of the diversity index (DI) as a predictor of school-level academic achievement, operationalized by the percentage of students in a school scoring proficient or above on state mandated reading and math tests. The relative strength of the DI as a predictor of achievement was compared to measures of socioeconomic diversity more closely tied to individual students and analogous to two components of the DI. These are common predictors of academic achievement made available by the school district and state education agency's website: (a) the percentage of students in a school receiving free or reduced-price lunch (\% FRL), (b) the percentage of students belonging to historically marginalized races/ethnicities (\% Black and Latin American students), and (c) the interaction between \% FRL and \% Black/Latin American students. Second, this study sought to identify possible peer effects of socioeconomic diversity on low SES students across schools in a large urban public school district by estimating regression equations of aggregated achievement growth scores for students of low SES across a spectrum of school socioeconomic contexts. The DI was utilized as an independent variable to test the theoretical framework of Lam (2014) against school socioeconomic heterogeneity (SSH), a transform of the DI which is used to test the theoretical proposition of cosmopolitan environments, attributed to Blau et al. (2001). 
In addition, covariates were used to control for school input and process variables known to affect academic outcomes: student mobility, the percentage of students within a school receiving special education services (\% ECE), the percentage of English Language Learners attending a school (\% ELL), the percentage of new and intern teachers, teacher turnover, and constructs of working conditions at each school operationalized by the Teaching, Empowering, Leading, and Learning (TELL) survey, including Community Engagement and Support, School Leadership, and Managing Student Conduct. As Hanushek et al. (2003), Kang (2007), Meier and O’Toole (2002), and Van Dorn et al. (2006) note, it is important to control for student, teacher and school characteristics known to influence student achievement. Hence, the methodological approach was to conduct an exploratory (stepwise) multiple regression analysis by estimating a family of Ordinary Least Squares (OLS) models using schools as the unit of analysis $(\mathrm{N}=130)$.

This section of the dissertation begins with a discussion on the context of the school district in this study, Jefferson County Public Schools (JCPS) serving Louisville, Kentucky. Next, a restatement of the research questions is provided followed by a description of the research design, procedures, and study hypotheses. Then, an overview is offered of the operationalization of independent and dependent variables as well as covariates chosen for inclusion in the regression equations constructed. Finally, I make explicit some limitations and assumptions of the present study.

\section{The Context of the Study}

In the school district from which the sample is drawn there exists great heterogeneity between schools in both student diversity and student achievement. This 
district incorporates an element of sch;ool choice for families while simultaneously seeking to ensure some level of socioeconomic diversity by establishing guidelines based on the DI. These guidelines are imposed voluntarily (as JCPS was declared unitary in 2000) by busing students, often long distances from the neighborhood in which they reside. Within the district, there is geographic stratification with concentrations of poverty and minority students in the western and southwestern portions of the district while students residing in the eastern portion of the district tend to be more affluent and White (see Appendix A).

The SAP of Jefferson County Public Schools (JCPS) might be envisioned as a tracking system in which students are siloed via school assignment and school progression/promotion patterns producing different trajectories, or tracks, from elementary to middle and high school based upon a student's SES. One school, which is typically among the highest performing schools in the state, serves the lowest percentage of students receiving free or reduced-price lunch (FRL) and the smallest percentage of minority students; while another, typically the lowest performing school in the state, serves a student body with the highest percentage of students receiving FRL. One example of how the district's SAP structures the siloing of students by SES can be seen in the district's traditional magnet program. Traditional elementary schools in JCPS tend to have relatively smaller proportions of students receiving FRL services. In 2015, the average percentage of students receiving FRL in the magnet traditional elementary schools, which feed into traditional middle schools, was 39\% while the average for all elementary schools in the district was $73 \%$; that is nearly double the percentage in the traditional elementary magnet schools. These traditional elementary schools also tend to 
be among the highest performing schools in the state. In 2015, an average of $28 \%$ more traditional elementary students scored proficient or higher in reading and an average of $25 \%$ more traditional school students scored proficient or above in state mathematics tests than the average district elementary school. Furthermore, as students from these traditional schools matriculate from elementary into middle school and then on into high school, they are preferentially chosen to continue into traditional middle and high schools to the exclusion of students in non-traditional schools, who tend to be of lower SES. Such feeding patterns perpetuate the siloing of students based on SES. Due to the variation between schools in socioeconomic diversity, JCPS provides an exquisite context to test hypotheses derived from the competing theories of Lam (2014) and Blau et al. (2001).

This study utilizes the DI as a measure of SES for three explicit purposes. First, the district that frames the context of the present study utilizes the DI in making student assignment decisions in an effort to structure within-school socioeconomic and, ultimately, racial diversity. Second, apparently very little is known about this metric of SES and its efficacy at predicting academic outcomes. Only a few pieces of scholarly literature could be found which mentioned the DI of JCPS (e.g., Diem \& Frankenberg, 2014; Frankenberg, 2017), yet the APA Task Force on Socioeconomic Status (APA, 2007) recommends that researchers "become better informed about state-of-the-art approaches to conceptualizing and measuring SES and social class" including the "intersection with measures of... race/ethnicity" (p. 26). Both the lack of literature related to the DI and the fact that the DI is a multiple-component measure of the intersection between more traditional SES metrics (income and education level) with 
information pertaining to race provides a response to the recommendation of the APA Task Force on SES. Moreover, this study provides an opportunity to explore the efficacy of individual versus neighborhood (or, collective) measures of SES compared to studentlevel measures of SES, race, and the interaction of such individual measures; the need for which is made explicit by Ross and Mirowsky (2008).

\section{Restatement of the Research Questions}

Questions one and two sought to compare the relative efficacy of JCPS's DI in predicting the aggregate academic achievement of a school relative to analogues of the DI's components, measures of SES more closely tied to individual students. Questions three and four sought to determine the extent to which the theories of Lam (2014) and Blau et al. (2001) hold true in JCPS. The following research questions are posed:

1. To what extent does the diversity index (DI) predict academic achievement, as measured by the percentage of students within a school scoring proficient or higher on state-mandated reading and math tests, while controlling for other school input and process variables?

2. What is the relative efficacy of the DI in predicting academic achievement to analogous student-level components: (a) the proportion of students receiving free or reduced-price lunch (FRL), (b) the proportion of students belonging to a historically marginalized race/ethnicity, and (c) the interaction between FRL and race/ethnicity, while controlling for other school input and process variables? 
3. To what extent does the DI significantly predict academic growth among students of low socioeconomic status (SES), while controlling for other school input and process variables?

4. Does school-level socioeconomic heterogeneity significantly improve academic growth among students of lower socioeconomic status (SES), while controlling for other school input and process variables?

\section{Research Design and Statistical Procedures}

The fundamental purpose of the present study was to explore relationships among variables. These relationships were explored using a correlational - multiple regression approach (Abbott \& McKinney, 2012). Correlation allows researchers to "investigate how changes in two variables are related to one another" (Abbott \& McKinney, 2012, p. 127). More to the point of the present research questions, I sought to compare the efficacy of different constructs of socioeconomic diversity in predicting academic achievement, while controlling for other possible predictors - as many variables have been shown to correlate to academic achievement. Abbott and McKinney (2012) state that multiple linear regression (a logical extension of simple correlational design) is "a way of explaining the variance in an outcome variable based on the influence of a set of predictor values" (p. 147). Using this approach, the present study not only examined individual correlational pairs of study variables, but also explored the combined effect of the set of independent variables identified in this study and allowed an examination of unique effects of specific predictors while monitoring for possible spurious effects. Although this study adds to the literature by providing an exploration of conceptualizing socioeconomic diversity in different ways, a deeper understanding of the intersections of 
poverty and race as well as the role of school-level socioeconomic diversity on the aggregate academic achievement of low SES students, correlation is limited to the study of relationships; therefore, cause and effect cannot be inferred as can be done using experimental designs. However, as Campbell and Stanley (1963) note, "the relatively inexpensive correlational design can provide a preliminary survey of hypotheses, and those which survive this can then be checked through more expensive experimental manipulations" (p. 64).

To investigate the research questions, a family of stepwise ordinary least squares (OLS) models were estimated for each of the dependent variables. This approach was chosen over possible alternatives due to a lack of a theoretical basis for selecting the successive introduction of variables into the equations constructed and to mitigate the potential effects of multicollinearity (Stevens, 1996). The unit of analysis was schoollevel $(\mathrm{N}=130)$. This family of OLS models was constructed based on a cross-section of the most recent data available; the 2015-2016 school year. However, some variables for the 2015-2016 school year simply did not exist at the time of this study, so the most recent school data available (2014-2015) were utilized for a sub-set of study covariates. For each model, all covariates and the primary independent variable were entered as possible independent variables into a stepwise procedure with the following criteria: variables were entered with probability of $F$-values less than 0.05 and were excluded if probability of $F$-values were greater than 0.10 .

To address the first research question, two models were estimated in which the DI and all study covariates were entered as possible independent variables: predicting reading and then math achievement. The second research question was addressed by 
repeating the process used to address question 1 , but replacing the DI with alternative independent variables, which culminated into four alternative models predicting reading achievement and four alternative models predicting math achievement. To address research questions 3 and 4, a family of four models were estimated to predict the aggregated achievement growth of low SES students. The DI was entered as the measure of socioeconomic diversity for question 3, as this construct of diversity most closely aligns to Harrison and Klein's (2007) notion of diversity as disparity; this is Lam's (2014) diversity. To test question 4, a transform of the DI was constructed, School Socioeconomic Heterogeneity (SSH), to align with Harrison and Klein's (2007) notion of diversity as variety, or heterogeneity; this is Blau et al.'s (2001) diversity. All study covariates were entered as independent variables for all models. Figure 1 provides an illustration of all OLS models estimated by question.

Adjusted $\mathrm{R}^{2}$ values were used to report the proportion of variance explained by each model and $\mathrm{R}^{2}$ change values were used to observe the proportion of the variance explained as successive independent variables were entered at each step. Cook's distance was used to monitor for influential data. Standardized coefficients $(\beta)$ were used to facilitate interpretation. A Bonferroni correction was applied to adjust for the probability of observing significance for a variable or variables due to chance, such that $\alpha=0.05 / 12$ $=0.004$ (Stevens, 1996). A correlation matrix was considered and special attention given to the variance inflation factor (VIF) to ensure multicollinearity did not undermine the estimates of coefficients (Stevens, 1996). Tests of the assumptions for multiple regression (independence of error variance) were conducted; specifically, scatterplots of standardized residuals against predicted values were considered, as recommended by 
Stevens (1996). Statistical Package for the Social Sciences (IBM SPSS, Version 24) was utilized for all analyses.

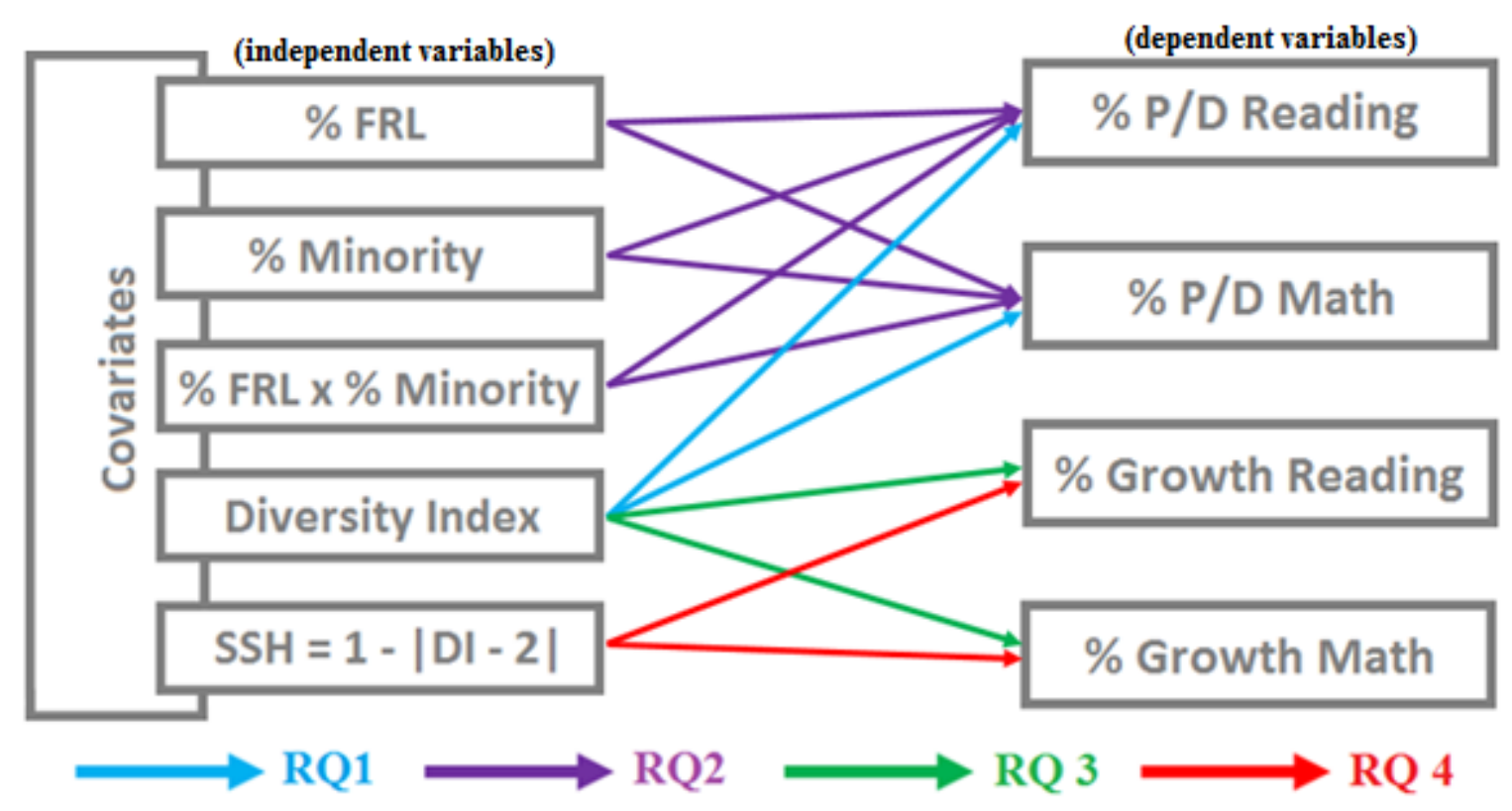

Figure 1. OLS models estimated by research question. All study covariates were entered into all models. Each colored arrow represents an OLS model estimated to address the identified research question. \% P/D Reading/Math $=$ the percentage of all students within a school scoring proficient or distinguished on reading/math tests. \% Growth $=$ the percentage of low SES students within a school making typical or higher yearly growth on reading/math tests. \% FRL $=$ the percentage of students within a school receiving free or reduced-price lunch. $\%$ Minority $=$ the percentage of students within a school who self-identified as Black or Latin American. $\mathrm{SSH}=$ School socioeconomic heterogeneity.

\section{Study Hypotheses}

The present study hypothesized a significant and positive relationship between the DI and the overall academic achievement of a school, as operationalized by aggregated test scores. In addition, it was hypothesized that student achievement would be negatively and significantly related to \% FRL, \% Black/Latin American students, and the interaction between FRL and \% Black/Latin American. The null hypothesis for this 
family of regression models is that there is no relationship between the primary independent variables and academic achievement.

In the socio-psychological analytical framework of Lam (2014), higher teacher expectations of tracks of higher SES students translate to higher actual student achievement, and therefore, students of lower-SES who are exposed to higher teacher expectations of their higher-SES peers should positively affect the actual academic achievement of lower-SES students. By this logic, low SES students attending low SES schools should fare worse, academically, than low SES student attending high SES schools. An alternative theoretical framework was considered, such that an increase in socioeconomic heterogeneity positively and significantly predicts an increase in achievement growth of low SES students (Benner \& Wang, 2014; Blau et al., 2001; Goldsmith, 2011; Hall \& Leeson, 2010). The null hypotheses express no relationship in typical or higher growth rates of low SES students across school socioeconomic contexts. This study sought to test these hypotheses in the context of a single urban public school district in the Southeastern United States exhibiting great diversity in socioeconomic heterogeneity between schools.

More formally, for research question 1:

$\mathrm{H}_{0}$ : There is no relationship between the DI and the aggregate academic achievement of students within a school.

$\mathrm{H}_{1}$ : There is a positive and statistically significant relationship between the DI and the aggregate academic achievement of students within a school.

For research question 2a: 
$\mathrm{H}_{0}$ : There is no relationship between the percentage of students receiving FRL services and the aggregate academic achievement of students within a school.

$\mathrm{H}_{1}$ : There is a negative and statistically significant relationship between the percentage of students receiving FRL services and aggregate academic achievement of students within a school.

For research question $2 \mathrm{~b}$ :

$\mathrm{H}_{0}$ : There is no relationship between the percentage of Minority (Black and Latin American) students and the aggregate academic achievement of students within a school.

$\mathrm{H}_{1}$ : There is a negative and statistically significant relationship between the percentage of Minority (Black and Latin American) students and the aggregate academic achievement of students within a school.

For research question 2c:

$\mathrm{H}_{0}$ : There is no relationship between the interaction (product) of students receiving FRL services and the percentage of Minority (Black and Latin American) students and aggregate academic achievement of students within a school.

$\mathrm{H}_{1}$ : There is a negative and statistically significant interaction (product) between the percentage of FRL participants and Minority (Black and Latin American) students and the aggregate academic achievement of students within a school.

For research question 3 :

$\mathrm{H}_{0}$ : There is no relationship between the DI and the percentage of low SES students within a school making typical or higher academic growth. 
$\mathrm{H}_{1}$ : There is a positive and statistically significant relationship between the DI and the percentage of low SES students within a school making typical or higher academic growth.

For research question 4:

$\mathrm{H}_{0}$ : School-level socioeconomic heterogeneity is not related to the percentage of low SES students within a school making typical or higher academic growth.

$\mathrm{H}_{1}$ : School-level socioeconomic hetero;geneity is positively and significantly related to the percentage of low SES students within a school making typical or higher academic growth.

\section{Independent Variables}

Diversity index. The diversity index (DI) is a multiple-component measure of what might be conceptualized as the approximate average SES of a school. The DI is utilized by JCPS to structure within-school diversity as part of its student assignment plan (SAP). In 2007, the district was mandated to cease the use of its prior SAP, which heavily weighed individual student race in student assignment decisions (Meredith $v$. Jefferson County Board of Education et al., 2007). In an effort to maintain within-school diversity, the district voluntarily adopted the DI to ensure a constitutional approach. The DI is approximate because it does not include information about individual students; rather, it relies upon Census block data of each student's neighborhood. More formally, the DI is the weighted average of all students attending a school belonging to one of three categories; category 1,2, and 3. The placement of a student into a category depends on (a) the household income of a student's ;Census block, (b) the average level of adult 
education attained in the student's Census block, and (c) the percentage of non-White people living within the student's Census block (see Figure 2).

Every Census block served by the school district is assigned to a socioeconomic category with a value of 1,2 , or 3 (where a higher value represents a higher average socioeconomic status). Students are assigned the category of the Census block in which they reside. The assignment of a category to a Census block is based upon a set of two traditional socioeconomic factors (household income and educational average) as well as a race factor (percent non-White residents) of the residents in each Census block.

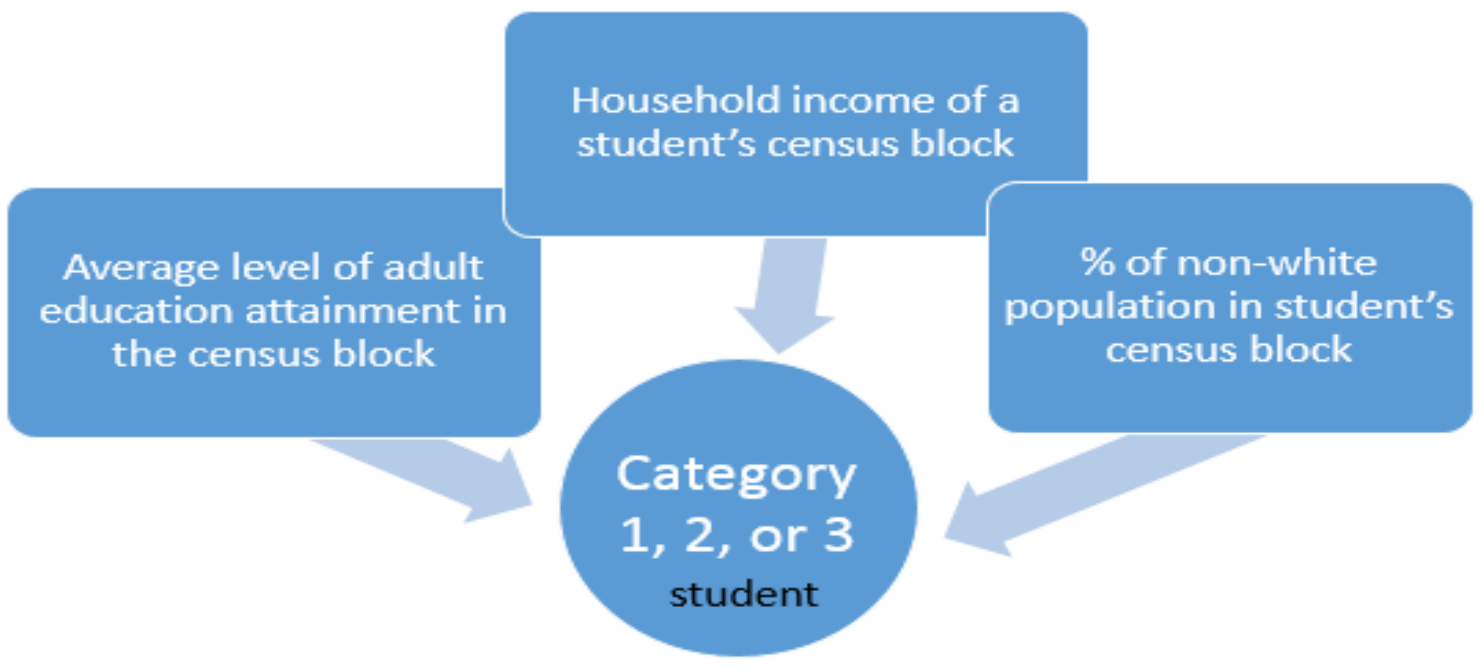

Figure 2. Factors in assigning students to a socioeconomic category. The DI is simply the weighted average of all students' category values within a school.

Household Income. This factor used in the construction of the DI is taken directly from the U.S. Census American Community Survey (ACS), a continuous sample survey conducted by the U.S. Census Bureau. Each Census block is assigned a category value of 1,2 , or 3 for the relative level of income of the Census block based upon the 
average household income. Table 2 shows the range of household incomes for each category value.

Educational Average. This factor is determined by a weighted average computed from Census ACS. The weights for each category of educational attainment for adults over the age of 25 are: 1 - finished grade 8 or less, 2 - did not finish high school, 3 finished high school, 3.5 - some college or associates degree, 4 - bachelor's degree, 5 masters or professional degree, and 6 - doctorate degree. These weights are used, in conjunction with the ACS data to compute the education average:

$$
\sum_{\text {over all categories }} \frac{\text { (Population of Category } \times \text { Weight per Category) }}{\text { Total Population }}
$$

The resultant sum, the education average, is a value between 1 and 6 , and is not, necessarily, an integer value. Table 2 shows the range of education averages for each categorical value $(1,2$, and 3$)$ of the educational average used in the calculation of a Census block's socioeconomic category.

Race Factor. This factor is based on the percentage of minority (non-White) residence in a Census block. Table 2 shows the range of the percentage of White residence in a Census block for each categorical value $(1,2$, and 3$)$ for the race factor component of the category.

Combining Income, Education, and Race. Each Census block is assigned a single integer value of 1, 2, or 3 based on the Socio-Economic Combination Category (SECC), where:

$$
\mathrm{SECC}=1+(0.23) *(\text { Income })+(0.33) *(\text { Education })+(0.33) *(\% \text { White })
$$


The specific values for the ranges for each category were apparently chosen based on “many iterations, simply to divide the district's grade 1 population into desired proportions and reveal the 'grain' of demographic distinctions across the country" (Orfield \& Frankenberg, 2011, p. 32). No specific mention of a theoretical justification for the values of each category weight in the SECC was made explicit by Orfield and Frankenberg (2011). The theoretical minimum and maximum values of the SECC are 1.89 and 3.67, respectively. The SECC is rounded down to the nearest integer value (1, 2, or 3), yielding the combined socioeconomic category of a Census block. There is one caveat worthy of mention here: If a Census block's socioeconomic category is calculated at 3 and has more than $35 \%$ minority (non-White) persons residing within, that Census block is re-assigned a category value of 2. Appendix A shows the distribution of categories across Census blocks in Jefferson County. A student is assigned to the category of the Census block in which they reside. The DI is simply the weighted average of all students' socioeconomic categories at the school.

\section{Table 1}

Classification Categories for Household Income, Educational Average, and Race

\section{Classification Category}

\section{Factor}

Household Income Educational Average

\begin{tabular}{ccc} 
Category 1 & Category 2 & Category 3 \\
\hline$<\$ 42,000$ & $\$ 42,000 \leq$ Income $\leq \$ 62,000$ & $>\$ 62,000$ \\
$<3.5$ & $3.5 \leq$ Education Average $\leq 3.7$ & $>3.7$ \\
$<73 \%$ & $73 \% \leq$ Percent White $\leq 88 \%$ & $>88 \%$
\end{tabular}

Race Factor

Note. All factors of a Census block are reduced to integer category values of 1,2 , or 3 using the ranges identified. Ranges for each factor were established by Orfield and Frankenberg (2011) who were paid consultants of JCPS. 
The theoretical minimum and maximum values of the DI are therefore 1 and 3, respectively. The "diversity guidelines" of the present school district establish a minimum and maximum value for a school's DI of 1.4 and 2.5 , respectively. In the 2015-2016 school year (the school year for which the latest data on the DI is available) the actual minimum and maximum values of the DI were 1.14 and 2.85 respectively. The district states that "students who are taught in self-contained (special education) classrooms and students who attend alternative or special schools will not be included in the calculation" (JCPS, 2016, p. 18). The values for each school's DI, excepting alternative or special schools, are publically available on the school district's website.

School Socioeconomic Heterogeneity. While the DI is a weighted average, representing the approximate average SES of a school, it is not a true measure of heterogeneity as the DI is symmetrical with respect to diversity across its theoretical range. A true metric of heterogeneity should increase as the diversity of a unit increases (Harrison \& Klein, 2007). Therefore, in order to determine the efficacy of socioeconomic heterogeneity in predicting the achievement growth of low SES students, a transform will be applied to the DI. To construct a measure of school socioeconomic heterogeneity, a variable will be constructed, such that:

$$
\text { School Socioeconomic Heterogeneity }(\mathrm{SSH})=1-|\mathrm{DI}-2|
$$

Hence, the closer a school's DI value is to its theoretical mid-point, the greater will be the measure of a school's socioeconomic heterogeneity and schools with disproportionately higher or lower concentrations of low SES students will have smaller values for school socioeconomic heterogeneity. 
The percentage of students receiving free or reduced-price lunch. Free or reduced-price lunch (FRL) was initially designed as a measure to ensure nutritionally balanced meals for children who qualified (Harwell \& LeBeau, 2010). This program was initiated by President Harry S. Truman in 1946 in response to the nation's needy children. Its objective was to ensure that every child had access to at least one hot meal a day. The National School Lunch Program (NSLP) was mandated under the National School Lunch Law to distribute domestically grown, inexpensive, nutritious meals and snacks to the nation's children through their schools (Mirtcheva \& Powell, 2009; NSLP, 2013). The criteria for children who qualified for free lunch was that they lived in households whose income was equal to or less than 130 percent of the federal poverty level. Reduced-price lunch was based on households whose income was between 130 and 185 percent of the poverty level (Harwell \& LeBeau, 2010). Children who qualified for reduced-price lunch are to pay no more than 40 cents for their lunches (Huang, Barnidge, \& Kim, 2015). The income for a household of four that qualifies for free lunch is $\$ 30,615$ and $\$ 43,568$ per household of four for children to qualify for reduced lunch (NSLP, 2013). This program currently operates in at least 100,000 schools serving more than 31 million children nationwide (NSLP, 2013). Free and reduced-price lunch is extensively used as a proxy variable for SES in education research despite growing criticism (Harwell et al., 2004; Harwell \& LeBeau, 2010; Hauser, 1994; Kurki, Boyle, \& Aladjem, 2005; Sirin, 2005).

Race/Ethnicity. The racial/ethnic profile of a school is reported on the school district's website as the percentage of students who self-identify as one of the following: American Indian, Asian, Black, Hispanic, Pacific Islander, White, or two or more races/ethnicities. Race/ethnicity are constructs often utilized in studies of education 
research (Benner \& Wang, 2014; Hanushek, 2003; Malecki \& Demaray, 2006). In the present study, race/ethnicity is operationalized by the percentage of students in a school identified as either Black or Hispanic (Latin American), as these races/ethnicities are considered "Gap groups" by the Commonwealth of Kentucky due to their historical underrepresentation in higher-achieving groups.

Interaction between FRL and Race/Ethnicity. To investigate the possible interaction effect between these analogues of components in the DI, an independent variable will be defined such that,

Interaction between FRL and Race/Ethnicity $=\%$ FRL x \% Black/Latin American students

An explicit purpose of this study is to investigate the relative efficacy of the DI at predicting academic outcomes and the DI is a multiple component measure of SES that includes measures of race. I am interested in how the possible interaction of these student-level analogues of the components of the DI (SES and race) compare to the neighborhood, or collective measures used in the construction of the DI. Such an analysis would help to resolve questions about the relative efficacy of unidimensional or multidimensional measures of SES made explicit by Ross and Mirowsky (2008).

\section{Covariates}

Several covariates were considered in the interest of controlling for various school input and process variables. These covariates are publically available on the state and local education agencies' websites.

English Language Learners (\% ELL). This study includes a measure of the percentage of students within a school identified as an English Language Learners (ELL). 
There is evidence that students identified as ELL's tend to score lower on achievement tests (Ardasheva, Tretter, \& Kinny, 2012; Cummins, 1979; Cummins, 2000). In addition, the Commonwealth of Kentucky has identified ELL's as a historically underrepresented demographic group among high achieving students.

Special Education Services (\% ECE). This study includes a measure of the percentage of students within each school receiving special education services via an Individualized Education Program (Individuals with Disabilities in Education Act of 1975). The effects of receiving special education services have been shown to negatively impact individual student educational outcomes (Morgan, Frisco, Farkas, \& Hibel, 2010; Reynolds \& Wolfe, 1999) and is identified by the Commonwealth of Kentucky as a historically underrepresented group among high achieving students.

Student mobility. The school district in the present study publishes data on each school's level of student mobility using a metric called the Mobility Index (MI), defined as the percentage of students who withdraw from another school within the district and re-enroll at a given school during an academic year. The inclusion of measures of student mobility are considered as potential covariates in the present exploratory analysis because they serve as a proxy for family stability and have been included as such in many empirical studies seeking control for family-level characteristics (Hanushek, Kain, \& Rivkin, 2004; Mehana \& Reynolds, 2004; Rumberger \& Larson, 1998; Sun \& Van Ryzin, 2014).

School and teacher characteristics. Several variables are utilized to control for teacher and school effects in an effort to isolate the effect of peer socioeconomic diversity. Three constructs from the Teaching, Empowering, Leading, and Learning 
(TELL) survey, which are highly correlated to teacher retention and student achievement in Kentucky (New Teacher Center, 2014) are used as control variables: Community Engagement and Support (CES), School Leadership (SL), and Managing Student Conduct (MSC). All three constructs are reported as the percentage of survey responses indicating strongly agree/agree, denoting a positive perception among the educators surveyed. TELL survey data were drawn from the most recent survey administration (2014-2015). In addition, the percentage of new and intern teachers at a school and the percentage of teacher turnover are considered as covariates of teacher effects within a school as empirical evidence exists of a link between teacher experience and academic achievement (Darling-Hammond \& Youngs, 2002; Goldhaber et al., 2015; Vanderhaar et al., 2006) as well as a link between teacher attrition and academic achievement (Ingersoll, 2003).

\section{Dependent Variables}

Measures of aggregate academic achievement. The Commonwealth of Kentucky mandates an assessment system for students in grades $3-8$, called the Kentucky Performance Rating for Educational Progress (K-PREP). Each year, students are assessed in reading and mathematics. In addition, reading and math achievement are assessed in high school using the ACT Quality Core End-of-Course Tests for English 2 and Algebra 2, respectively. The Commonwealth of Kentucky categorizes student performance as Novice, Apprentice, Proficient, or Distinguished based on theoretically derived cut scores. Measures of a school's aggregate academic achievement are often reported as the percent of students scoring proficient or distinguished in a given tested subject, which are used for accountability measures. In the present study, a school's 
percent of students scoring proficient or distinguished (\%PD) in reading and math are utilized as measures of overall student achievement of a school.

Measures of aggregate academic growth. The present study also considers measures of yearly academic growth, also included in the school accountability system, for students of low SES. Since the second research question focuses on achievement of low SES students in particular, it is important to control for prior academic achievement, as recommended by Benner et al. (2016) and Schmidt-Wilson (2013).

A total of four dependent variables are considered in this study: (a) the percentage of all students in a school scoring proficient or higher in reading, (b) the percentage of all students in a school scoring proficient or higher in math, (c) the percentage of low SES students in a school making typical or higher yearly growth in reading, and (d) the percentage of low SES students in a school making typical or higher yearly growth in math.

\section{Study Limitations and Delimitations}

The context of the current study suggests caution should be taken in generalizing the findings to other school districts. The school district in which this study occurs is a district which allows school choice with guidelines established by the district to maintain socioeconomic diversity within schools. While the district does allow for some level of school choice, the Commonwealth of Kentucky does not currently allow for charter schools. It should also be noted that a high degree of geographic stratification exists across the school district with clusters of lower SES neighborhoods concentrated to the

west and southwest, while neighborhoods in the east tend to be of higher SES. Moreover, 
measures of student achievement can vary widely across state lines and time. Another possible limitation exists in the way socioeconomic diversity is operationalized. The DI is an approximate measure of a school's average aggregate SES and the validity of using the DI to operationalize the aggregate SES of a school is dependent on the degree to which the compositional hypothesis is true in the Census block groups served by JCPS and the degree to which demographic shifts have occurred across block groups since the SECC values were fixed by the district, which were based on 2010 Census data.

Another important limitation of this study arises from the methodological approach. Regression modeling cannot be used to base arguments of causality. Therefore, the present study is limited to simply exploring the relationships between peer SES and academic outcomes. Assumptions will be tested by considering a scatterplot of standardized residuals against predicted values will be considered to check the assumption of independent error variance, as recommended by Stevens (1996). Cook's distance for all variables will be monitored in order to identify influential points, which will be removed. Furthermore, multicollinearity may compromise the reliability of the regression coefficients. A stepwise approach will be employed in the construction of all equations and attention will be given to the variance inflation factor (VIF) in an effort to identify and mitigate multicollinearity.

This study was delimited to a single, urban public school district in the Southeastern United States. In addition, not all schools were considered. Special and alternative schools were omitted from the analysis as these schools often serve a special purpose and their DI values are not reported by the school district. Furthermore, the present study only included elementary (K-5), middle (6-8) and high (9-12) schools. 
Four mixed grade-level schools were omitted from the analysis because it was not possible to differentiate between grade-level covariates and several independent variables. In addition, one elementary school was omitted because it was opened in 2015-2016 and multiple covariate values could not be procured or simply did not exist. 


\section{CHAPTER IV}

\section{RESULTS}

The present study examined the efficacy of Jefferson County Public School's (JCPS) diversity index (DI) in predicting the aggregate academic achievement of schools, relative to other common measures of socioeconomic status (SES) analogous and more proximal to individual students' SES. Another purpose of this study was to investigate the relationship between socioeconomic diversity, operationalized in two distinct ways, on the aggregate achievement growth of low SES students.

This chapter begins with a brief descriptive analysis of all study variables. Next, a correlation analysis is considered to explore the relationships between all study variables. The chapter is thereafter organized by research question, discussing the separate analyses and results for each. A summary of key findings is offered at the conclusion of the chapter.

\section{Descriptive Analysis}

Jefferson County Public Schools (JCPS) is a large urban public school district in the Southeastern U.S. that served more than 100,000 students (PK-12) in the 2015-2016 school year and is a minority-majority school system. According to the state education agency, $46.6 \%$ of students were identified as White, $36.1 \%$ as Black, $9.6 \%$ as Latin American, 3.8\% as Asian, $0.1 \%$ as Alaskan Native or Native American, $0.1 \%$ as 
Hawaiian or Other Pacific Islander, and 3.8\% as two or more races. Furthermore, $60.9 \%$ of students in JCPS are enrolled in the free or reduced-price lunch (FRL) program. The present analysis included 130 regular schools: elementary $(n=89)$, middle $(n=23)$ and high $(n=18)$. Table 2 provides means and standard deviations of all study variables by school level and for the district as a whole. The DI tended to increase, on average, across school level: from elementary $\left(M_{\text {elementary }}=1.81\right)$ to middle $\left(M_{\text {middle }}=1.87\right)$ and high $\left(M_{\text {high }}=1.88\right)$ school, while the percentage of students receiving FRL decreased $\left(M_{\text {elementary }}=72.68 \% ; M_{\text {middle }}=67.05 \% ; M_{\text {high }}=60.98 \%\right)$. The percentage of Black and Latin American students tended to remain relatively stable across school level, yet Minority enrollment decreased from middle to high school $\left(M_{\text {elementary }}=47.50 \% ; M_{\text {middle }}=\right.$ $\left.47.61 \% ; M_{\text {high }}=47.11 \%\right)$.

Compared to elementary and high schools in the sample, middle schools tended to have a smaller proportion of students achieving at the level of proficient or higher in both reading and math and a smaller proportion of low SES students making typical or higher annual growth in reading and math (see Table 2). Middle schools also tended to have a higher rate of teacher turnover $\left(M_{\text {middle }}=20.04 \%\right.$, versus $M_{\text {elementary }}=17.76 \%$ and $M_{\text {high }}=$ $18.92 \%)$, but a lower percentage of new teachers $\left(M_{\text {middle }}=6.05 \%\right.$, versus $M_{\text {elementary }}=$ $7.44 \%$ and $M_{h i g h}=6.64 \%$ ). Elementary schools tended to serve higher proportions $\left(M_{\text {elementary }}=9.40 \%\right)$ of students identified as English Language Learners (ELL's) than middle $\left(M_{\text {middle }}=4.42 \%\right)$ and high $\left(M_{\text {high }}=5.05 \%\right)$ schools. The percentage of students within a school receiving special education services decreased across school level $\left(M_{\text {elementary }}=12.52 \% ; M_{\text {middle }}=10.62 \% ; M_{\text {high }}=10.17 \%\right)$, as did the average Mobility Index $(\mathrm{MI})$ from middle to high school $\left(M_{\text {elementary }}=10.13 \% ; M_{\text {middle }}=10.69 \% ; M_{\text {high }}=\right.$ 
8.64\%). Furthermore, levels of agreement with positive educator perceptions on all TELL constructs (Community Engagement and Support [CES], School Leadership [SL], and Managing Student Conduct [MSC]) tended to decrease across school level as well, and in some cases, quite drastically (see Table 2).

When considering the shapes of the distributions of schools across measures of school socioeconomic diversity operationalized in the present study, patterns emerge (see Figure 3). The distribution of school DI values (see Figure 3a) is slightly skewed toward the higher values (skewness $=0.31)$; a greater proportion of schools $(n=88,67.69 \%)$ have DI values below the theoretical mid-point value (DI $=2)$ and $n=25$ schools (19.23\%) were outside of the diversity guidelines $(1.4-2.5$, minimum and maximum, respectively). School Socioeconomic Heterogeneity (SSH) was also slightly skewed (see Figure 3b), but toward the lower values (skewness $=-0.36$ ). The distribution of schools based on the percentage of students receiving FRL services (see Figure 3c) is also slightly skewed toward the lower values (skewness $=-0.79): n=76$ schools $(58.46 \%)$ serve a greater proportion of students receiving FRL services than the average school in JCPS $\left(M_{\text {district }}=70.07 \%\right)$. Furthermore, $n=; 58$ schools $(44.62 \%)$ serve student populations with more than $80 \%$ of students receiving FRL services. The distribution of the percentage of Minority (Black and Latin American) students in schools (see Figure 3d) is also slightly skewed toward the higher values (skewness $=0.51$ ). While most schools are clustered about the district average $\left(M_{\text {district }}=47.46 \%\right), 11$ schools serve student bodies in which more than $80 \%$ of students identify as Black or Latin American. The interaction (product) of \% FRL and \% Minority exhibits a noticeable skew toward the higher values as well (skewness $=0.53$, see Figure 3e). 


\section{Table 2}

Means (and Standard Deviations) of Study Variables ( $\mathrm{N}=130)$

\begin{tabular}{|c|c|c|c|c|}
\hline & $\begin{array}{c}\text { Elementary } \\
\mathrm{n}=89\end{array}$ & $\begin{array}{c}\text { Middle } \\
\mathrm{n}=23\end{array}$ & $\begin{array}{c}\text { High } \\
\mathrm{n}=18\end{array}$ & $\begin{array}{c}\text { District Total } \\
\mathrm{N}=130\end{array}$ \\
\hline \multicolumn{5}{|l|}{ Independent Variable } \\
\hline DI & $1.81(0.40)$ & $1.87(0.25)$ & $1.88(0.33)$ & $1.83(0.37)$ \\
\hline$\% \mathrm{FRL}$ & $72.68(21.36)$ & $67.05(17.79)$ & $60.98(19.79)$ & $70.07(20.85)$ \\
\hline$\%$ Minority & $47.50(21.76)$ & $47.61(12.53)$ & 47.11(17.74) & $47.46(19.78)$ \\
\hline$\%$ FRL x \% Minority & $37.67(23.40)$ & $33.20(14.90)$ & $31.16(18.66)$ & $35.98(21.53)$ \\
\hline \multicolumn{5}{|l|}{ Input Covariates } \\
\hline Mobility Index & $10.13(5.41)$ & $10.69(4.92)$ & $8.64(4.48)$ & $10.02(5.21)$ \\
\hline$\% \mathrm{ECE}$ & $12.52(3.12)$ & $10.62(4.58)$ & $10.17(4.68)$ & $11.86(3.75)$ \\
\hline$\%$ ELL & $9.40(10.31)$ & $4.42(5.01)$ & $5.05(6.03)$ & $7.92(9.30)$ \\
\hline \multicolumn{5}{|l|}{ Process Covariates } \\
\hline$\%$ New Teachers & $7.44(8.05)$ & $6.05(4.86)$ & $6.64(4.92)$ & 7.08 (7.19) \\
\hline$\%$ Teacher Turnover & $17.76(12.00)$ & $20.04(13.21)$ & $18.92(11.43)$ & 18.33(12.09) \\
\hline TELL CES & $82.74(12.46)$ & $78.24(12.23)$ & $75.90(15.63)$ & $81.00(13.06)$ \\
\hline TELL SL & $86.50(8.63)$ & $82.72(9.58)$ & $80.89(9.12)$ & $85.06(9.07)$ \\
\hline TELL MSC & 82.97(13.39) & $74.54(15.15)$ & $69.27(16.19)$ & $79.58(14.94)$ \\
\hline \multicolumn{5}{|l|}{ Dependent Variables } \\
\hline \% PD Reading & $45.99(16.77)$ & $43.65(18.21)$ & $45.82(20.81)$ & $45.55(17.50)$ \\
\hline$\%$ PD Math & $46.01(15.68)$ & $33.63(17.71)$ & $35.66(20.37)$ & $42.39(17.46)$ \\
\hline$\%$ G Reading & $55.13(12.30)$ & $47.39(7.88)$ & $51.39(12.50)$ & $53.08(11.94)$ \\
\hline$\%$ G Math & $54.30(13.62)$ & $43.13(8.25)$ & $52.43(10.26)$ & $51.88(12.96)$ \\
\hline \multicolumn{5}{|c|}{$\begin{array}{l}\text { Note. } \mathrm{DI}=\text { diversity index. \%FRL }=\text { percentage of students in a school receiving free or } \\
\text { reduced price lunch. \%Minority }=\text { the percentage of students in a school self-identifying } \\
\text { as Black or Latin American. \%ECE }=\text { the percentage of students within a school } \\
\text { receiving special education services. \%ELL = the percentage of students within a school } \\
\text { identified as English Language Learners. CES = Community Engagement and Support } \\
\text { (TELL construct). SL = School leadership (TELL construct). MSC = Managing Student } \\
\text { Conduct (TELL construct). \%PD = percentage of students scoring proficient or } \\
\text { distinguished. \%G = percentage of low SES students making typical or higher annual } \\
\text { growth. }\end{array}$} \\
\hline
\end{tabular}




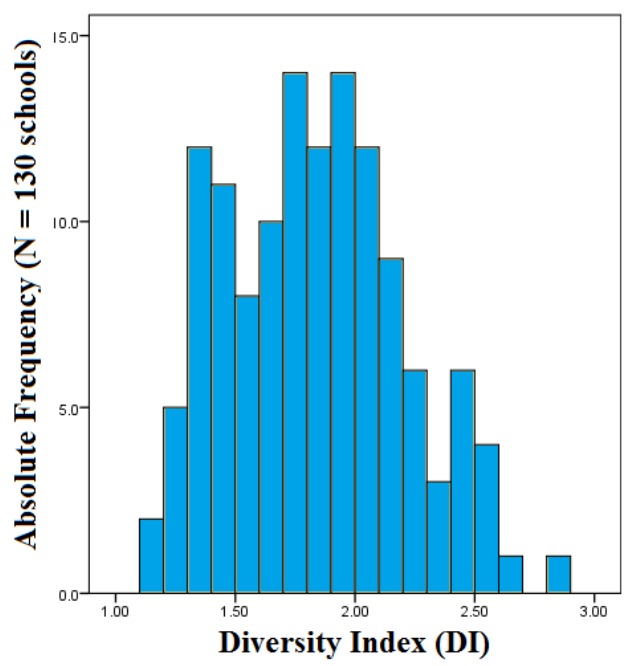

(a)

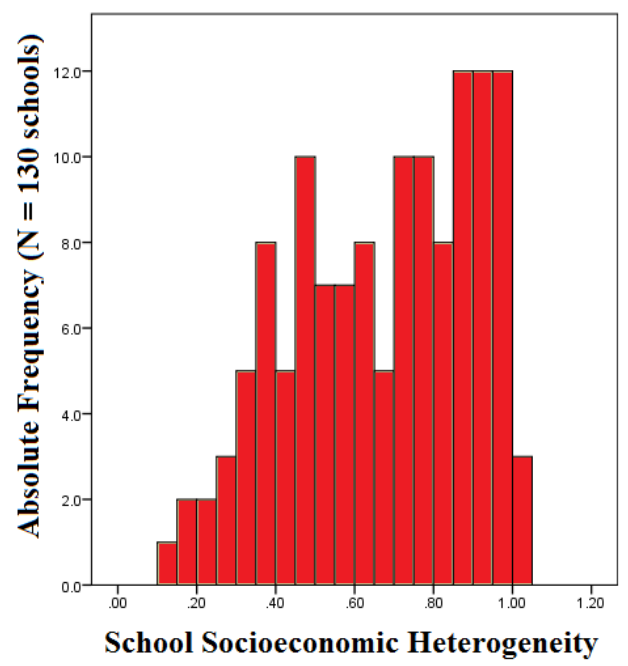

(b)

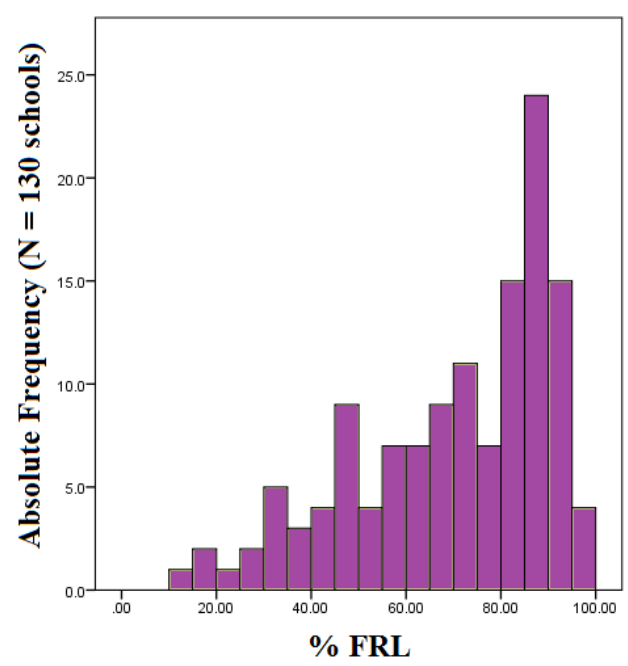

(c)

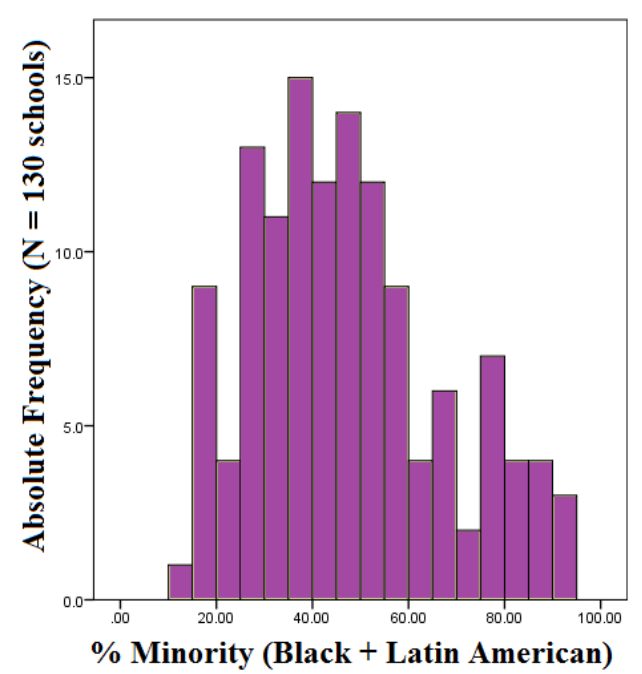

(d)

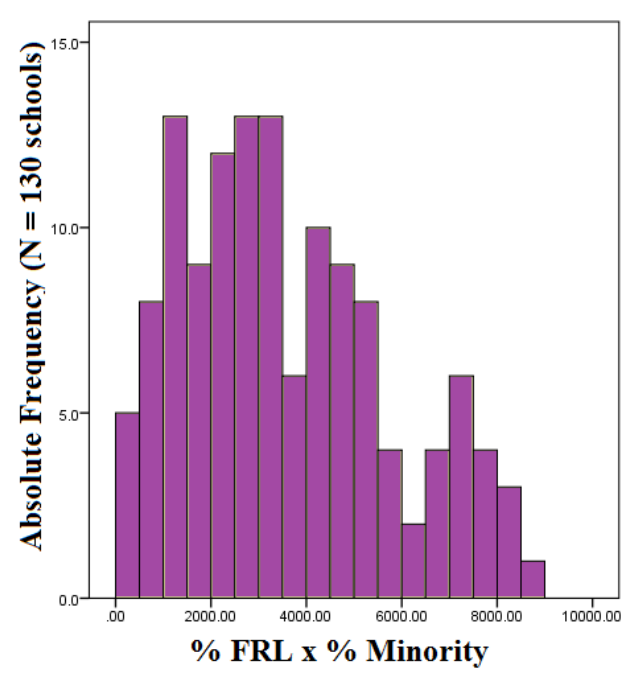

(e)

Figure 3. Distributions of school socioeconomic diversity: absolute frequency histograms for each measure. 
While some skew was noted in all variables, one had a value of skewness and kurtosis outside the range of \pm 2 , suggested by Field (2013) as warranting concern in conducting parametric tests. This specific variable was teacher turnover, which had values for skewness and kurtosis of 2.60 and 10.80, respectively. A descriptive analysis showed variation in all study variables between schools and school levels in JCPS and the shapes of the distributions of schools across variables of the study revealed some inequities between schools. These distributions demonstrate that while many schools served a highly diverse group of students some schools were more racially and socioeconomically isolated.

\section{Correlational Analysis}

A bivariate correlation matrix (Pearson's $r$-values) of all independent variables (including covariates) demonstrated that many pairs of these variables are highly and significantly correlated (see Table 3). This is not atypical in social science research (Stevens, 1996). This observation strengthens the argument for utlizing a stepwise procedure in entering the independent variables into OLS regression models, as multicollinearity can bias estimates of regression coefficients (Stevens, 1996). The strongest correlations among independent variables occurred between the DI and other measures of socioeconomic and racial diversity used in the present study: \% FRL $(r=-$ 0.86, $p<0.001), \%$ Minority $(r=-0.84, p<0.001)$, and the interaction (product) of FRL and Minority $(r=-0.90, p<0.001)$. This finding was expected, as the DI is very closely related to these variables (recall that the DI includes measures of poverty and race in its construction). School Socioeconomic Heterogeneity (SSH) was significantly correlated to the other measures of socioeconomic diversity: positively to the DI ( $r=0.46, p<$ 
$0.001)$ and negatively to $\%$ FRL $(r=-0.26, p=0.003), \%$ Minority $(r=-0.55, p<0.001)$, and the interaction of FRL and Minority $(r=-0.60, p<0.001)$.

The percentage of students identified as English Language Learners (\% ELL) and students receiving special education services (\% ECE) were not significantly correlated with one another $(r=0.12, p=0.16)$ but were weakly to moderately correlated to other covariates, although significance was observed in a limited number of observed pairs. The percentage of students receiving special education services (\% ECE) was correlated with the percentage of new teachers $(r=0.24, p=0.006)$ and with the TELL CES construct $(r=-0.31, p<0.001)$. In addition, \% ECE was significantly correlated to teacher turnover $(r=0.19, p=0.047)$ and the mobility index (MI, $r=0.56, p<0.001)$, while the only covariate correlated with \% ELL was the TELL CES construct $(r=-0.24$, $p=0.006)$. Neither \% ELL nor \% ECE were significantly correlated with the TELL constructs, School Leadership (SL, $r=-0.06, p=0.49$; and $r=0.02, p=0.86$; respectively) and Managing Student Conduct (MSC, $r=0.02, p=0.87$; and $r=-0.09, p=$ 31; respectively). The MI was also correlated with teacher turnover $(r=0.19, p=0.29)$, the percentage of new teachers $(r=0.60, p<0.001)$, TELL CES $(r=-0.45, p<0.001)$, and TELL MSC $(r=-0.32, p<0.001)$. All of the TELL constructs were moderately to strongly and significantly correlated with one another (see Table 3 ).

When comparing the relative strengths and levels of significance of correlations between the covariates and the primary independent variables (measures of school socioeconomic diversity), the TELL CES construct, the percentage of new teachers, and the MI stand out as being particularly strong in relation to others. For example, correlations of the TELL CES construct have $r$-values above 0.60 with all measures of 
Table 3

$\underline{\text { Pearson Correlations (2-tail) of Predictor Variables }}$

\begin{tabular}{|c|c|c|c|c|c|c|c|c|c|c|c|c|c|}
\hline & $\bar{\Delta}$ & $\overrightarrow{\underline{x}}$ & 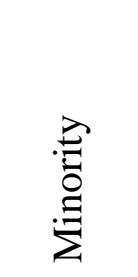 & 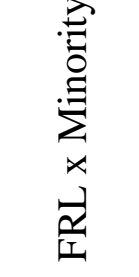 & $\begin{array}{l}\bar{I} \\
\tilde{\approx}\end{array}$ & $\underbrace{\text { II }}_{\text {II }}$ & $\overrightarrow{\underline{\mid c}}$ & $\bar{\Sigma}$ & 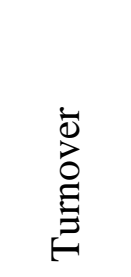 & 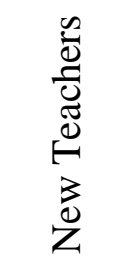 & 㜽 & 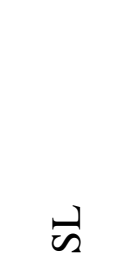 & $\sum_{\Sigma}^{\mathscr{L}}$ \\
\hline DI & - & $-0.86 * * *$ & $-0.84 * * *$ & $-0.90 * * *$ & $0.46 * * *$ & $-0.32 * * *$ & $-0.31 * * *$ & $-0.53 * * *$ & $-0.39 * * *$ & $-0.54 * * *$ & $0.65 * * *$ & $0.28 * *$ & $0.40^{* * * *}$ \\
\hline FRL & & 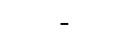 & $0.67 * * *$ & $0.81 * * *$ & $-0.26 * *$ & $0.55 * * *$ & $0.42 * * *$ & $0.66 * * *$ & $0.33 * * *$ & $0.50 * * *$ & $-0.64 * * *$ & $-0.19 *$ & $-0.28 * *$ \\
\hline Minority & & & - & $0.96^{* * *}$ & $-0.55 * * *$ & $0.22 *$ & $0.33 * * *$ & $0.43 * * *$ & $0.47 * * *$ & $0.50 * * *$ & $-0.60 * * *$ & $-0.25 * *$ & $-0.45^{* * *}$ \\
\hline FRL x Minority & & & & - & $-0.60 * * *$ & $0.35 * * *$ & $0.39 * * *$ & $0.54 * * *$ & $0.47 * * *$ & $0.56^{* * *}$ & $-0.66 * * *$ & $-0.24 * *$ & $-0.41 * * *$ \\
\hline SSH & & & & & - & $0.19^{*}$ & $-0.16^{*}$ & $-0.26^{* *}$ & $-0.30 * * *$ & $-0.46 * * *$ & $0.31 * * *$ & 0.06 & $0.17 * * *$ \\
\hline ECE & & & & & & - & 0.13 & $0.58 * * *$ & $0.19 *$ & $0.24 * *$ & $-0.34 * * *$ & 0.002 & -0.11 \\
\hline ELL & & & & & & & - & 0.11 & 0.04 & $0.17^{*}$ & $-0.21^{*}$ & -0.05 & 0.04 \\
\hline MI & & & & & & & & - & $0.17^{*}$ & $0.37 * * *$ & $-0.52 * * *$ & -0.09 & $-0.26 * *$ \\
\hline Turnover & & & & & & & & & - & $0.58 * * *$ & $-0.45 * * *$ & $-0.25 * *$ & $-0.35^{* * *}$ \\
\hline New Teachers & & & & & & & & & & - & $-0.49 * * *$ & $-0.32 * * *$ & $-0.40 * * *$ \\
\hline CES & & & & & & & & & & & - & $0.65 * * *$ & $0.70^{* * *}$ \\
\hline SL & & & & & & & & & & & & - & $0.72 * * *$ \\
\hline MSC & & & & & & & & & & & & & - \\
\hline
\end{tabular}

Note. DI $=$ Diversity Index. FRL $=\%$ of students within a school receiving free or reduced-price lunch. Minority $=\%$ Black/Latin American. FRL x Minority $=\%$ FRL x $\%$ Black/Latin American. SSH $=$ School Socioeconomic Heterogeneity. ECE $=\%$ of students within a school with an individual education plan (IEP). ELL $=\%$ of students within a school identified as English Language Learners. MI = Mobility Index. Turnover $=$ Teacher turnover. CES $=$ Community Engagement and Support $($ TELL construct $)$. SL $=$ School Leadership (TELL construct). MSC = Managing Student Conduct (TELL construct). ${ }^{*} p<0.05 . * * p<0.01 . * * * p<0.001$. 
socioeconomic diversity and all have $p$-values less than 0.001 , excepting $\mathrm{SSH}(r=0.29, p$ $=0.001)$. The TELL CES construct and the percentage of new teachers are significantly correlated to all study variables (see Table 3 ).

With a few notable exceptions, all independent variables are significantly correlated to all dependent variables (see Table 4). School Socioeconomic Heterogeneity (SSH) was weakly, yet positively and significantly correlated with reading achievement $(r=0.29, p=0.001)$ and math achievement $(r=0.18, p=0.04)$ but was not significantly correlated with achievement growth in reading $(r=0.10, p=0.28)$ or with math $(r=$ $0.09, p=0.32$ ). The percentage of ELL's in a school was negatively and significantly correlated to reading achievement $(r=-0.31, p<0.001)$, but not to measures of math achievement $(r=-0.16, p=0.07)$ or low SES student achievement growth in reading $(r=$ $0.04, p=0.66)$ or math $(r=-0.01, p=0.89)$.

For measures of academic achievement, the DI was positively, strongly and significantly correlated to both reading achievement $(r=0.81, p<0.001)$ and math achievement $(r=0.67, p<0.001)$. However, \% FRL was stronger (although negative) in its correlation to both reading achievement $(r=-0.90, p<0.001)$ and math achievement $(r=-0.72, p<0.001)$. The percentage of Minority students was not as strong, but was also negative and significant in its correlations to reading achievement $(r=-0.68, p<$ $0.001)$ and math achievement $(r=-0.60, p<0.001)$. The correlations between the interaction of FRL and Minority were of intermediate strength relative to the factors of the product and were also negative and significant in their correlations with reading achievement $(r=-0.79, p<0.001)$ and math achievement $(r=-0.66, p<0.001)$. 


\section{Table 4}

\section{$\underline{\text { Pearson Correlations (2-tail): Predictors and Outcomes }}$}

\begin{tabular}{|c|c|c|c|c|}
\hline & 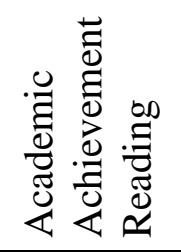 & 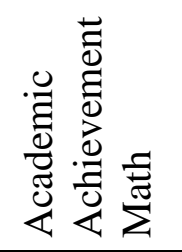 & 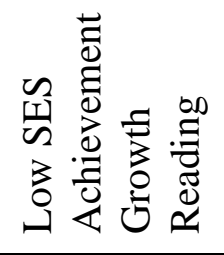 & 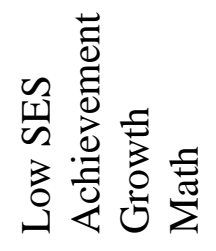 \\
\hline \multicolumn{5}{|c|}{ Independent Variables } \\
\hline DI & $0.81 * * *$ & $0.67 * * *$ & $0.25^{* *}$ & $0.21 *$ \\
\hline FRL & $-0.90 * * *$ & $-0.72 * * *$ & $-0.33 * * *$ & $-0.26 * *$ \\
\hline Minority & $-0.68 * * *$ & $-0.60 * * *$ & $-0.26 * *$ & $-0.32 * * *$ \\
\hline FRL x Minority & $-0.79 * * *$ & $-0.66 * * *$ & $-0.28 * *$ & $-0.31 * *$ \\
\hline SSH & $0.29 * *$ & $0.18 *$ & 0.10 & 0.09 \\
\hline \multicolumn{5}{|l|}{ Covariates (Input) } \\
\hline ECE & $-0.54 * * *$ & $-0.43 * * *$ & $-0.31 * *$ & $-0.19 *$ \\
\hline ELL & $-0.31 * * *$ & -0.16 & 0.04 & -0.01 \\
\hline MI & $-0.69 * * *$ & $-0.61 * * *$ & $-0.34 * * *$ & $-0.31 * *$ \\
\hline \multicolumn{5}{|l|}{ Covariates (Process) } \\
\hline Turnover & $-0.42 * * *$ & $-0.39 * * *$ & $-0.32 * * *$ & $-0.31 * *$ \\
\hline New Teachers & $-0.53 * * *$ & $-0.49 * * *$ & $-0.28 * *$ & $-0.26 * *$ \\
\hline CES & $0.77 * * *$ & $0.76 * * *$ & $0.46 * * *$ & $0.41 * * *$ \\
\hline SL & $0.26 * *$ & $0.31 * * *$ & $0.30 * *$ & $0.23 *$ \\
\hline MSC & $0.46 * * *$ & $0.53 * * *$ & $0.41 * * *$ & $0.42 * * *$ \\
\hline \multicolumn{5}{|c|}{$\begin{array}{l}\text { Note. } \text { DI }=\text { Diversity Index. FRL }=\% \text { Free or reduced-price lunch. Minority }=\% \\
\text { Black/Latin American. SSH }=\text { School socioeconomic heterogeneity. ECE }=\% \text { Students } \\
\text { with an individual education plan (IEP). ELL }=\% \text { of English Language Learners. MI = } \\
\text { Mobility Index. Turnover }=\text { Teacher turnover. CES }=\text { Community Engagement and } \\
\text { Support (TELL construct). SL }=\text { School Leadership (TELL construct). MSC = Managing } \\
\text { Student Conduct (TELL construct). } \\
* p<0.05 . * * p<0.01 . * * * p<0.001 .\end{array}$} \\
\hline
\end{tabular}

Correlational pairs with low SES student achievement growth in reading and math were relatively weaker, in general (see Table 4). Moreover, measures of school socioeconomic diversity tended to be weaker in their correlations as compared to study covariates. Whereas measures of school socioeconomic diversity were stronger than 
covariates in predicting academic achievement, the converse is true with respect to correlations with measures of low SES achievement growth. Noteably, the TELL constructs CES and MSC had the highest correlations to measures of low SES achievement growth. The TELL CES construct had the strongest correlation to low SES student achievement growth in reading $(r=0.46, p<0.001)$, followed by TELL MSC ( $r$ $=0.41, p<0.001)$, the MI $(r=-0.34, p<0.001)$, teacher turnover $(r=-0.32, p<0.001)$, $\% \operatorname{ECE}(r=-0.31, p<0.001)$, TELL SL $(r=0.30, p=0.001)$, and the percentage of new teachers $(r=-0.28, p=0.002)$. The TELL MSC construct had the strongest correlation to low SES student achievement growth in math $(r=0.42, p<0.001)$, followed by TELL CES $(r=0.41, p<0.001)$, the MI $(r=-0.31, p=0.001)$, teacher turnover $(r=-0.30, p=$ $0.001)$, the percentage of new teachers $(r=-0.26, p=0.005)$, TELL SL $(r=0.23, p=$ $0.011)$ and $\% \operatorname{ECE}(r=-0.19, p=0.04)$.

When considering correlational pairs between measures of school socioeconomic diversity and low SES student achievement growth, an interesting pattern emerges. The DI was stronger and had a higher level of significance in its correlation to low SES achievement growth in reading $(r=0.25, p=0.006)$ than in math $(r=0.21, p=0.02)$. With the exception of SSH, correlations of achievement growth with the DI were the weakest and least significant of the measures of school diversity. SSH was not significantly correlated to either measure of achievement growth. Of the measures of school socioeconomic diversity, \% FRL was most strongly correlated to low SES student achievement growth in reading $(r=-0.33, p<0.001)$. Furthermore, all measures of school diversity that included race as a component were weaker and/or less significant in predicting reading achievement: \% Minority $(r=-0.26, p=0.004)$, and the intersection of 
FRL and Minority $(r=-0.28, p=0.002)$. Correlations with measures of low SES achievement growth in math revealed the opposite: that measures which included race were generally stronger and, in some cases, more significant. The \% Minority was the strongest and most significant $(r=-0.32, p<0.001)$, followed by $\%$ interaction (product) of $\%$ FRL and $\%$ Minority $(r=-0.31, p=0.001)$.

\section{The Relationship between Diversity and School-Level Academic Achievement}

The first two research questions sought to explore the relative efficacy of four distinct measures of school socioeconomic diversity in predicting reading and math achievement. First, the DI, followed by two measures analogous to components of the DI: the percentage of students receiving free or reduced-price lunch (\% FRL, analogous to the measure of household income in the DI) and the percentage of Minority (\% Black +\% Latin American) students (analogous to the race component of the DI). Finally, a measure of socioeconomic diversity was constructed to explore the intersection of poverty and race, albeit in a different way than is operationalized by the DI: the product of $\%$ FRL and $\%$ Minority. For all four of these measures of socioeconomic diversity, an OLS regression equation was constructed using the stepwise method that included all study covariates predicting reading achievement and then predicting math achievement.

Research Question 1. To what extent does the diversity index (DI) predict academic achievement, as measured by the percentage of students within a school scoring proficient or higher on state-mandated reading and math tests, while controlling for other school input and process variables? The first research question sought to explore the relationship between the diversity index (DI) and the aggregate academic achievement of a school, operationalized by the percentage of students within a school scoring proficient 
or higher on state-mandated reading (\% PD Reading) and mathematics (\% PD Math) tests, while controlling for covariates of school inputs and processes.

To address this research question, two ordinary least squares (OLS) regression models were estimated in which the DI and all other covariates were entered as independent variables in a step-wise procedure; predicting reading and then math achievement. This allowed for decisions about selecting the order of inputs for all possible variables to be based solely on mathematical parameters, as this study is exploratory in nature and to mitigate the risk of multicollinearity due to the high correlations between study variables (see Table 3 ).

The Diversity Index Predicting Reading Achievement. The model constructed to explore the relationship between the diversity index (DI) and reading achievement met the assumption of constant variance (see Figure 4). Table 5 provides a summary of the model. All values for the VIF were well below Stevens' (1996) recommendation of a maximum value of 10. An analysis of Cook's distances revealed no values greater than one; therefore, no school cases were removed from the analysis (Cook \& Weisburg, 1982).

Using a conservative estimate (adjusted $R^{2}$ ) the model explained $84.40 \%$ of the variance observed in the sample. The DI was a significant and positive predictor of a school's aggregate reading achievement $(\beta=0.41, t=8.49, p<0.001)$. All other variables remaining constant, an increase in one standard deviation of the DI (0.31) predicts a 0.41 standard deviation increase in the percentage of students within a school scoring proficient or higher in reading (7.2\%). The $R$-squared change value indicated 
that the DI explained much of the total variance explained by the model $\left(\Delta R^{2}=0.65, \Delta F\right.$ $=241.58, p<0.001)$.

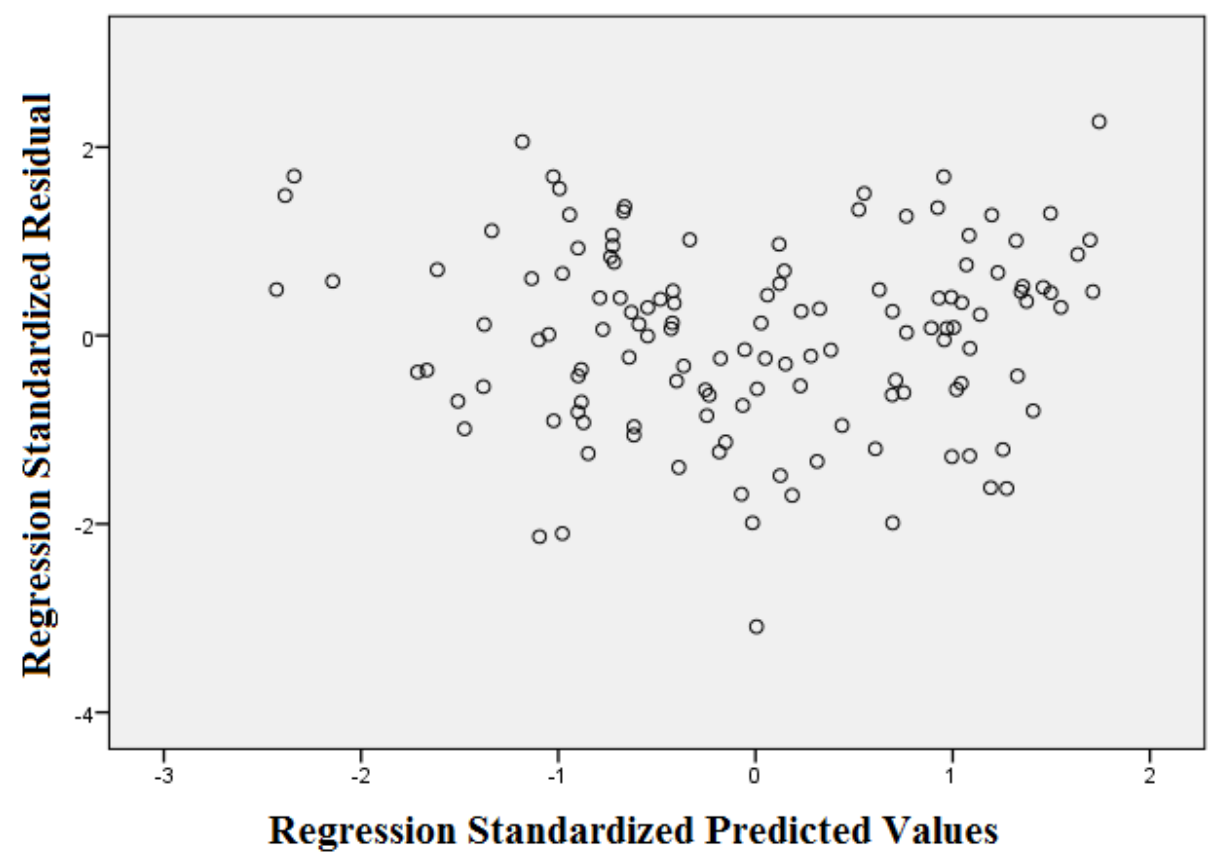

Figure 4. DI Predicting Reading Achievement: Standardized predicted values plotted against standardized residuals for the OLS model of the diversity index (DI) predicting aggregate reading achievement.

The TELL survey construct, Community Engagement and Support (CES) had the greatest effect size $(\beta=0.52, t=7.79, p<0.001)$ and the highest partial correlation (0.54), thus it was entered second into the model. The TELL CES construct contributes to the total variance accounted for by the model $\left(\Delta R^{2}=0.10, \Delta F=241.58, p<0.001\right)$. The percentage of students receiving special education services (\% ECE) and the TELL SL construct were significant and negative predictors of reading achievement as well $(\beta=$ $-0.17, t=-3.97, p<0.001$; and $\beta=-0.21, t=-4.08, p<0.001$; respectively), even after applying the Bonferroni correction $(\alpha=0.004)$. The mobility index (MI) had a negative 
impact on reading achievement $(\beta=-0.12, t=-2.46, p=0.02)$, but was not significant after the Bonferroni correction was applied.

\section{Table 5}

OLS Models: DI Predicting Reading Achievement

\begin{tabular}{|c|c|c|c|c|c|c|}
\hline & $b$ & $S E$ & $\beta$ & $t$ & $\Delta \mathrm{R}^{2}$ & $\Delta F$ \\
\hline Constant & 1.07 & 6.80 & & & & \\
\hline DI & 19.50 & 2.30 & 0.41 & $8.49^{\dagger}$ & 0.65 & $241.58^{\dagger}$ \\
\hline CES & 0.69 & 0.09 & 0.52 & $7.79^{\dagger}$ & 0.10 & $52.84^{\dagger}$ \\
\hline$\% \mathrm{ECE}$ & -0.79 & 0.20 & -0.17 & $-3.96^{\dagger}$ & 0.06 & $41.41^{\dagger}$ \\
\hline SL & -0.40 & 0.10 & -0.21 & $-4.08^{\dagger}$ & 0.03 & $21.19^{\dagger}$ \\
\hline MI & -0.41 & 0.17 & -0.12 & $-2.46^{*}$ & 0.01 & $6.05^{*}$ \\
\hline $\begin{array}{l}\text { Note. Depend } \\
\text { on state-mand } \\
=\text { standardized } \\
\text { Community E } \\
\text { school with an } \\
\text { Independent } \mathrm{v} \\
\text { mobility index } \\
{ }^{*} p<0.05 \text {. } \\
{ }^{\dagger} p<0.004 \text {. }\end{array}$ & $\begin{array}{l}\text { ariable } \\
\text { eading } \\
\text { icient. } \\
\text { ment at } \\
\text { idual e } \\
\text { es are } 1\end{array}$ & $\begin{array}{l}b=\mathrm{f} \text { all st } \\
b=\mathrm{ur} \\
=\mathrm{R}-\mathrm{sc} \\
\text { pport ( } \\
\text { on pro } \\
\mathrm{n} \text { the }\end{array}$ & $\begin{array}{l}\text { S withir } \\
\text { ardized } \\
\text { l chang } \\
\text { constr } \\
\text { SL = } \\
\text { n whic }\end{array}$ & $\begin{array}{l}\text { hool sco } \\
\text { ficient. } \\
=\text { diver } \\
\text { ECE }= \\
\text { ol Leade } \\
\text { were er }\end{array}$ & $\begin{aligned} & \text { profic } \\
&= \text { stand } \\
& \text { index. } \\
& \text { f studer } \\
& \text { p (TEL } \\
& \text { ed by S }\end{aligned}$ & $\begin{array}{l}\text { t or highel } \\
\text { error. } \beta \\
\text { ES = } \\
\text { within a } \\
\text { construct). } \\
\text { S. } \mathrm{MI}=\end{array}$ \\
\hline
\end{tabular}

Diversity Index Predicting Math Achievement. The model constructed to explore the relationship between the diversity index (DI) and math achievement met the assumption of constant variance (see Figure 5). Table 6 provides a summary of the model. An analysis of VIF's revealed no values greater than 10 and Cook's distance values were all less than one. The adjusted $\mathrm{R}^{2}$ value indicated the model explains $67.90 \%$ of the variance observed in the sample.

The DI was entered third into this model and contributed to the total variance explained by the model $\left(\Delta R^{2}=0.029, \Delta F=11.15, p=0.001\right)$. The DI was positively correlated with a school's math achievement and was significant at the nominal alpha, but 
was not significant after the Bonferroni correction was applied $(\beta=0.19, t=2.79, p=$ 0.006). All other variables remaining constant, an increase in one standard deviation of the DI (0.31) predicts a 0.19 standard deviation increase in the percentage of students within a school scoring proficient or higher in reading (3.3\%).

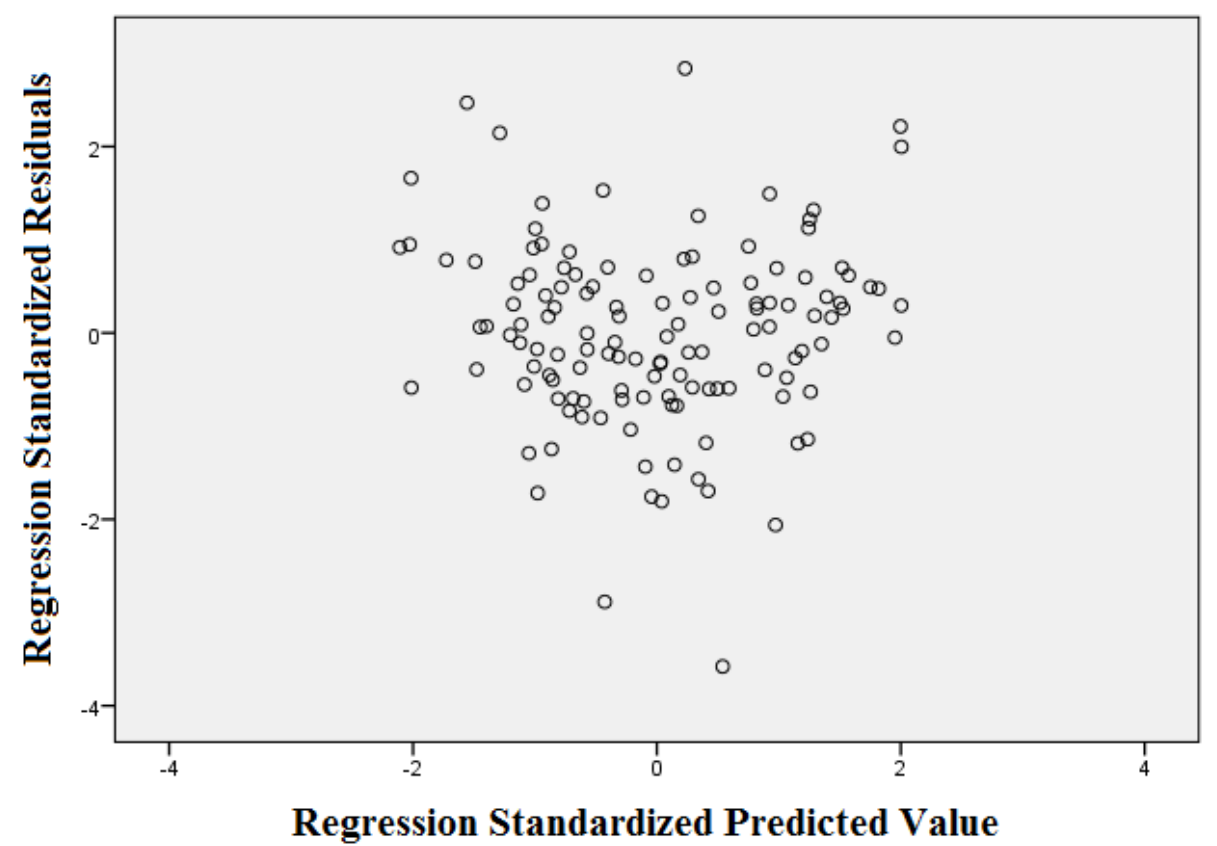

Figure 5. DI Predicting Math Achievement. Standardized predicted values plotted against standardized residuals for the OLS model for the diversity index (DI) predicting aggregate math achievement.

The TELL survey construct, Community Engagement and support (CES), again, had the greatest effect size $(\beta=0.68, t=7.23, p<0.001)$, and was the only predictor entered which was significant after the Bonferroni correction. Furthermore, TELL CES contributed to the total variance explained by the model $\left(\Delta R^{2}=0.58, \Delta F=179.10, p<\right.$ 0.001). The TELL construct, Student Leadership (SL) was negatively related and had the largest partial correlation (-0.31), and was therefore entered second into the model. However, as with the DI, the coefficient for TELL SL was not significant after applying the Bonferroni correction $(\beta=-0.21, t=-2.91, p=0.004)$. The Mobility Index (MI) also 
had a negative effect size and was only significant at the nominal alpha $(\beta=-0.17, t=-$ 2.61, $p=0.01)$. The TELL SL construct and the MI each added to the total variance explained by the model $\left(\Delta R^{2}=0.06, \Delta F=21.39, p<0.001\right.$ and $\Delta R^{2}=0.02, \Delta F=6.28, p$ $=0.01$; respectively) .

\section{Table 6}

OLS Models: DI Predicting Math Achievement

\begin{tabular}{lcccccr}
\hline & $b$ & $S E$ & $\beta$ & $t$ & $\Delta R^{2}$ & $\Delta F$ \\
\cline { 2 - 7 } Constant & -8.64 & 9.58 & & & & \\
CES & 0.91 & 0.13 & 0.68 & $7.22^{\dagger}$ & 0.58 & $179.10^{\dagger}$ \\
SL & -0.40 & 0.14 & -0.21 & $-2.91^{*}$ & 0.06 & $21.39^{\dagger}$ \\
DI & 9.16 & 3.29 & 0.19 & $2.79^{*}$ & 0.03 & $11.15^{\dagger}$ \\
MI & -0.57 & 0.22 & -0.17 & $-2.61^{*}$ & 0.02 & $6.83^{*}$ \\
\hline Note. Dependent Variable $=\%$ of all students within a school scoring proficient or higher \\
on state-mandated math tests. $b=$ unstandardized coefficient. SE= standard error. $\beta=$ \\
standardized coefficient. $\Delta R^{2}=R$-squared change. CES = Community Engagement and \\
Support (TELL construct). SL = School Leadership (TELL construct). DI = diversity \\
index. MI = mobility index. \\
${ }^{*} p<0.05$. \\
${ }^{\dagger} p<0.004$.
\end{tabular}

Research Question 2. What is the relative efficacy of the DI in predicting academic achievement to analogous student-level components: the proportion of students receiving free or reduced-price lunch (FRL), the racial/ethnic composition of the school and the interaction between FRL and race/ethnicity, while controlling for other school input and process variables? To address this research question, two sets of OLS regression models were constructed: four predicting school-level reading achievement, operationalized by the percentage of students scoring proficient or higher (\% PD) on state mandated reading tests and four predicting school-level math achievement, operationalized by the \% PD on state mandated math tests. For each OLS regression 
model, one primary independent variable (DI, \% FRL, \% Minority, and the interaction of $\%$ FRL and \% Minority) was entered along with all study covariates to estimate relationships with reading and then math achievement. Models of the DI predicting reading and math achievement were described in the regression analysis for research question 1. Following a description of each of the OLS regression models, a comparison of models is offered to address research question 2.

\% FRL Predicting School-Level Reading Achievement. The model constructed to explore the relationship between the percentage of students receiving FRL services (\% FRL) and reading achievement met the assumption of constant variance (see Figure 6). Table 7 provides a summary of the model. All values for the VIF were well below Stevens' (1996) recommendation of a maximum value of 10. An analysis of Cook's distances revealed no values greater than one; therefore no schools were removed from the analysis (Cook \& Weisburg, 1982).

Using a conservative estimate (adjusted $R^{2}$ ) the model explained $88.90 \%$ of the variance observed in the sample. The percentage of students receiving FRL services (\% FRL) was a significant and negative predictor of a school's aggregate reading achievement; it also had the greatest effect size of any predictor and was entered first into the equation $(\beta=-0.64, t=-15.25, p<0.001)$. All other variables remaining constant, an increase in one standard deviation of \% FRL (20.85\%) predicts a 0.64 standard deviation decrease in the percentage of students within a school scoring proficient or higher in reading (-11.20\% PD). The $R$-squared change $\left(\Delta R^{2}\right)$ value indicated that \% FRL contributed much of the total variance explained by the model $\left(\Delta R^{2}=0.80, \Delta F=514.08\right.$, $p<0.001)$. 


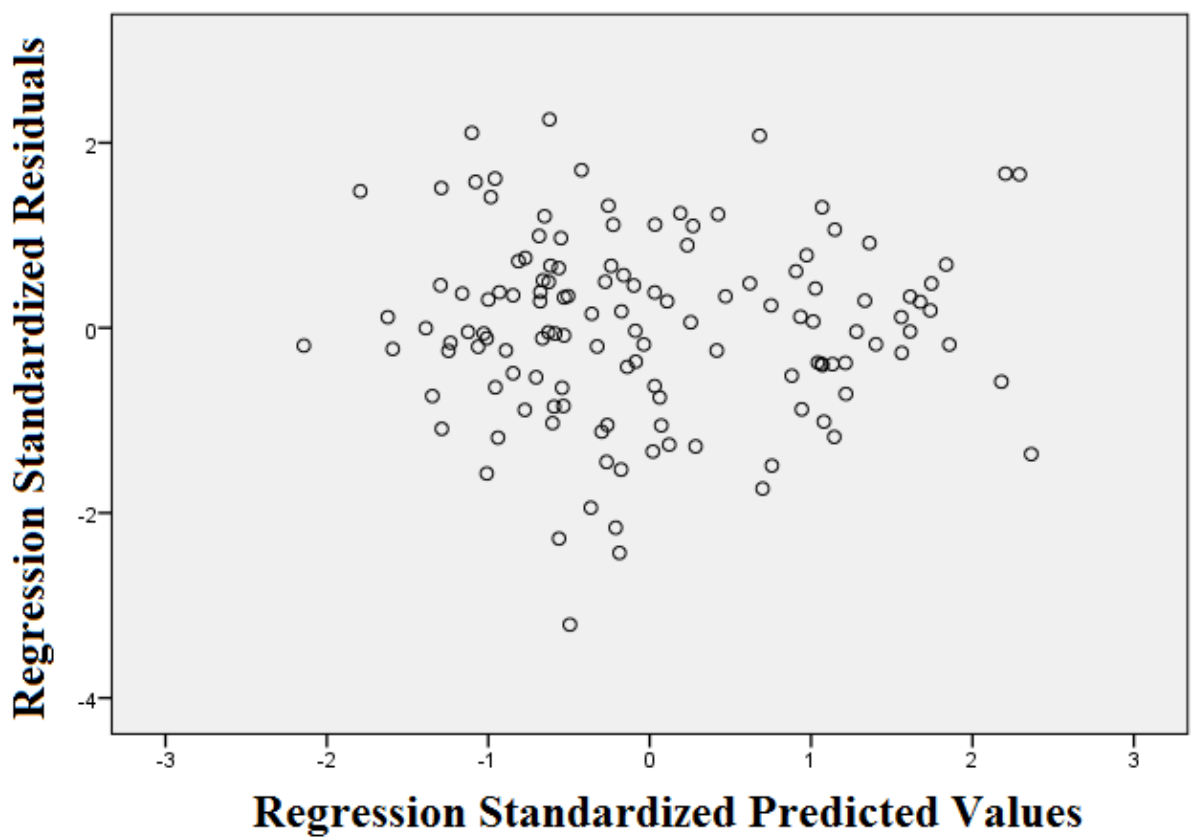

Figure 6. \% FRL Predicting Reading Achievement. Standardized predicted values plotted against standardized residuals for the OLS model for the percentage of students within a school predicting aggregate reading achievement.

Following the input of \% FRL, all three TELL survey constructs were the only other variables to be entered into the model: Community Engagement and Support (CES) had the greatest effect size $(\beta=0.40, t=6.61, p<0.001)$ and the highest partial correlation (0.57), thus it was entered second into the model. In addition to \% FRL, the TELL CES construct contributes to the total variance explained by the model $\left(\Delta R^{2}=\right.$ 0.07, $\Delta F=60.76, p<0.001)$. The TELL survey constructs, School Leadership (SL) and Managing Student Conduct (MSC), were significant and negative predictors of reading achievement $(\beta=-0.25, t=-5.48, p<0.001 ;$ and $\beta=0.17, t=3.55, p=0.001$; respectively), even after applying the Bonferroni correction, and also added to the total variance explained by the model $\left(\Delta R^{2}=0.01, \Delta F=12.58, p=0.001\right)$. 


\section{Table 7}

OLS Models: \% FRL Predicting Reading Achievement

\begin{tabular}{lrrrrrr}
\hline & $b$ & $S E$ & $\beta$ & \multicolumn{1}{c}{$t$} & $\Delta R^{2}$ & \multicolumn{1}{c}{$\Delta F$} \\
\cline { 2 - 7 } Constant & 65.09 & 6.45 & & & & \\
\% FRL & -0.54 & 0.04 & -0.64 & $-15.25^{\dagger}$ & 0.80 & $514.08^{\dagger}$ \\
CES & 0.53 & 0.08 & 0.40 & $6.61^{\dagger}$ & 0.07 & $60.76^{\dagger}$ \\
SL & -0.48 & 0.09 & -0.25 & $-5.48^{\dagger}$ & 0.02 & $17.95^{\dagger}$ \\
MSC & 0.20 & 0.06 & 0.17 & $3.55^{\dagger}$ & 0.01 & $12.59^{\dagger}$ \\
\hline
\end{tabular}

Note. Dependent Variable $=\%$ of all students within a school scoring proficient or higher on state-mandated reading tests. $b=$ unstandardized coefficient. $S E=$ standard error. $\beta=$ standardized coefficient. $\Delta R^{2}=R$-squared change. $\% \mathrm{FRL}=$ the percentage of students within a school receiving free or reduced-price lunch services. CES $=$ Community Engagement and Support (TELL construct). SL = School Leadership (TELL construct). MSC $=$ Managing Student Conduct (MSC). Independent variables are listed in the order in which they were entered by SPSS.

${ }^{*} p<0.05$

${ }^{\dagger} p<0.004$

\% Minority Predicting School-Level Reading Achievement. The model

constructed to explore the relationship between the percentage of Minority (Black and Latin American) students (\% Minority) and reading achievement met the assumption of constant variance (see Figure 7). Table 8 provides a summary of the model. All values for the VIF were well below Stevens' (1996) recommendation of a maximum value of 10. An analysis of Cook's distances revealed no values greater than one; therefore no schools were removed from the analysis (Cook \& Weisburg, 1982). Using a conservative estimate (adjusted $R^{2}$ ) the model explained $90.1 \%$ of the variance observed in the sample.

The percentage of Minority students (\% Minority) was found to be a significant and negative predictor of a school's aggregate reading achievement $(\beta=-0.22, t=4.10, p$ $<0.001)$. All other variables remaining constant, an increase in one standard deviation of 
$\%$ Minority (19.78\%) predicts a 0.22 standard deviation decrease in the percentage of students within a school scoring proficient or higher in reading (-3.85\% PD).

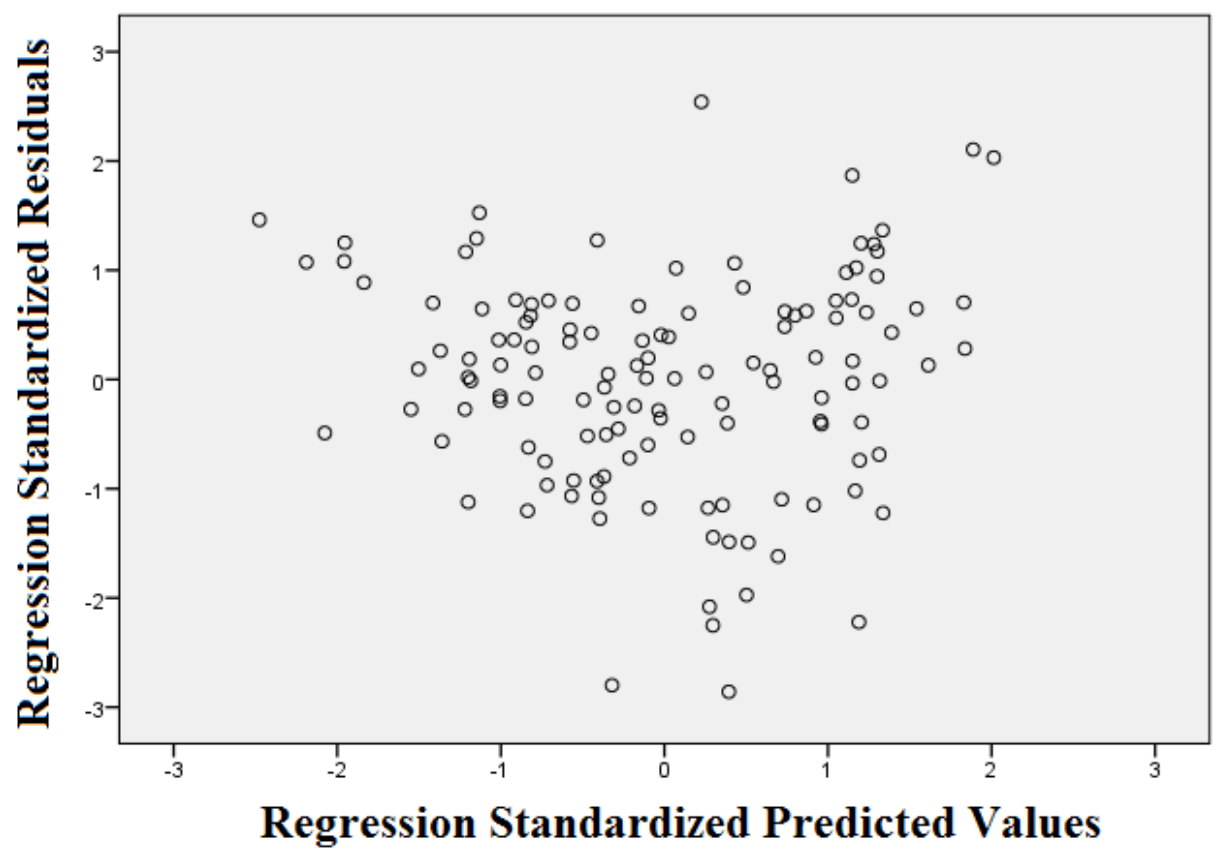

Figure 7. \% Minority Predicting Reading Achievement. Standardized predicted values plotted against standardized residuals for the OLS model for the percentage of Minority students within a school predicting aggregate reading achievement.

However, \% Minority was neither the first nor the second variable entered into the model. The TELL CES construct was entered first. The TELL CES construct was a positive and significant predictor of a school's aggregate reading achievement $(\beta=0.60, t$ $=8.07, p<0.001)$. The TELL CES construct explained much of the total variance explained by the model $\left(\Delta R^{2}=0.59, \Delta F=184.07, p<0.001\right)$. Following the input of the TELL CES construct, the MI had the greatest partial correlation (-0.51) and was therefore entered second into the model. The MI was found to be a negative and significant predictor of aggregated reading achievement, but was not significant after the Bonferroni correction ( $\beta=-0.16, t=-2.79, p=0.006)$. The addition of the MI contributed to the predictive power of the model $\left(\Delta R^{2}=0.11, \Delta F=43.85, p<0.001\right)$. 


\section{Table 8}

OLS Models: \% Minority Predicting Reading Achievement

\begin{tabular}{lcccccc}
\hline & $b$ & $S E$ & $\beta$ & $t$ & $\Delta R^{2}$ & $\Delta F$ \\
\cline { 2 - 7 } Constant & 46.24 & 8.35 & $;$ & & & \\
CES & 0.81 & 0.10 & 0.60 & $8.07^{\dagger}$ & 0.59 & $184.07^{\dagger}$ \\
MI & -0.52 & 0.19 & -0.16 & $-2.79^{\dagger}$ & 0.11 & $43.85^{* *}$ \\
\% Minority & -0.19 & 0.05 & -0.22 & $-4.10^{\dagger}$ & 0.05 & $26.16^{\dagger}$ \\
\% ECE & -0.83 & 0.23 & -0.18 & $-3.71^{\dagger}$ & 0.03 & $18.56^{\dagger}$ \\
SL & -0.47 & 0.11 & -0.24 & $-4.18^{\dagger}$ & 0.02 & $14.34^{\dagger}$ \\
New Teachers & -0.27 & 0.12 & -0.11 & $-2.33^{*}$ & 0.01 & $5.42^{*}$ \\
\hline
\end{tabular}

Note. . Dependent Variable $=\%$ of all students within a school scoring proficient or higher on state-mandated reading tests. $b=$ unstandardized coefficient. $S E=$ standard error. $\beta=$ standardized coefficient. $\Delta R^{2}=R$-squared change. $\mathrm{CES}=$ Community Engagement and Support (TELL construct). MI = Mobility Index. \% Minority $=$ the percentage of students within a school identifying as Black or Latin American. \%ECE $=$ the percentage of students within a school receiving special education services. SL = School Leadership (TELL construct). New Teachers $=$ the percentage of new or intern teachers in a school. Independent variables are listed in the order in which they were entered by SPSS. ${ }^{*} p<0.05 . * * p<0.01$. ${ }^{\dagger} p<0.004$.

The percentage of Minority students (\% Minority) was entered third into the model, followed by \% ECE, which was negatively and significantly related to aggregated reading achievement $(\beta=-0.18, t=-3.71, p<0.001)$ and contributed to the total proportion of the variance explained by the model $\left(\Delta R^{2}=0.03, \Delta F=18.56, p<0.001\right)$.

The TELL SL construct was entered fourth into the model and was found to be a significant and negative predictor of aggregated reading achievement as well $(\beta=-0.24, t$ $=-4.18, p<0.001)$ and also contributed to the total variance explained by the model $\left(\Delta R^{2}\right.$ $=0.02, \Delta F=14.34, p<0.001)$. Finally, the percentage of new teachers at a school was entered into the model and was found to be a negative and significant predictor of aggregated reading achievement, although not after applying the Bonferroni correction ( $\beta$ 
$=-0.11, t=-2.33, p=0.2$ ). The percentage of new teachers further contributed to the total proportion of the variance explained by the model, at least prior to applying the Bonferroni correction $\left(\Delta R^{2}=0.008, \Delta F=5.42, p=0.02\right)$.

The Interaction of FRL and Minority on Predicting Reading Achievement. The model constructed to explore the relationship between the interaction of FRL and Minority and reading achievement met the assumption of constant variance (see Figure 8). Table 9 provides a summary of the model. All values for the VIF were below Stevens' (1996) recommendation of a maximum value of 10. An analysis of Cook's distances revealed no values greater than one; therefore no schools were removed from the analysis (Cook \& Weisburg, 1982). Using a conservative estimate (adjusted $R^{2}$ ) the model explained $81.4 \%$ of the variance observed in the sample.

The interaction of FRL and Minority was a significant and negative predictor of a school's aggregate reading achievement; while it did not have the greatest effect size, it was entered first into the equation $(\beta=-0.35, t=-6.37, p<0.001)$. All other variables remaining constant, an increase in one standard deviation of the interaction of FRL and Minority $(2,153.26)$ predicts a 0.35 standard deviation decrease in the percentage of students within a school scoring proficient or higher in reading (-6.13\% PD). The $R$ squared change value indicated that the interaction of FRL and Minority contributed much of the total variance explained by the model $\left(\Delta R^{2}=0.62, \Delta F=208.90, p<0.001\right)$. Following the input of the interaction of FRL and Minority, four additional variables were entered into the model. The TELL CES construct was the second variable entered into the model, having the greatest partial correlation (0.54). The TELL CES construct also had the largest effect size of all variables entered $(\beta=0.54, t=7.24, p<0.001)$. 


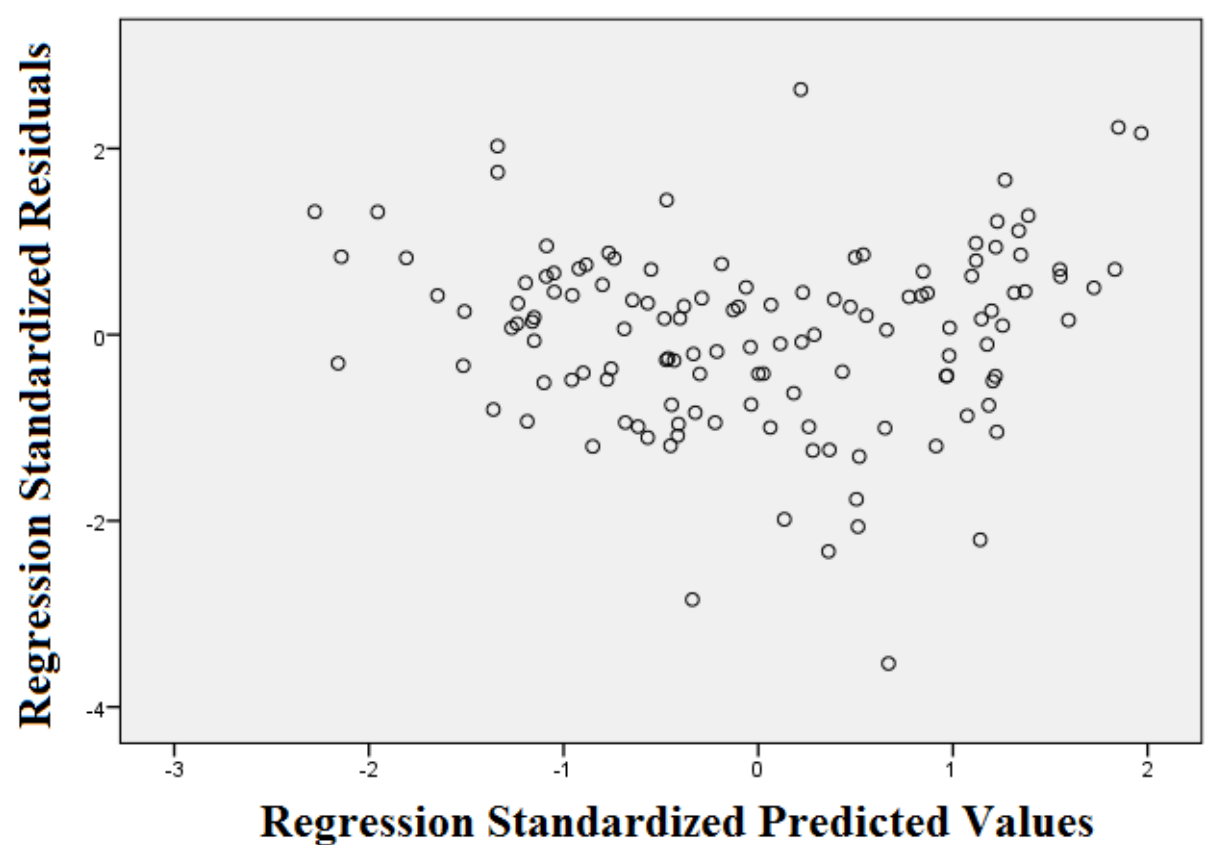

Figure 8. Interaction of \% FRL and \% Minority Predicting Reading Achievement. Standardized predicted values plotted against standardized residuals for the OLS model for the interaction of \% FRL and \% Minority within a school predicting aggregate reading achievement.

In addition to the interaction between FRL and Minority, the TELL CES construct contributed to the total variance explained by the model $\left(\Delta R^{2}=0.11, \Delta F=52.64, p<\right.$ 0.001). The percentage of students receiving special education services (\% ECE), the TELL SL construct, and the MI were significant and negative predictors of reading achievement as well $(\beta=-0.16, t=-3.47, p=0.001 ; \beta=-0.19, t=-3.42, p=0.001$; and $\beta$ $=-0.14, t=-2.63, p=0.01$; respectively). All were significant after applying the Bonferroni correction, excepting the MI. Furthermore, \% ECE, TELL SL, and the MI also contributed to the total variance explained by the model $\left(\Delta R^{2}=0.06, \Delta F=33.69, p\right.$ $<0.001 ; \Delta R^{2}=0.02, \Delta F=15.34, p<0.001 ;$ and $\Delta R^{2}=0.01, \Delta F=6.92, p=0.01$; respectively). 


\section{Table 9}

OLS Models: Interaction of FRL and Minority Predicting Reading Achievement

\begin{tabular}{lcccccr}
\hline & $b$ & $S E$ & $\mathrm{~B}$ & $t$ & $\Delta R^{2}$ & \multicolumn{1}{c}{$\Delta F$} \\
\cline { 2 - 7 } Constant & 42.33 & 7.62 & & & & \\
FRL x Min. & -0.003 & - & -0.35 & $-6.37^{\dagger}$ & 0.62 & $208.90^{\dagger}$ \\
CES & 0.72 & 0.10 & 0.54 & $7.24^{\dagger}$ & 0.11 & $52.64^{\dagger}$ \\
ECE & -0.75 & 0.22 & -0.16 & $-3.47^{\dagger}$ & 0.06 & $33.69^{\dagger}$ \\
SL & -0.37 & 0.11 & -0.19 & $-3.42^{\dagger}$ & 0.02 & $15.34^{\dagger}$ \\
MI & -0.48 & 0.18 & -0.14 & $-2.63^{*}$ & 0.01 & $6.92^{*}$ \\
\hline
\end{tabular}

Note. Dependent Variable $=\%$ of all students within a school scoring proficient or higher on state-mandated reading tests. $b=$ unstandardized coefficient. $S E=$ standard error. $\beta=$ standardized coefficient. $\Delta R^{2}=R$-squared change. $\% \mathrm{FRL}=$ the percentage of students within a school receiving free or reduced-price lunch services. CES $=$ Community Engagement and Support (TELL construct). SL = School Leadership (TELL construct). MSC $=$ Managing Student Conduct (MSC). Independent variables are listed in the order in which they were entered by SPSS.

* $p<0.05$.

${ }^{\dagger} p<0.004$.

Comparisons of Diversities in Predicting Reading Achievement. While each of

the models constructed to predict a school's aggregated reading achievement with the four primary independent variables included different arrangements of covariates, all four primary independent variables were significant predictors of a school's reading achievement. Table 10 summarizes each of the models estimated from the sample. A comparison of adjusted $R^{2}$ values indicates the model including \% FRL explained the greatest proportion of the variance observed in the sample among all four models (adjusted $R^{2}=0.89$ ). The model utilizing the DI to operationalize socioeconomic diversity had a slightly lesser adjusted $R^{2}$ value than the model that included \% FRL (adjusted $R^{2}=0.84$ ). The model that included the interaction of FRL and Minority as a measure of socioeconomic diversity explained a smaller proportion of the variance still 
(adjusted $R^{2}=0.81$ ). Finally, the model that included \% Minority explained the least amount of variance (adjusted $R^{2}=0.80$ ).

\section{Table 10}

A Comparison of OLS Models Predicting Reading Achievement

\begin{tabular}{lcccc}
\hline & Model 1 & Model 2 & Model 3 & Model 4 \\
\cline { 2 - 5 } Adjusted $R^{2}$ & 0.84 & 0.89 & 0.80 & 0.81 \\
Independent Variables & & & & \\
$\quad$ DI & $0.41^{\dagger}$ & - & - & - \\
FRL & - & $-0.64^{\dagger}$ & - & - \\
Minority & - & - & $-0.22^{\dagger}$ & - \\
FRL x Minority & - & - & - & $-0.35^{\dagger}$ \\
Covariates (Input) & & & & $-0.16^{\dagger}$ \\
ECE & $-0.17^{\dagger}$ & $\mathrm{a}$ & $-0.18^{\dagger}$ & $-0.14^{*}$ \\
MI & $0.15^{*}$ & $\mathrm{a}$ & $-0.16^{*}$ & $0.54^{\dagger}$ \\
Covariates (Process) & $0.52^{\dagger}$ & $0.40^{\dagger}$ & $0.60^{\dagger}$ & $-0.19^{\dagger}$ \\
CES & $-0.21^{\dagger}$ & $-0.25^{\dagger}$ & $-0.24^{\dagger}$ & $\mathrm{a}$ \\
$\quad$ SL & $\mathrm{a}$ & $0.17^{\dagger}$ & $-0.11^{*}$ & \\
New Teachers & &
\end{tabular}

Note. . Dependent variable $=\%$ of all students within a school scoring proficient or higher on state-mandated math tests. Model 1 includes the DI as the primary independent variable. Model 2 includes FRL as the primary independent variable. Model 3 includes Minority as the primary independent variable. Model 4 includes FRL x Minority as the primary independent variable. DI $=$ diversity index. $\mathrm{FRL}=\%$ of students receiving free/reduced price lunch. Minority $=\%$ of students self-identifying as Black/Latin American. $\mathrm{ECE}=\%$ of students with an individual education program. $\mathrm{MI}=$ mobility index. CES = Community Engagement and Support (TELL construct). SL = School Leadership (TELL construct). New Teachers $=$ the percent of new/intern teachers. ${ }^{a}$ Did not meet inclusion criteria for the model.

" $p<0.05$. ${ }^{\dagger} p<0.004$.

The directions of the relationships hypothesized for each primary independent variable were supported by the OLS regression models constructed. Based on the relative magnitudes of the standardized coefficients, \% FRL had the greatest effect size ( $\beta=-$ 
$0.64, t=-15.25, p<0.001)$, followed by the DI $(\beta=0.41, t=8.49, p<0.001)$, the interaction of FRL and Minority $(\beta=-0.35, t=-6.37, p<0.001)$, and finally, the $\%$ Minority $(\beta=-0.22, t=-4.10, p<0.001)$. Of the four models estimated to predict reading achievement, the only one in which the primary independent variable was not entered into the model first was model that utilized \% Minority to operationalize school diversity. Based on this analysis, \% FRL had greater efficacy in predicting the aggregated reading achievement of a school than the DI. However, the DI had a greater predictive efficacy than both \% Minority and the interaction between FRL and Minority.

\% FRL Predicting School-Level Math Achievement. The model constructed to explore the relationship between the percentage of students receiving FRL services (\% FRL) and school-level math achievement met the assumption of constant variance (see Figure 9). Table 11 provides a summary of the model. All values for the VIF were well below Stevens' (1996) recommendation of a maximum value of 10. An analysis of Cook's distances revealed no values greater than one; therefore no schools were removed from the analysis (Cook \& Weisburg, 1982). Using a conservative estimate (adjusted $R^{2}$ ) the model explained $73.6 \%$ of the variance observed in the sample.

The percentage of students receiving FRL services (\% FRL) was a significant and negative predictor of a school's aggregate reading achievement but was entered second into the equation $(\beta=-0.46, t=-6.67, p<0.001)$. All other variables remaining constant, an increase in one standard deviation of \% FRL (20.85\%) predicts a 0.46 standard deviation decrease in the percentage of students within a school scoring proficient or higher in reading (-11.20\% PD). The $R$-squared change $\left(\Delta R^{2}\right)$ value indicated that $\%$ FRL explained much of the total variance explained by the model $\left(\Delta R^{2}=0.11, \Delta F=\right.$ 
$44.51, p<0.001)$ on top of the variance explained by the first variable entered into the equation: the TELL CES construct $\left(\Delta R^{2}=0.58, \Delta F=179.19, p<0.001\right)$. In this model, the TELL CES construct explained much of the variance observed in the sample $(\beta=-$ $0.53, t=5.64, p<0.001)$.

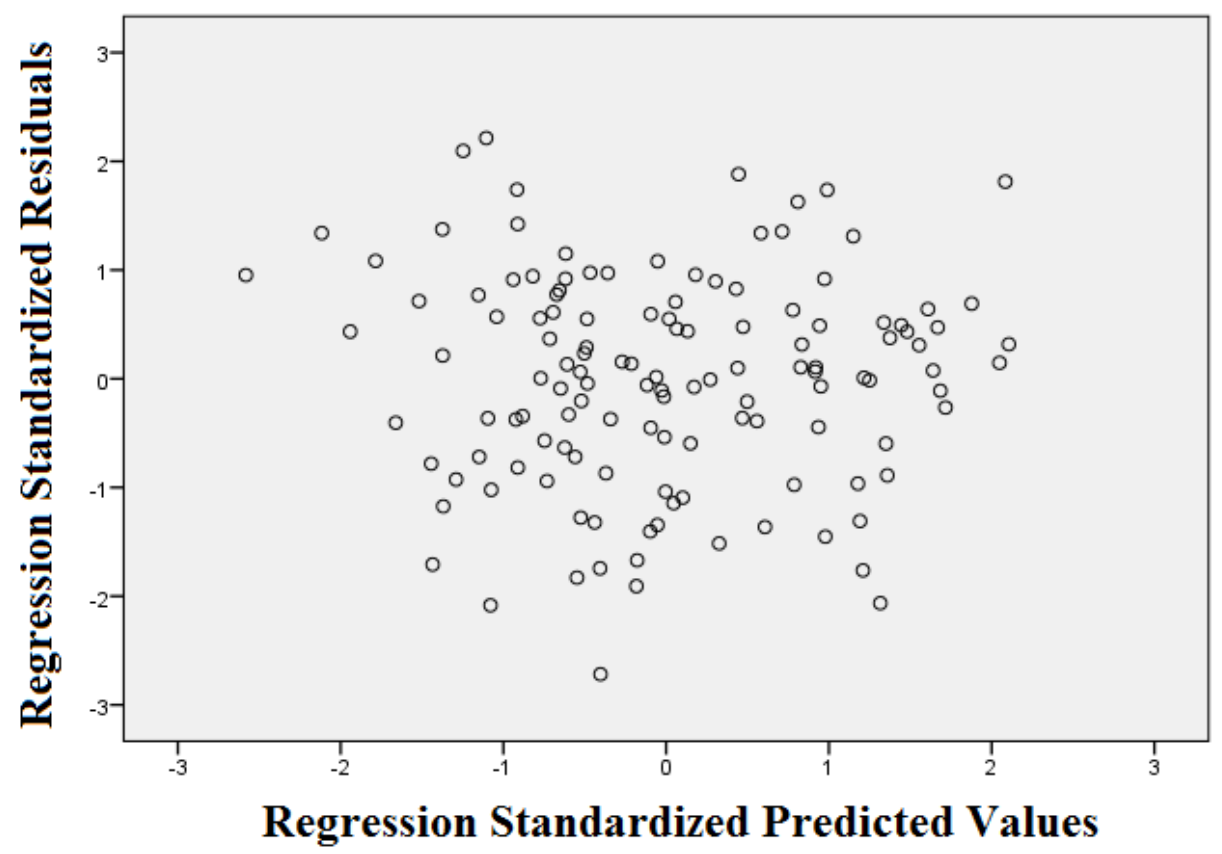

Figure 9. \% FRL Predicting Math Achievement. Standardized predicted values plotted against standardized residuals for the OLS model of the percentage of students within a school receiving FRL services predicting aggregate math achievement.

Following the input of TELL CES and \% FRL, \% ELL and two TELL survey constructs (SL and MSC) were the only other variables to be entered into the model: \% ELL was positively related to math achievement, but was not significant after applying the Bonferroni correction $(\beta=0.14, t=2.73, p=0.007)$ and contributed to the total variance explained by the model $\left(\Delta R^{2}=0.02, \Delta F=10.23, p=0.002\right)$. The TELL SL construct was a negative and significant predictor of math achievement $(\beta=-0.26, t=-$ 6.67, $p<0.001)$ and also added to the total variance explained by the model $\left(\Delta R^{2}=0.02\right.$, 
$\Delta F=7.49, p=0.007)$. The TELL MSC construct was a positive and significant predictor of math achievement ( $\beta=0.21, t=2.72, p=0.007)$ and also added to the total variance explained by the model $\left(\Delta R^{2}=0.02, \Delta F=7.40, p=0.007\right)$.

\section{Table 11}

OLS Models: \% FRL Predicting Math Achievement

\begin{tabular}{lcccccc}
\hline & $b$ & $S E$ & $\mathrm{~B}$ & $t$ & $\Delta R^{2}$ & \multicolumn{1}{c}{$\Delta F$} \\
\cline { 2 - 7 } Constant & 33.50 & 9.96 & & & & \\
CES & 0.70 & 0.12 & 0.53 & $5.64^{\dagger}$ & 0.80 & $514.08^{\dagger}$ \\
\% FRL & -0.38 & 0.06 & -0.46 & $-6.67^{\dagger}$ & 0.07 & $60.76^{\dagger}$ \\
\% ELL & 0.26 & 0.10 & 0.14 & $2.73^{* *}$ & & \\
SL & -0.50 & 0.14 & -0.26 & $-3.68^{\dagger}$ & 0.02 & $17.95^{\dagger}$ \\
MSC & 0.24 & 0.09 & 0.21 & $2.72^{* *}$ & 0.01 & $12.59^{\dagger}$ \\
\hline
\end{tabular}

Note. . Dependent Variable $=\%$ of all students within a school scoring proficient or higher on state-mandated reading tests. $b=$ unstandardized coefficient. $S E=$ standard error. $\beta=$ standardized coefficient. $\Delta R^{2}=R$-squared change. $\mathrm{CES}=$ Community Engagement and Support (TELL construct). \%FRL $=$ the percentage of students within a school receiving free or reduced-price lunch services. \%ELL $=$ the percentage of students within a school receiving special education services. $\mathrm{SL}=$ School Leadership (TELL construct). MSC $=$ Managing Student Conduct (MSC). Independent variables are listed in the order in which they were entered by SPSS.

${ }^{*} p<0.05 .{ }^{* *} p<0.01$. ${ }^{\dagger} p<0.004$.

\% Minority Predicting School-Level Math Achievement. The model constructed to explore the relationship between the percentage of Minority (Black and Latin American) students (\% Minority) and math achievement met the assumption of constant variance (see Figure 10). Table 12 provides a summary of the model. All values for the VIF were well below Stevens' (1996) recommendation of a maximum value of 10. An analysis of Cook's distances revealed no values greater than one; therefore no schools were removed from the analysis (Cook \& Weisburg, 1982). Using a conservative 
estimate (adjusted $R^{2}$ ) the model explained $67.30 \%$ of the variance observed in the sample.

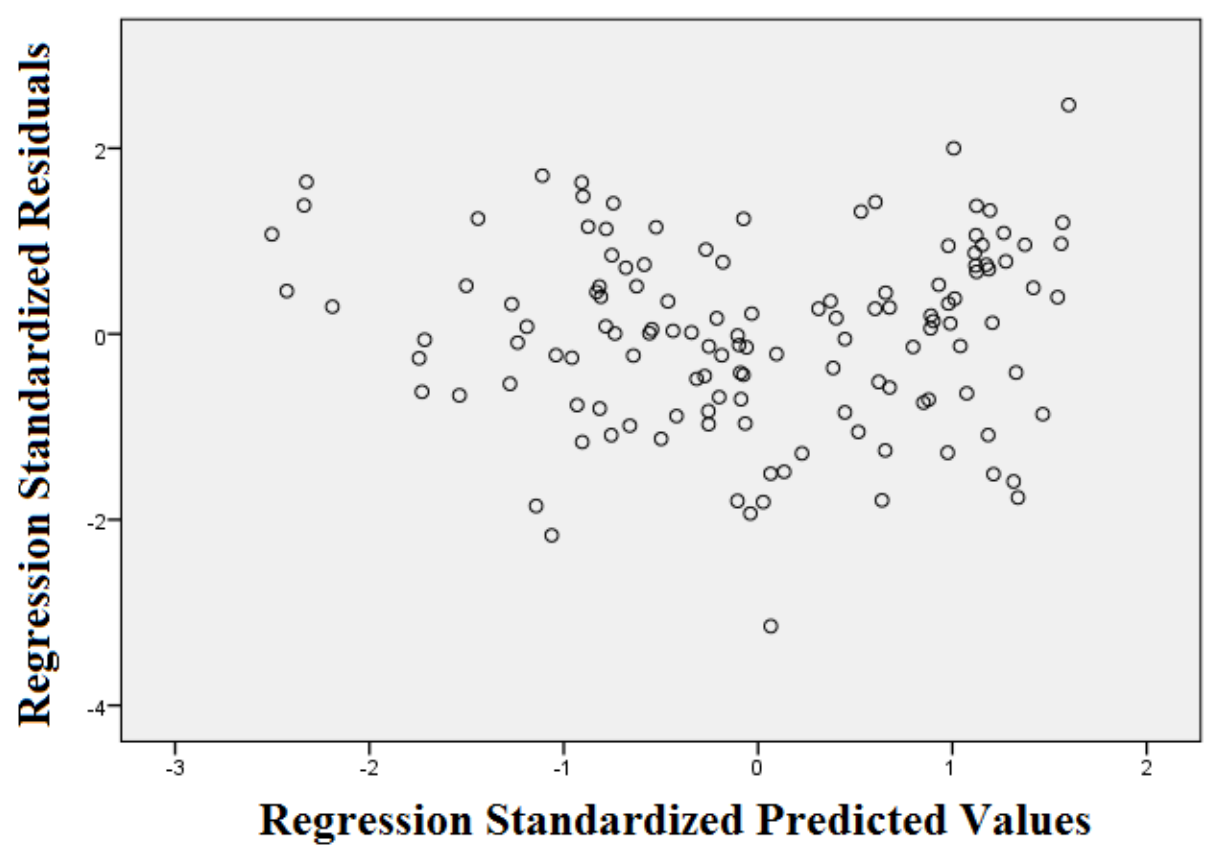

Figure 10. \% Minority Predicting Math Achievement. Standardized predicted values plotted against standardized residuals for the OLS model for the percentage of Minority students within a school predicting aggregate math achievement.

The percentage of Minority (Black/Latin American) students (\% Minority) was found to not be a significant and negative predictor of a school's aggregate math achievement, after controlling for school input and process variables in the present. The TELL CES construct was entered into the model first. The TELL CES construct was a positive and significant predictor of a school's aggregate math achievement $(\beta=0.77, t=$ 9.07, $p<0.001)$. The $R$-squared change value $\left(\Delta R^{2}\right)$ indicated that the TELL CES construct explained much of the total variance explained by the model $\left(\Delta R^{2}=0.58, \Delta F=\right.$ 179.10, $p<0.001)$. Following the input of the TELL CES construct, the TELL SL construct had the greatest partial correlation (-0.38) and was therefore entered second. The TELL SL construct was found to be a negative and significant predictor of aggregate 
math achievement $(\beta=-0.26, t=-3.59, p<0.001)$. The addition of the TELL SL construct contributed to the total variance explained by the model $\left(\Delta R^{2}=0.06, \Delta F=\right.$ 21.39, $p<0.001)$.

Table 12

OLS Models: \% Minority Predicting Math Achievement

\begin{tabular}{lcccccr}
\hline & $b$ & $S E$ & $\mathrm{~B}$ & $t$ & $\Delta R^{2}$ & $\Delta F$ \\
\cline { 2 - 7 } Constant & 8.95 & 9.64 & & & & \\
CES & 1.03 & 0.11 & 0.77 & $9.07^{\dagger}$ & 0.58 & $179.10^{\dagger}$ \\
SL & -0.49 & 0.14 & -0.26 & $-3.59^{\dagger}$ & 0.06 & $21.39^{\dagger}$ \\
MI & -0.60 & 0.22 & -0.18 & $-2.74^{* *}$ & 0.03 & $10.17^{\dagger}$ \\
New Teachers & -0.32 & 0.14 & -0.13 & $-2.27^{*}$ & 0.01 & $5.16^{*}$ \\
\hline Note. Dependent Variable $=\%$ of all students within a school scoring proficient or higher \\
on state-mandated math tests. $b=$ unstandardized coefficient. $S E=$ standard error. $\beta=$ \\
standardized coefficient. $\Delta R^{2}=R$-squared change. CES = Community Engagement and \\
Support (TELL construct). SL = School Leadership (TELL construct). MI = Mobility \\
Index. New Teachers = the percentage of new or intern teachers in a school. Independent \\
variables are listed in the order in which they were entered by SPSS. \\
${ }^{*} p<0.05 . * * p<0.01$. \\
${ }^{\dagger} p<0.004$.
\end{tabular}

The MI was entered next into the model and was found to be a negative and significant predictor of aggregate math achievement only prior to the application of the Bonferroni correction $(\beta=-0.18, t=-2.74, p=0.007)$. The addition of the MI contributed to the total variance explained by the model $\left(\Delta R^{2}=0.03, \Delta F=10.17, p=\right.$ 0.002). Finally, the percentage of new teachers was added to the model and was found to be a negative predictor of school-level math achievement, but was not significant after the application of the Bonferroni correction $(\beta=-0.13, t=-2.27, p=0.03)$. The addition of the percentage of new teachers added to the total variance explained by the model $\left(\Delta R^{2}\right.$ $=0.01, \Delta F=5.16, p=0.02)$. 
The Interaction of FRL and Minority Predicting Math Achievement. The

model constructed to explore the relationship between the interaction of FRL and Minority and math achievement met the assumption of constant variance (see Figure 11). Table 13 provides a summary of the model. All values for the VIF were below Stevens' (1996) recommendation of a maximum value of 10. An analysis of Cook's distances revealed no values greater than one; therefore no schools were removed from the analysis (Cook \& Weisburg, 1982). Using a conservative estimate (adjusted $R^{2}$ ) the model explained $67.3 \%$ of the variance observed in the sample.

The interaction of FRL and Minority was not a significant predictor of a school's aggregate math achievement and did not meet the criteria for inclusion in the model. Indeed, the model predicting math achievement using the interaction of FRL and Minority was identical to the model predicting math achievement using the \% Minority (described above). The TELL CES construct was entered into the model first. The TELL CES construct was a positive and significant predictor of a school's aggregate math achievement $(\beta=0.77, t=9.07, p<0.001)$. The $R$-squared change value $\left(\Delta R^{2}\right)$ indicated that the TELL CES construct explained much of the total variance explained by the model $\left(\Delta R^{2}=0.58, \Delta F=179.10, p<0.001\right)$.

Following the input of the TELL CES construct, the TELL SL construct had the greatest partial correlation (-0.38) and was therefore entered second. The TELL SL construct was found to be a negative and significant predictor of aggregate math achievement $(\beta=-0.26, t=-3.59, p<0.001)$. The addition of the TELL SL construct contributed to the total variance explained by the model $\left(\Delta R^{2}=0.06, \Delta F=21.39, p<\right.$ $0.001)$. 


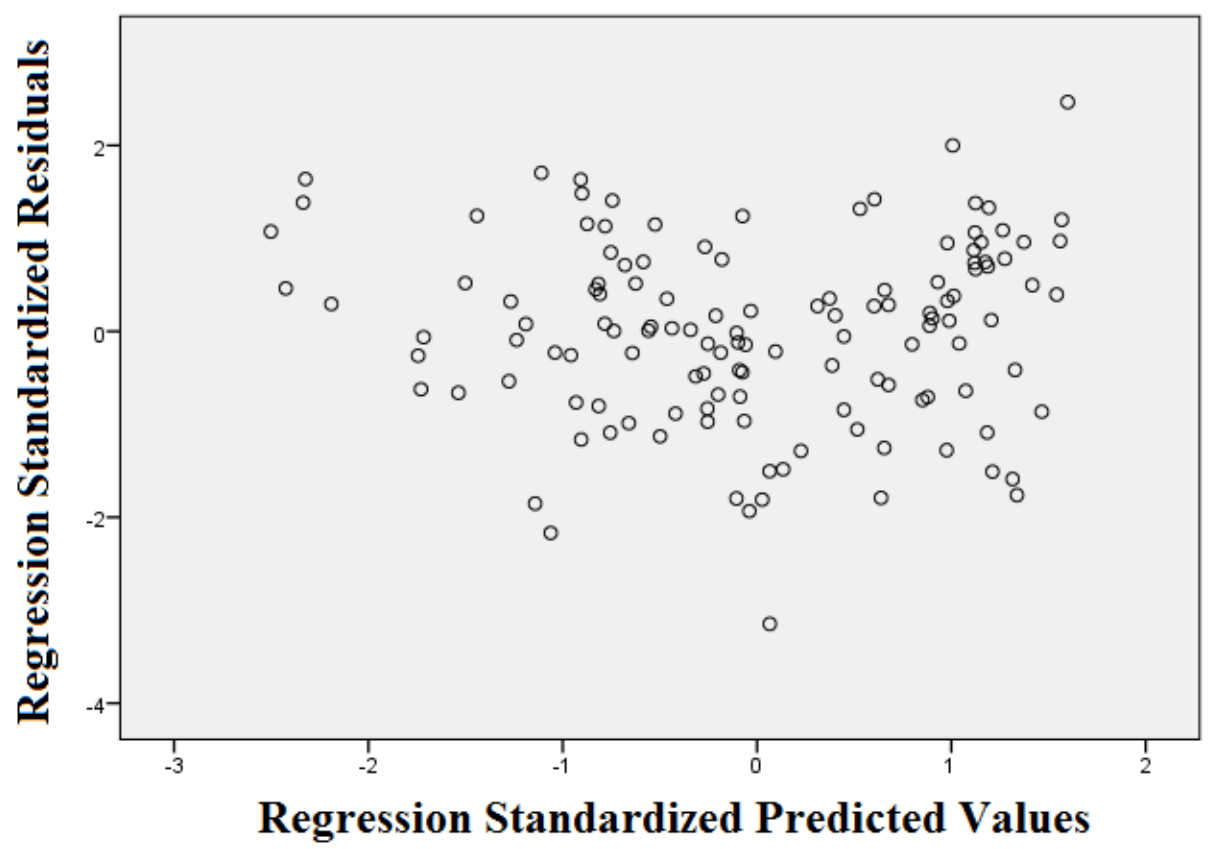

Figure 11. Interaction of \% FRL and \% Minority Predicting Math Achievement. Standardized predicted values plotted against standardized residuals for the OLS model for the interaction of \% FRL and \% Minority within a school predicting aggregate reading achievement.

The MI was entered next into the model and was found to be a negative and significant predictor of aggregate math achievement only prior to the application of the Bonferroni correction $(\beta=-0.18, t=-2.74, p=0.007)$. The addition of the MI contributed to the total variance explained by the model $\left(\Delta R^{2}=0.03, \Delta F=10.17, p=\right.$ 0.002). Finally, the percentage of new teachers was added to the model and was found to be a negative predictor of school-level math achievement, but was not significant after the application of the Bonferroni correction $(\beta=-0.13, t=-2.27, p=0.03)$. The addition of the percentage of new teachers added to the total variance explained by the model ( $\Delta R^{2}$ $=0.01, \Delta F=5.16, p=0.02)$. 


\section{Table 13}

OLS Models: Interaction of FRL and Minority Predicting Math Achievement

\begin{tabular}{lcccccr}
\hline & $b$ & $S E$ & $\mathrm{~B}$ & $t$ & $\Delta R^{2}$ & \multicolumn{1}{c}{$\Delta F$} \\
\cline { 2 - 7 } Constant & 8.95 & 9.64 & & & & \\
CES & 1.03 & 0.11 & 0.77 & $9.07^{\dagger}$ & 0.58 & $179.10^{\dagger}$ \\
SL & -0.49 & 0.14 & -0.26 & $-3.59^{\dagger}$ & 0.06 & $21.39^{\dagger}$ \\
MI & -0.60 & 0.22 & -0.18 & $-2.74^{* *}$ & 0.03 & $10.17^{\dagger}$ \\
New Teachers & -0.32 & 0.14 & -0.13 & $-2.27^{*}$ & 0.01 & $5.16^{*}$ \\
\hline
\end{tabular}

Note . Dependent Variable $=\%$ of all students within a school scoring proficient or higher on state-mandated math tests. $b=$ unstandardized coefficient. $S E=$ standard error. $\beta=$ standardized coefficient. $\Delta R^{2}=R$-squared change. CES $=$ Community Engagement and Support (TELL construct). SL $=$ School Leadership (TELL construct). MI = Mobility Index. New Teachers $=$ the percentage of new or intern teachers in a school. Independent variables are listed in the order in which they were entered by SPSS.

${ }^{*} p<0.05 . * * p<0.01$.

${ }^{\dagger} p<0.004$.

Comparisons of Diversities in Predicting Math Achievement. Predicting schoollevel math achievement with the study variables ; did not always produce an OLS regression model that included the primary independent variable, as neither \% Minority nor the interaction between FRL and Minority meet the inclusion criteria of the respective models. Table 14 summarizes each of the models estimated from the sample. In general, variables of socioeconomic diversity operationalized in the present study did not explain as much variation in the models predicting math achievement as those predicting reading achievement. A comparison of adjusted $R^{2}$ values indicates that of the models that included measures of socioeconomic diversity, \% FRL explained the greatest proportion of the variance attributed to the model among all four models (adjusted $R^{2}=$ $0.74)$. 


\section{Table 14}

\section{$\underline{\text { A Comparison of OLS Models Predicting Math Achievement }}$}

\begin{tabular}{|c|c|c|c|c|}
\hline & Model 1 & Model 2 & Model 3 & Model 4 \\
\hline Adjusted $R^{2}$ & 0.68 & 0.74 & 0.67 & 0.67 \\
\hline \multicolumn{5}{|c|}{ Independent Variables } \\
\hline DI & $0.19 * *$ & - & - & - \\
\hline FRL & - & $-0.46^{\dagger}$ & - & - \\
\hline Minority & - & - & $\mathrm{a}$ & - \\
\hline FRL x Minority & - & - & - & a \\
\hline \multicolumn{5}{|l|}{ Covariates (Input) } \\
\hline MI & $-0.17 *$ & a & $-0.18 * *$ & $-0.18 * *$ \\
\hline ELL & $\mathrm{a}$ & $0.14 * *$ & $\mathrm{a}$ & a \\
\hline \multicolumn{5}{|l|}{ Covariates (Process) } \\
\hline CES & $0.68^{\dagger}$ & $0.53^{\dagger}$ & $0.77^{\dagger}$ & $0.77^{\dagger}$ \\
\hline SL & $-0.27 * *$ & $-0.26^{\dagger}$ & $-0.26^{\dagger}$ & $-0.26^{\dagger}$ \\
\hline MSC & $\mathrm{a}$ & $0.21 * *$ & $\mathrm{a}$ & a \\
\hline New Teachers & a & $\mathrm{a}$ & $-0.13 *$ & $-0.13 *$ \\
\hline \multicolumn{5}{|c|}{$\begin{array}{l}\text { Note. Dependent variable }=\% \text { of all students within a school scoring proficient or higher } \\
\text { on state-mandated math tests. Model } 1 \text { includes the DI as the primary independent } \\
\text { variable. Model } 2 \text { includes FRL. Model } 3 \text { includes Minority. Model } 4 \text { includes FRL x } \\
\text { Minority. DI = diversity index. FRL }=\% \text { of students receiving free/reduced price lunch. } \\
\text { Minority }=\% \text { of students self-identifying as Black/Latin American. MI = mobility index. } \\
\text { ELL }=\% \text { of students within a school with limited English proficiency. CES = } \\
\text { Community Engagement and Support (TELL construct). SL }=\text { School Leadership (TELL } \\
\text { construct). MSC = Managing Student Conduct (TELL construct). New Teachers = the } \\
\text { percent of new/intern teachers. } \\
{ }^{a} \text { Did not meet inclusion criteria for the model. } \\
{ }^{*} p<0.05 . * * p<0.01 . \\
{ }^{\dagger} p<0.004 .\end{array}$} \\
\hline
\end{tabular}

The model utilizing the DI to operationalize socioeconomic diversity had a slightly lesser adjusted $R^{2}$ value than $\%$ FRL (adjusted $R^{2}=0.68$ ). The models that intended to include $\%$ Minority the interaction of FRL and Minority as a measure of socioeconomic diversity did not include those measures as these variables did not meet the inclusion criteria specified by the models. 
The directions of the relationships hypothesized for the DI and \% FRL were supported by the OLS regression models constructed. Based on the relative magnitudes of the standardized coefficients, $\%$ FRL had the greatest effect size $(\beta=-0.46, t=-6.67, p$ $<0.001)$, followed by the DI $(\beta=0.19, t=2.79, p=0.006)$. Again, $\%$ Minority and the interaction of FRL and Minority did not meet the inclusion criteria for the respective models. Based on this analysis, \% FRL had greater efficacy in predicting the aggregated math achievement of a school than the DI. However, the DI had a greater predictive efficacy than both \% Minority and the interaction between FRL and Minority, for math achievement.

\section{Low SES Students' Achievement Growth across Diversity Contexts}

Research questions 3 and 4 sought to explore the empirical evidence in the sample for the competing theories of socioeconomic diversity described by Lam (2014) and Blau et al. (2001), respectively. The DI was used to operationalize Lam's (2014) diversity in question three: that tracks of low SES students lead to predictable outcomes because of differential self, parent, and teacher expectations such that low SES students attending lower SES schools fare worse, academically, than low SES students attending higher SES schools. The DI is one way to operationalize the relative concentrations of students based on SES (and also, to an extent, on race). As the results from question one show, the DI is a positive and significant predictor of reading and math achievement for all students within a school. Furthermore, the results of the correlational analysis (see above) indicate that the DI is positively and significantly correlated to measures of low SES student achievement growth. Question three tests the proposition that school 
socioeconomic diversity, as operationalized by the DI, matters for low SES student achievement growth, after controlling for school input and process covariates.

School Socioeconomic Heterogeneity (SSH), a simple transform of the DI where $\mathrm{SSH}=1-|\mathrm{DI}-2|$, was used to conceptualize diversity as variety (Harrison \& Klein, 2007), by accounting for the distance of a school's DI from the theoretical midpoint of the DI - where a school with a DI value near zero had lesser heterogeneity and a DI value near one indicated a school had greater heterogeneity: This is Blau et al.'s (2001) diversity. Question four sought to test an extension of Blau et al.'s (2001) hypothesis: that socioeconomic heterogeneity matters in predicting the outcomes of low SES students in a school. The correlational analysis (see above) demonstrated that SSH was positively and significantly correlated to school-level reading and math achievement, but was not significantly correlated with measures of low SES student growth. Due to these results, it was considered unlikely that SSH would be a significant predictor after accounting for school input and process covariates. Nonetheless, the analysis was conducted in spite of this omen.

Research Question 3. To what extent does the DI significantly predict academic growth among students of low socioeconomic status (SES), while controlling for other school input and process variables? This research question sought to explore the relationship between the diversity index (DI) and the aggregate low SES achievement growth of a school, operationalized by the percentage of low SES students within a school making typical or higher yearly growth on state-mandated reading and mathematics tests, while controlling for covariates of school input and process. 
To address this research question, two ordinary least squares (OLS) regression models were estimated in which the DI and all other covariates were entered as independent variables in a step-wise procedure; predicting low SES student growth in reading and then math. This allowed for decisions about selecting the order of inputs for all possible variables to be based solely on mathematical parameters, as this study is exploratory in nature and to mitigate the risk of multicollinearity due to the high correlations between study variables.

Socioeconomic Tracks and Low SES Student Growth in Reading. The model constructed to explore the relationship between the diversity index (DI) and low SES student growth in reading met the assumption of constant variance (see Figure 12). Table 15 provides a summary of the model. All values for the VIF were well below Stevens' (1996) recommendation of a maximum value of 10. An analysis of Cook's distances revealed no values greater than one.

The DI was not a significant predictor of a school's aggregate low SES student growth in reading. Indeed, the only variable entered into the model was the TELL CES construct. Using a conservative estimate (adjusted $R^{2}$ ) this model accounted for $20.9 \%$ of the total variance observed in the sample $\left(\Delta R^{2}=0.215, \Delta F=32.39, p<0.001\right)$. The TELL CES construct was a positive and significant predictor of low SES student growth in reading ( $\beta=0.46, t=5.69, p<0.001)$. According to this model, an increase in one standard deviation of the percentage of positive educator perceptions on the TELL CES construct (13.04\%) yields a 0.46 standard deviation increase in the percentage of low SES students making typical or higher yearly growth in reading $(11.94 \%)$. 


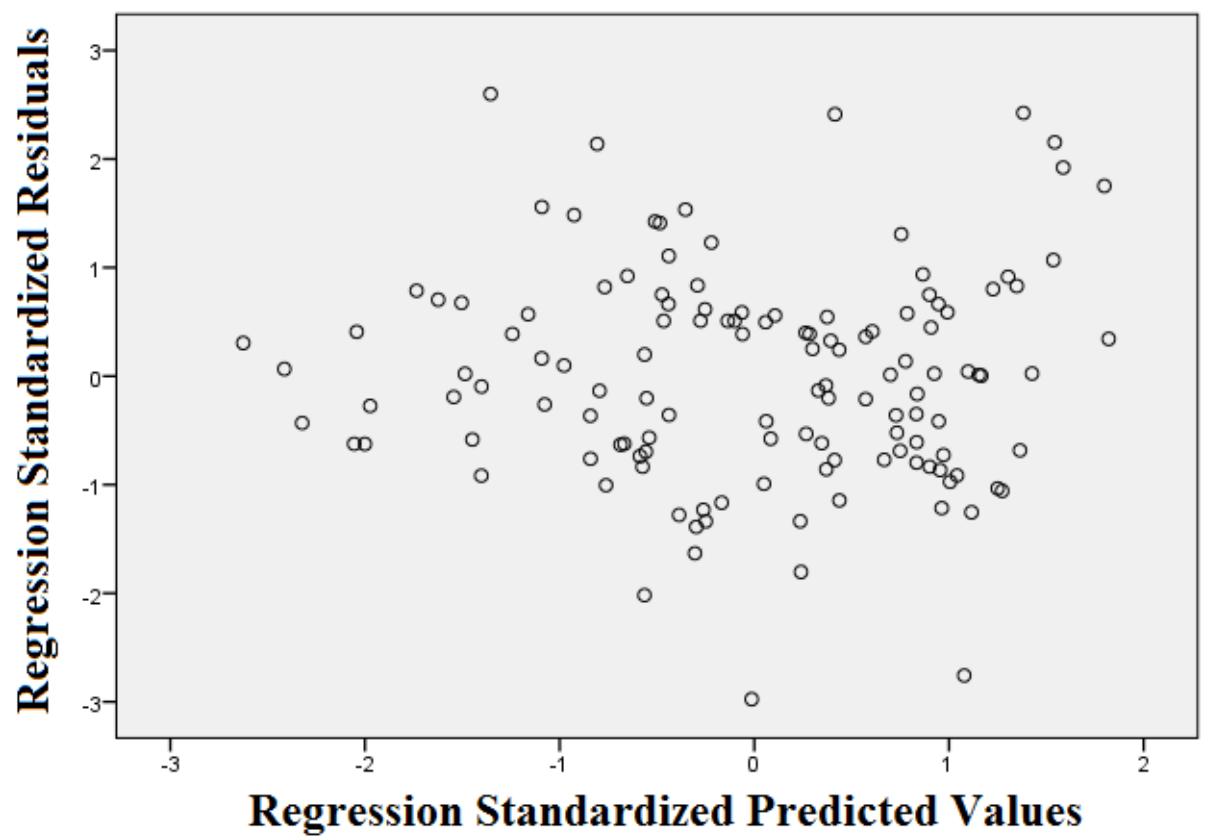

Figure 12. DI Predicting Low SES Student Reading Growth. Standardized predicted values plotted against standardized residuals for the OLS model of the diversity index (DI) predicting aggregate low SES student reading growth.

While no other variables met the parameters for entry into the model, an analysis of partial correlations of excluded variables reveals that several other variables may be worthy of mention. The strongest partial correlation was with \% ECE (-0.18) and would be expected to enter the model next, if parameters for variable selection were sufficiently expanded, followed by \% ELL (0.16). This finding was particularly interesting, given the lack of significance with the Pearson correlation (noted above) between \% ELL and low SES student growth in reading. The DI had a relatively low partial correlation with low SES student growth in reading $(-0.07)$. 


\section{Table 15}

OLS Model: DI Predicting Low SES Student Growth in Reading

\begin{tabular}{lcccccc}
\hline & $b$ & $S E$ & $\mathrm{~B}$ & $t$ & $\Delta R^{2}$ & $\Delta F$ \\
\cline { 2 - 7 } Constant & 19.03 & 6.06 & & $3.14^{\dagger}$ & & \\
CES & 0.43 & 0.08 & 0.46 & $5.69^{\dagger}$ & 0.22 & $32.39^{\dagger}$ \\
\hline Note. Dependent Variable $=\%$ of low SES students within a school making typical or \\
higher achievement growth on state-mandated reading tests. $b=$ unstandardized \\
coefficient. $S E=$ standard error. $\beta=$ standardized coefficient. $\Delta R^{2}=$ R-squared change. \\
CES = Community Engagement and Support (TELL construct). \\
${ }^{*} p<0.05$.
\end{tabular}

Socioeconomic Tracks and Low SES Student Growth in Math. The model constructed to explore the relationship between the diversity index (DI) and low SES student growth in math met the assumption of constant variance (see Figure 13). Table 16 provides a summary of the model.

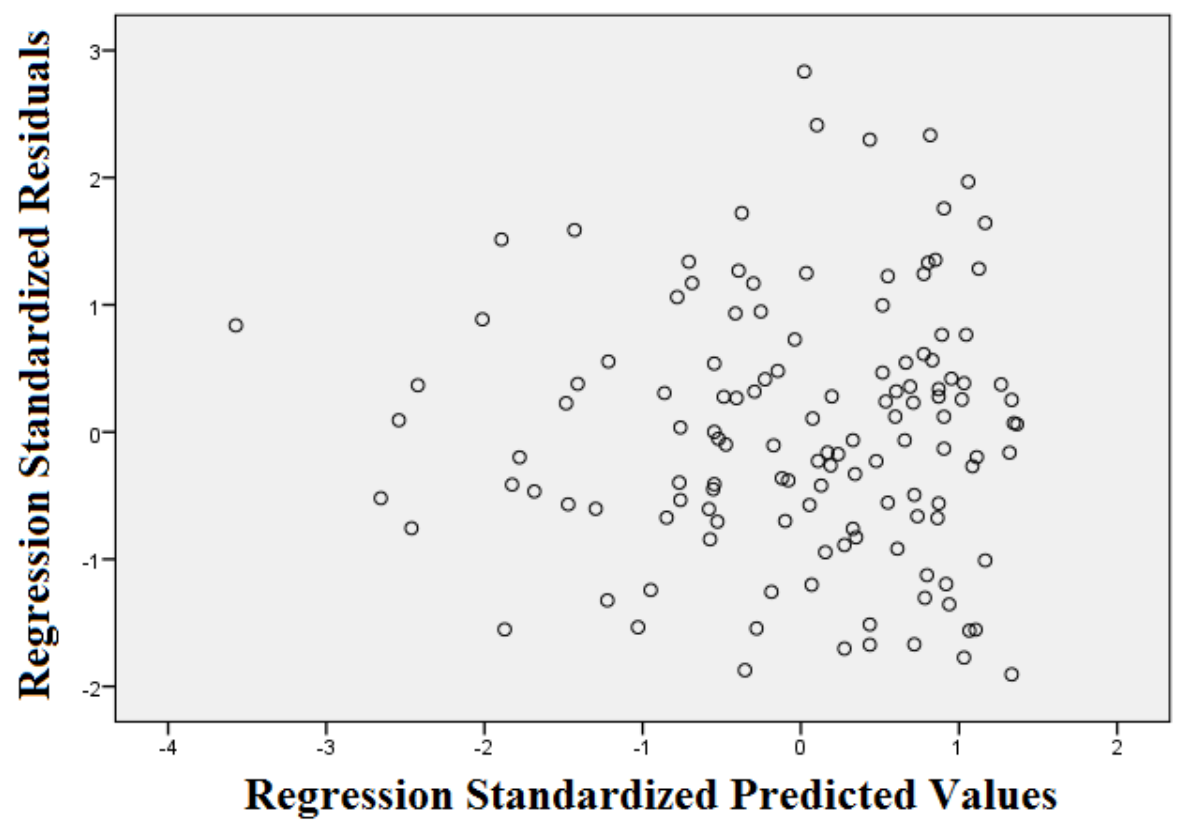

Figure 13. DI Predicting Low SES Math Growth. Standardized predicted values plotted against standardized residuals for the OLS model of the diversity index (DI) predicting aggregate low SES student math growth. 
All values for the VIF were below Stevens' (1996) recommendation of a maximum value of 10. An analysis of Cook's distances revealed no values greater than one. The DI was not a significant predictor of a school's aggregate low SES student growth in math. Two variables fit the model parameters: TELL MSC and the MI. Using a conservative estimate (adjusted $R^{2}$ ) this model accounted for $20.5 \%$ of the total variance observed in the sample. The TELL MSC construct accounted for most of the variance $\left(\Delta \mathrm{R}^{2}=0.18, \Delta F=25.73, p<0.001\right)$ while the MI contributed less $\left(\Delta \mathrm{R}^{2}=0.04, \Delta F=\right.$ $5.95, p=0.02)$. The TELL MSC construct was a positive and significant predictor of low SES student growth in math $(\beta=0.36, t=4.26, p<0.001)$. The MI was a negative predictor of low SES student growth in math, but was not significant after the Bonferroni correction $(\beta=-0.21, t=-2.44, p=0.02)$. As with its partial correlation with low SES student growth in reading, the partial correlation between the DI and low SES student growth in math was relatively low (0.07) compared to other excluded variables. Teacher turnover, for example, had the highest partial correlation of all excluded variables $(-0.18)$, followed by TELL CES (0.09).

\section{Table 16}

\section{OLS Models: DI Predicting Low SES Student Growth in Math}

\begin{tabular}{lrrrrrr}
\hline & $b$ & $S E$ & $\mathrm{~B}$ & $t$ & $\Delta R^{2}$ & $\Delta F$ \\
\cline { 2 - 7 } Constant & 32.45 & 6.82 & & $4.76^{\dagger}$ & & \\
MSC & 0.31 & 0.07 & 0.63 & $4.26^{\dagger}$ & 0.18 & $25.73^{\dagger}$ \\
MI & -0.51 & 0.21 & -0.21 & $-2.44^{*}$ & 0.04 & $5.95^{*}$ \\
\hline Note. Dependent Variable $=\%$ of low SES students within a school making typical or \\
higher achievement growth on state-mandated math tests. $b=$ unstandardized coefficient. \\
SE= standard error. $\beta=$ standardized coefficient. $\Delta R^{2}=R$-squared change. MSC = \\
Managing Student Conduct (TELL construct). MI = Mobility Index. \\
${ }^{*} p<0.05$. \\
${ }^{\dagger} p<0.004$.
\end{tabular}


Research Question 4. Does school-level socioeconomic heterogeneity significantly predict academic growth among students of lower socioeconomic status (SES), while controlling for other school input and process variables? This research question sought to explore the relationship between school socioeconomic heterogeneity (SSH) and the aggregate low SES achievement growth of a school, operationalized by the percentage of low SES students within a school making typical or higher yearly growth on state-mandated reading and mathematics tests, while controlling for covariates of school input and process.

To address this research question, two ordinary least squares (OLS) regression models were estimated in which SSH and all other covariates were entered as independent variables in a step-wise procedure; predicting low SES student growth in reading and then math. This allowed for decisions about selecting the order of inputs for all possible variables to be based solely on mathematical parameters, as this study is exploratory in nature and to mitigate the risk of multicollinearity due to the high correlations between study variables.

Socioeconomic Heterogeneity and Low SES Student Growth in Reading. The model constructed to explore the relationship between SSH and low SES student growth in reading met the assumption of constant variance (see Figure 14). Table 17 provides a summary of the model. All values for the VIF were below Stevens' (1996) recommendation of a maximum value of 10. An analysis of Cook's distances revealed no values greater than one. 


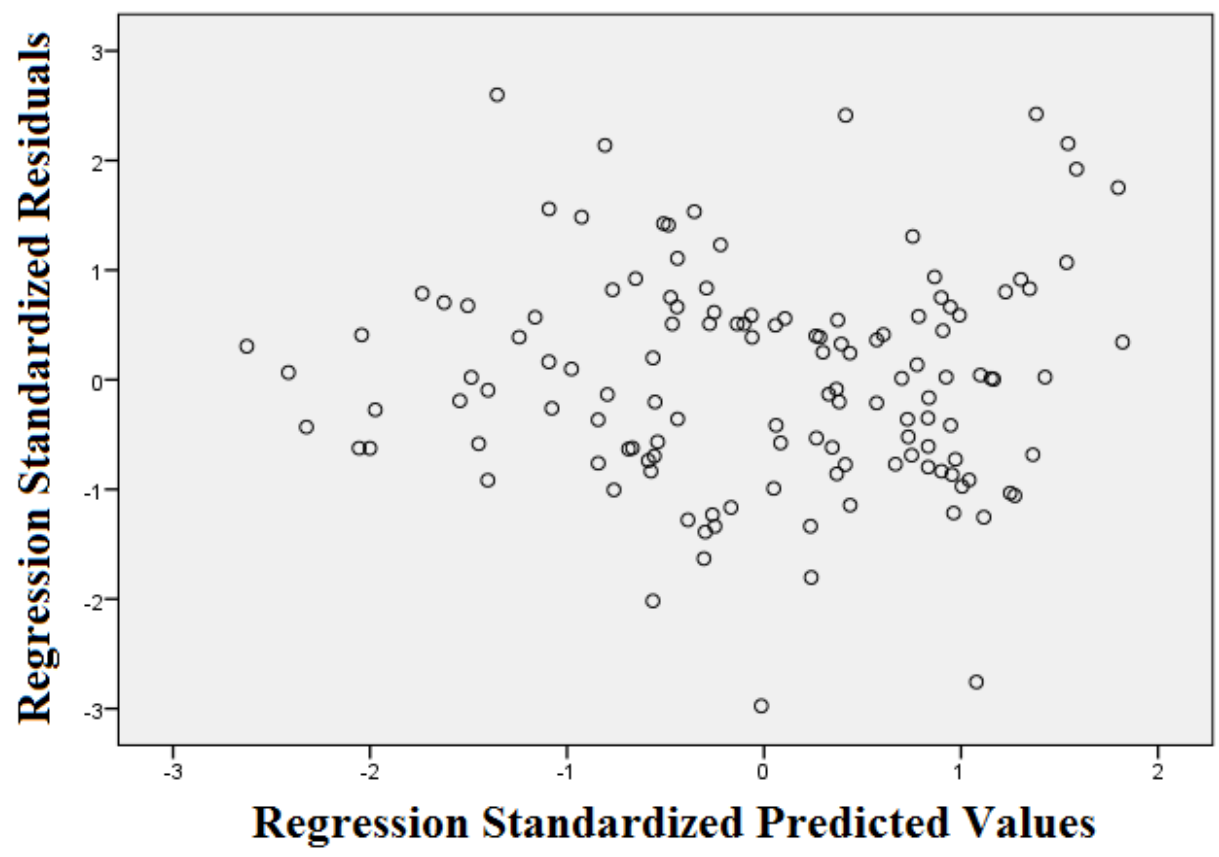

Figure 14. SSH Predicting Low SES Reading Growth. Standardized predicted values plotted against standardized residuals for the OLS model of school socioeconomic heterogeneity $(\mathrm{SSH})$ predicting aggregate low SES student reading growth.

School Socioeconomic Heterogeneity ( $\mathrm{SSH}$ ) was not a significant predictor of a school's aggregate low SES student growth in reading. As was the case in predicting low SES growth in reading using the DI, only one variable was entered into the model: the TELL CES construct. The models are, indeed, identical. Using a conservative estimate (adjusted $R^{2}$ ) this model accounted for $20.9 \%$ of the total variance observed in the sample $\left(\Delta R^{2}=0.215, \Delta F=32.39, p<0.001\right)$. The TELL CES construct was a positive and significant predictor of low SES student growth in reading $(\beta=0.46, t=5.69, p<0.001)$. According to this model, an increase in one standard deviation of the percentage of positive educator perceptions on the TELL CES construct (13.04\%) yields a 0.46 standard deviation increase in the percentage of low SES students making typical or higher yearly growth in reading $(11.94 \%)$. Had the parameters specified for the models been expanded sufficiently, teacher turnover would likely be the next variable entered 
into the equation as it had the highest partial correlation of all excluded variables $(-0.18)$.

The partial correlation of SSH was relatively low among excluded variables $(-0.03)$.

\section{Table 17}

OLS Model: SSH Predicting Low SES Student Growth in Reading

\begin{tabular}{lrccccc}
\hline & $b$ & $S E$ & $\mathrm{~B}$ & $t$ & $\Delta R^{2}$ & $\Delta F$ \\
\cline { 2 - 7 } Constant & 19.03 & 6.06 & & $3.14^{\dagger}$ & & \\
CES & 0.43 & 0.08 & 0.46 & $5.69^{\dagger}$ & 0.22 & $32.39^{\dagger}$ \\
\hline
\end{tabular}

Note. . Dependent Variable $=\%$ of low SES students within a school making typical or higher achievement growth on state-mandated reading tests. $b=$ unstandardized coefficient. $S E=$ standard error. $\beta=$ standardized coefficient. $\Delta R^{2}=R$-squared change. CES $=$ Community Engagement and Support (TELL construct). *p $<0.05$. $\dagger_{p}<0.004$.

Socioeconomic Heterogeneity and Low SES Student Growth in Math. The model constructed to explore the relationship between School Socioeconomic Heterogeneity (SSH) and low SES student growth in math met the assumption of constant variance (see Figure 15). Table 18 provides a summary of the model. All values for the VIF were below Stevens' (1996) recommendation of a maximum value of 10. An analysis of Cook's distances revealed no values greater than one. School Socioeconomic Heterogeneity (SSH) was not a significant predictor of a school's aggregate low SES student growth in math. As was the case in predicting low SES growth in math using the DI, only two variables were entered into the model: TELL MSC and the MI. The models are, indeed, identical. 


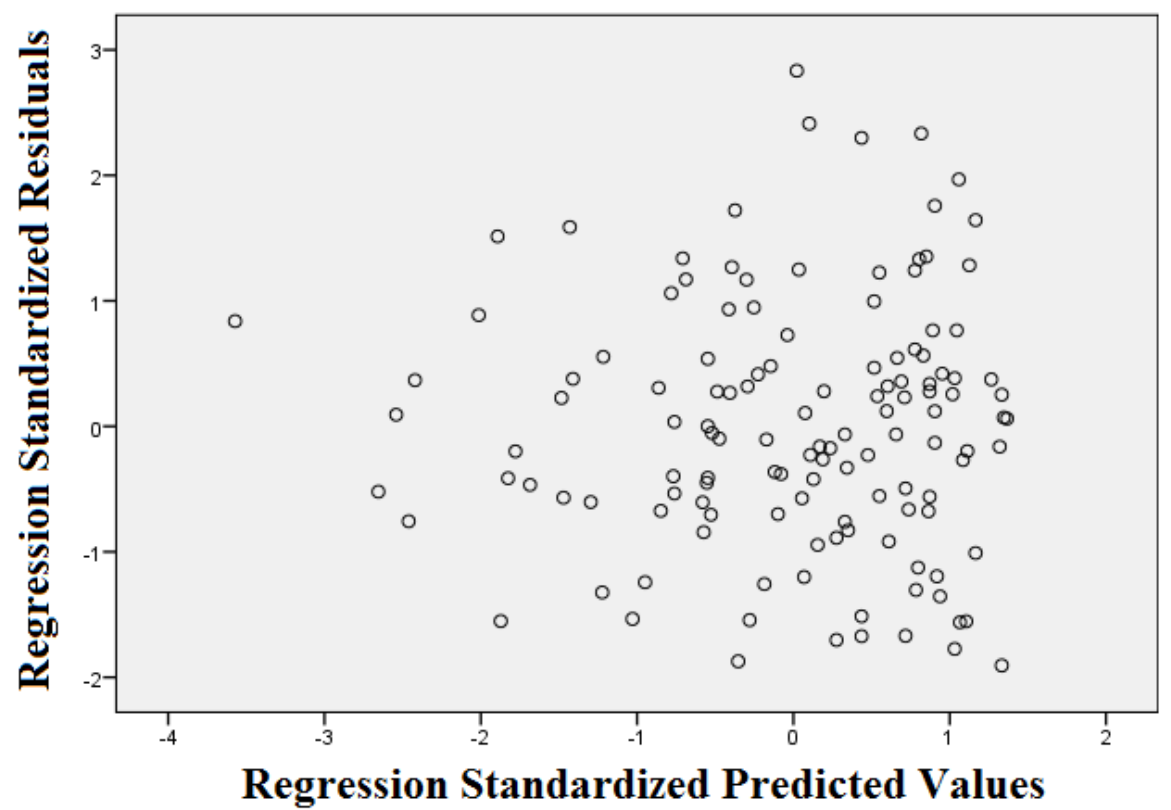

Figure 15. SSH Predicting Low SES Math Growth. Standardized predicted values plotted against standardized residuals for the OLS model of school socioeconomic heterogeneity (SSH) predicting aggregate low SES student math growth.

Using a conservative estimate (adjusted $R^{2}$ ) this model accounted for $20.5 \%$ of the total variance observed in the sample. The TELL MSC construct accounted for most of the variance $\left(\Delta R^{2}=0.18, \Delta F=25.73, p<0.001\right)$ while the MI contributed less $\left(\Delta R^{2}=\right.$ $0.04, \Delta F=5.95, p=0.02$ ). The TELL MSC construct was a positive and significant predictor of low SES student growth in math $(\beta=0.36, t=4.26, p<0.001)$. The MI was a negative predictor of low SES student growth in math, but was not significant after the Bonferroni correction $(\beta=-0.21, t=-2.44, p=0.02)$. As with its partial correlation with low SES student growth in reading, the partial correlation between SSH and low SES student growth in math was relatively low (-0.03) compared to other excluded variables. Teacher turnover, for example, had the highest partial correlation of all excluded variables (-0.18), followed by TELL CES (0.09). Had the parameters specified for the 
models been expanded sufficiently, teacher turnover would likely be the next variable entered into the equation as it had the highest partial correlation of all excluded variables (-0.18). The partial correlation of SSH was relatively low among excluded variables ($0.03)$.

\section{Table 18}

OLS Models: SSH Predicting Low SES Student Growth in Math

\begin{tabular}{lcccccr}
\hline & $b$ & $S E$ & $\mathrm{~B}$ & $t$ & $\Delta R^{2}$ & \multicolumn{1}{c}{$\Delta F$} \\
\cline { 2 - 7 } Constant & 24.37 & 5.68 & & $4.29^{\dagger}$ & & \\
MSC & 0.31 & 0.07 & 0.36 & $4.62^{\dagger}$ & 0.18 & $25.73^{\dagger}$ \\
MI & -0.51 & 0.21 & -0.28 & $-2.44^{\dagger}$ & 0.04 & $5.96^{*}$ \\
\hline
\end{tabular}

Note. Dependent Variable $=\%$ of low SES students within a school making typical or higher achievement growth on state-mandated math tests. $b=$ unstandardized coefficient. $S E=$ standard error. $\beta=$ standardized coefficient. $\Delta R^{2}=R$-squared change. MSC $=$ Managing Student Conduct (TELL construct). MI = Mobility Index.

*p $<0.05$. $\dagger_{\mathrm{p}}<0.004$.

\section{Summary of Key Findings}

A descriptive analysis illustrated the distribution of inequities that still exist in JCPS in spite of a continued commitment to diversity and tremendous resources expended in an effort to structure within-school socioeconomic and racial diversity. These data show that a substantial percentage of schools are, to some extent, socioeconomically isolated: $14.62 \%$ of schools in the sample $(n=19)$ served student populations with greater than $90 \%$ of students receiving FRL services: 18 elementary schools and one middle school. Furthermore, $8.46 \%$ of schools in the sample $(n=11)$ served student populations with greater than $90 \%$ of students identifying as Black or 
Latin American. Ten of these schools were elementary schools and one, a high school, is a Historically Black Institution (HBI).

Analysis also reveals that middle schools struggle to retain teachers more than elementary and high schools and that middle schools tend to have lower proficiency rates and smaller proportions of low SES students making typical or higher annual achievement growth in reading and math. The dramatic increase in the average socioeconomic diversity (as seen in the increase in average DI values and a decrease in $\%$ FRL) from elementary to middle school warrants further study. It is unclear whether this influx of students from Whiter and more affluent census blocks into JCPS middle schools is due to more recent demographic shifts or more stable enrollment patterns across time.

The correlational analysis of independent variables with dependent variables is agreeable with the hypotheses put forth in the present study, with one major exception: SSH did not appear to be significantly correlated with low SES student achievement growth. Furthermore, \% FRL was most strongly correlated to measures of academic achievement operationalized herein than other measures of socioeconomic and/or racial diversity, followed by the DI. In addition, low SES student achievement growth in reading and math were more highly correlated to several study covariates than to measures of school diversity operationalized in the present study; most notably with TELL CES and MSC. Moreover, concentrations of students in poverty tended to be more strongly correlated to low SES student growth in reading than measures of racial diversity and the opposite appeared to be true for models predicting low SES student growth in math. 
The results from the regression analysis are mixed in their support for the alternative hypotheses in the present study. The diversity index was found to be a positive and significant predictor of a school's aggregate level of reading and math achievement. Although the regression equations support the assertion that \% FRL is a stronger predictor of school-level reading and math achievement, the DI seems to be a better predictor than \% Minority and the interaction between FRL and Minority. Nonetheless, \% Minority and the interaction between FRL and Minority were negative and significant predictors of school-level reading achievement as well: between the two, the interaction of FRL and Minority was a stronger predictor of reading achievement than $\%$ Minority alone. Given the set of independent variables and covariates offered in the present study, the regression equations predicted more of the variation in school-level reading achievement than for math achievement.

The models estimating relationships between Minority and the interaction between FRL and Minority did not support the hypothesis that these measures of school diversity were significant predictors of math achievement. Furthermore, the TELL construct, Community Engagement and Support (CES) was a powerful predictor of both reading and math achievement, and was also a stronger predictor of math achievement than any measure of socioeconomic and racial diversity. In considering school-level reading achievement outcomes, only \% FRL had a greater correlation coefficient than the TELL CES construct. While the DI was entered first into the stepwise model estimating its relationship with reading achievement, the TELL CES construct had a larger correlation coefficient than the DI. The TELL construct, School Leadership (SL) is also worthy of mention, as it was consistently entered into all models predicting reading and 
math achievement and was consistently a negative predictor of both school-level reading and math achievement.

The models constructed to explore the relationships between socioeconomic diversity and low SES student achievement growth explained less of the variance observed in the sample. Indeed, socioeconomic diversity, as operationalized herein, did not significantly predict low SES student achievement growth in reading or math. Only TELL CES met the inclusion criteria of the models estimated to test hypotheses of low SES student achievement growth in reading and only the TELL MSC and the MI met the inclusion criteria for the models estimated to test hypotheses of low SES student achievement growth in math. 


\section{CHAPTER V \\ DISCUSSION}

This final chapter begins with a brief summary of the study, including a restatement of the study purpose and research questions with a brief synopsis of the methodological approach. Next, two strands of key findings are discussed and are then situated in the body of related literature with some discussion about a few notable surprises. Finally, this chapter ends with implications for policy and future research, followed by a few concluding remarks.

\section{Overview of the Study}

Jefferson County Public Schools (JCPS), a large urban public school district in the Southeastern U.S., is a district committed to structuring socioeconomic and, ultimately, racial diversity within its schools. In 2000, JCPS was declared unitary and was no longer under court mandate to continue its student assignment plan (SAP) to mitigate extant de facto segregation. Nevertheless, JCPS continued to use its SAP to structure within-school diversity until the Supreme Court's ruling in the Meredith (2007) case. This landmark decision of the Court forced JCPS (and other school districts across the U.S. with voluntary integration policies) to more narrowly focus the use of an individual student's race in student assignment decisions. Since 2013, JCPS has utilized a managed-choice SAP that uses a metric called the diversity index (DI) to ensure some level of socioeconomic/racial diversity in schools. 
The DI might be defined as the approximate average socioeconomic status (SES) of students within a school. It is approximate because it is based on neighborhood characteristics of the neighborhood in which each student resides, not on the characteristics of individual students themselves. The DI is also a composite measure of SES, meaning that it combines a set of variables, drawn from American Community Survey (ACS) data, to construct a latent variable which categorizes each student's census-block as low, medium, or high SES. There is nothing particularly special about these qualities of the DI, except that one of its components is race - which is, at the very least, rare in conceptualizing and operationalizing SES. To this extent, the DI offers a response to calls from the APA Task Force on SES that researchers should "become better informed about state-of-the-art approaches to conceptualizing and measuring SES and social class" including the "intersection with measures of race/ethnicity" (APA, 2007, p. 26).

While some literature exists on the efficacy of the DI to structure within-school socioeconomic/racial diversity compared to simulations of neighborhood school assignment and a simulation based solely on school-choice in JCPS (Frankenberg, 2017), no literature could be found on the relationship between the DI and academic outcomes. The present study provides an explicit definition of the DI as well as an exploratory analysis of the relationships between socioeconomic/racial diversity operationalized in different ways, including JCPS's DI, and school-level academic achievement, operationalized by the percentage of students within a school scoring proficient or higher on state-mandated reading and math tests while controlling for other school input and process variables known to influence achievement. 
An exploratory analysis was also conducted to test tenable hypotheses derived from competing theories on the relationship between conceptions of socioeconomic diversity and the achievement growth of poor/minority students (Blau et al., 2001; Lam, 2014). Harrison and Klein (2007) state that when "diversity of unit members... may be meaningfully conceptualized in different ways... [this] allows theorists to differentiate and compare conceptual models... paving the way for empirical tests of contrasting conceptions" of diversity (p. 1210). While research on the effects of peer socioeconomic diversity on academic achievement remains inconclusive, several studies have demonstrated such a relationship (Hanushek et al., 2003; Kang, 2007; Malecki \& Demaray, 2006; Vandenberg, 2002). Furthermore, this relationship seems to vary with the ways in which researchers conceptualize and operationalize SES, the unit of analysis when considering a "group" of students, and covariates that are either included in or omitted from the regression models constructed (Ewijk \& Sleegers, 2010). The peereffects literature is dominated by the use of multiple regression techniques.

\section{Restatement of the Purpose and Research Questions}

One purpose of this study was to investigate the relative efficacy of the DI in predicting the aggregate academic achievement of students within a school compared to measures of socioeconomic/racial diversity analogous to components of the DI: specifically, the percentage of students within a school receiving free or reduced-price lunch (\% FRL), the percentage of Black and Latin American students (\% Minority) within a school, and the interaction (product) of \% FRL and \% Minority. Another purpose of the present study was to test two competing theories on the relationship between socioeconomic/racial diversity and academic achievement of low SES students 
within a school. Lam (2014) theorizes that tracks, or relative concentrations of low SES students in different groupings, lead to predictable outcomes because of differential self, parent, and teacher expectations. Here, low SES students attending high SES schools should have higher levels of academic achievement than low SES students attending low SES schools. Conversely, an extension of the idea of cosmopolitan environments, attributed to Blau et al. (2001), postulates that since all learning is social (evoking the voice of John Dewey), marginalized students should perform better when the heterogeneity of a group approaches equality. Here, low SES students should fare better when the relative proportions of students from different socioeconomic/racial categories approach equality. The following research questions are posed:

1. To what extent does the diversity index (DI) predict academic achievement, as measured by the percentage of students within a school scoring proficient or higher on state-mandated reading and math tests, while controlling for other school input and process variables?

2. What is the relative efficacy of the DI in predicting academic achievement to analogous student-level components: (a) the proportion of students receiving free or reduced-price lunch (FRL), (b) the racial/ethnic composition of the school and (c) the interaction between FRL and race/ethnicity, while controlling for other school input and process variables?

3. To what extent does the DI significantly predict academic growth among students of low socioeconomic status (SES), while controlling for other school input and process variables? 
4. Does school-level socioeconomic heterogeneity $(\mathrm{SSH})$ significantly predict academic growth among students of lower socioeconomic status (SES), while controlling for other school input and process variables?

\section{Review of the Methodological Approach}

The present study sought to explore relationships among variables; therefore, a correlational/multiple-regression approach was utilized (Abbott \& McKinney, 2012). The findings presented provide a descriptive analysis followed by a correlational analysis of all study variables. Finally, since the purpose of the study was exploratory in nature, a family of ordinary least squares (OLS) regression models were constructed using a stepwise method. All study covariates were entered into each of the OLS models in addition to the specific primary independent variable (measure of socioeconomic/racial diversity) for each model (see Figure 1). The possibility of spurious effects arising from multicollinearity were monitored using the variance inflation factor (VIF) and Cook's distance values were used to identify and remove possible influential data points, as recommended by Stevens (1996). These OLS regression models were reported and comparisons were drawn between regression models to address each of the four research questions posed.

\section{Key Findings: On the Viability of the DI in Predicting Achievement}

One purpose of this study was to establish the viability of the DI as a predictor of school-level academic achievement, operationalized by state-mandated reading and math tests in one large, urban public school district in the Southeastern U.S. The DI is a

multiple-component, collective (or, generalized) measure of the average SES of a school 
that represents one possible way to operationalize the intersection between race and poverty. With respect to a school's aggregate level of reading achievement, all measures of school socioeconomic/racial diversity operationalized herein were significant and strong predictors, even when accounting for other school input and process variables. While concentrations of students receiving FRL services was the strongest predictor, providing a response to Harrison and Klein's (2007) critique of the use of FRL as a proxy measure of SES in the education literature, the DI was also strong and significant in its relationship to school-level reading achievement. Racial diversity, as operationalized in this study, seemed to be less powerful of a predictor of reading achievement while controlling for other input and process variables. The interaction of FRL and Minority (measures of poverty and race more closely tied to individual students), was more efficacious in its predictive power on reading achievement than minority concentration alone but was not as efficacious as the DI.

The results from the analysis of OLS regression models predicting school-level math achievement show a similar trend in the relative efficacy of these measures of socioeconomic/racial diversity operationalized in the present study: That the concentration of students receiving FRL services is a more powerful predictor than the DI, although the DI is significantly related to school-level math achievement as well. However, in the regression models predicting school-level math achievement, neither the concentration of minority students nor the interaction of FRL and Minority enrollment were entered into the respective models, suggesting that the covariates entered into these models were better predictors than minority student concentration and the interaction of FRL and Minority enrollment. Specifically, educator perceptions of working conditions 
captured by the Teaching, Empowering, Leading, and Learning (TELL) constructs, Community Engagement and Support (CES) and School Leadership (SL) seem to be more powerful predictors of school-level math achievement than any measure of socioeconomic/racial diversity operationalized in the present study - excepting the concentrations of students living in poverty, as measured by the percentage of FRL participants in a school.

In short, based upon data drawn from the present sample, the DI - an amalgam of more traditional measures of SES with race - appears to be a significant predictor of school-level achievement; albeit slightly better at predicting school-level reading achievement than math achievement. Concentrations of students in poverty tended to be a stronger predictor of school-level academic achievement, with higher concentrations of FRL participants predicting lower aggregate levels of achievement. Measures of socioeconomic/racial diversity that more heavily weighted concentrations of Minority students were not as strong in predicting academic achievement. Indeed, it appears that poverty seems to matter more than race in predicting aggregate levels of academic achievement among schools in the sample.

It should also be noted that two constructs from the TELL survey were also important factors worthy of consideration in predicting aggregate reading and math achievement in the sample: Community Engagement and Support (CES) and School Leadership (SL). Furthermore, it is important to acknowledge the strong and significant correlations between measures of socioeconomic/racial diversity and all TELL constructs in the sample for the purpose of calling attention to the fact that schools with low 
concentrations of low SES students tend to have educators with more positive perceptions of their working conditions.

\section{Situating these Findings in the Literature}

I interpret these results as suggesting concentrations of students living in poverty is a more powerful predictor of school-level reading and math achievement than concentrations of minority students in a school and either conception of intersections of poverty and race, operationalized by the DI and the interaction of FRL and Minority enrollment. The question of whether it is the DI's collective nature in conceptualizing SES based on a student's neighborhood characteristics or the importance of adult educational attainment in a student's neighborhood explains the greater efficacy of the DI relative to the interaction of FRL and Minority warrants further research. One thing is clear: concentrations of students living in poverty within a school yield predictable school-level achievement outcomes, as is consistent with the literature (Muñoz, Clavijo, \& Koven, 1999; Sirin, 2005; White, 1995). For example, Muñoz, Clavijo, and Koven (1999) found that concentration of students receiving FRL services was a powerful predictor of school-level academic achievement in JCPS; moreover, that poverty was a stronger predictor than race (as measured by the percentage of Black students in a school).

In considering the ways in which socioeconomic/racial diversity are operationalized in the present study, the findings of Ewijk and Sleegers (2010) offer an interesting point of comparison in relation to the larger literature base. In their metaanalysis of the effect of peer socioeconomic status on student achievement, Ewijk and Sleegers (2010) found that when researchers "measure SES dichotomously (e.g., free 
lunch eligibility) or include several average SES-variables in one model, they find smaller effects than when using a composite that captures several SES-dimensions" (p. 134). To the extent to which socioeconomic diversity in schools is operationalized in the present study, it seems as though the DI (a composite measure) has a smaller effect size on school-level academic achievement than the percentage of FRL students within a school (a variable ultimately derived from a dichotomous state of individual students). While Harwell and LeBeau (2010) criticize the literature base on the use of student eligibility for FRL as a proxy measure of SES, the findings of the present study suggest that the percent of FRL participants within a school may be a better predictor of schoollevel achievement outcomes than other measures of SES, including the DI.

It should also be noted, in considering the present analysis that associations between socioeconomic background and school climate (TELL constructs) are not, necessarily, independent of one another, as indicated by the strengths of Pearson correlations between these two groups of variables. Yet, VIF values of these variables did not raise concern in the construction of OLS regression models. The relative strength of the TELL constructs in predicting academic achievement, specifically Community Engagement and Support (CES) and School Leadership (SL), compared to school socioeconomic diversity operationalized herein demonstrates that while these two groups of variables often competed for a greater proportion of the total variation explained across OLS regression models, the two are highly correlated with one another and with all measures of school socioeconomic/racial diversity operationalized herein.

This finding suggests that school climate factors may play a role in moderating the effects of socioeconomic background. Berkowitz, Moore, Astor, \& Benbenishty 
(2017) provide an interesting perspective on the directionality of the relationship between socioeconomic background, school climate, and academic achievement in their research synthesis. Through systematic review of 78 research articles which met the inclusion criteria for their analysis, Berkowitz et al. (2017) found "evidence that school climate has a role in changing the strength of the relationship between SES and academic achievement” (p. 453), for better or for worse. While the findings of Berkowitz et al. (2017) imply "schools with lower SES backgrounds should not necessarily demonstrate poor climate" (p. 458), the strength and direction of Pearson correlations between TELL constructs and measures of socioeconomic diversity suggest JCPS schools with higher concentrations of students from lower SES backgrounds tend to have lower levels of agreement with respect to educator perceptions of community engagement and support and less positive perceptions of school leadership. While the present study is limited to simply describing relationships, these findings suggest that, indeed, lower SES schools tend to have a "poor" climate, at least as measured by educator perceptions of working conditions operationalized by the TELL survey.

In summary, school socioeconomic/racial diversity seems to predict school-level academic achievement across JCPS schools in the present sample, even when controlling for other factors known to influence student achievement. Moreover, this seems to hold true across distinct measures of socioeconomic diversity, yet some measures of socioeconomic/racial diversity seem to be better predictors of academic achievement than others. Specifically, measures that place greater emphasis on poverty seem to explain a greater proportion of the variance explained in the present sample than measures that place greater emphasis on race. Moreover, the DI, a measure of socioeconomic/racial 
diversity based on neighborhood characteristics, tends to be a stronger predictor of school-level academic achievement than another composite measure of socioeconomic/racial diversity more closely tied to individual students, the interaction of FRL and Minority concentrations in a school.

\section{Key Findings: Conceptions of Diversity in Predicting Low SES Student Growth}

The variation in low SES student achievement growth in reading and math proved more difficult to predict than aggregated levels of academic achievement among all students. In this family of regression models, the TELL CES and managing student conduct (MSC) constructs, along with the mobility index (MI), were the only predictors which explained any portion of the variance in aggregated low SES student reading (TELL CES) and math (TELL MSC and the MI) achievement growth.

The correlational analysis does, on the other hand, provide some evidence to address the research questions pertaining to how the conceptions of diversity operationalized herein correlate to aggregated levels of achievement growth of low SES students. Nearly all measures of school socioeconomic and racial diversity were significantly, yet weakly to moderately, correlated with low SES student achievement growth in reading and math. Student characteristics (\% FRL, \% Minority, and their interaction) had stronger correlations and greater levels of statistical significance than measures based on collective measures of socioeconomic/racial diversity (the DI and SSH). Moreover, measures of diversity emphasizing concentrations of poverty (\% FRL) had stronger correlations to low SES student reading achievement growth and measures of concentrations of Minority students had stronger correlations to low SES student math 
achievement growth. The strength of the interaction effect of FRL and Minority was intermediate in strength.

Correlations between the DI and aggregated low SES student achievement growth in reading and math were weaker than any other measure of socioeconomic diversity, excepting School Socioeconomic Heterogeneity ( $\mathrm{SSH}$ ), yet were still significant. The transformation of the DI, SSH, was not significantly correlated to low SES student reading or math achievement growth. These results from the correlational analysis are interpreted as lending limited support for the theory of Lam (2014) and do not provide any evidence of a relationship between diversity conceptualized as variety, or heterogeneity (Blau et al., 2001) and low SES student achievement growth in reading or in math.

\section{Situating these Findings in the Literature}

There is great debate among researchers and policy makers alike as to whether proficiency cut scores or student growth scores should be used in school and district accountability systems since the universal proficiency mandate of NCLB (Betebenner, 2009; Ho, 2008). While using the percentage of proficient students (PPS) in a school to make judgements about a school's educational efficacy is conceptually simpler than using student growth scores, when PPS is utilized as an outcome variable much information is lost and "interpretation of these depictions generally leads to incorrect or incomplete inferences about distributional change" (Ho, 2008, p. 351). The fundamental distinction between proficiency (status) and growth models is "whether or not prior achievement should be taken into account" (Betebenner, 2009, p. 43). Since the third and fourth research questions are specific to achievement growth outcomes of low SES 
students, who are underrepresented in high achieving groups, this study considered student growth in order to account for prior achievement of low SES students.

While the present study did not support the theories of Lam (2014) or Blau et al. (2001), Ewijk and Sleegers (2007) found that studies investigating peer socioeconomic diversity and academic achievement included in their meta-analysis tended to demonstrate stronger evidence of a relationship when researchers used smaller groups of students (i.e., classroom-level) as the unit of analysis than larger units (grade- or schoollevel). Hornstra et al. (2015), for example, found that growth in reading scores were lower for low SES students in classrooms with higher concentrations of middle- and high-SES classmates and were higher in classes with more ethnic minority students in The Netherlands. It is therefore possible that the unit of analysis is simply too large to observe discernable relationships, which may be due to within-school tracking not accounted for in the present study. Nonetheless, it is possible that peer socioeconomic diversity is not important in considering the factors which might bolster achievement growth of low SES students in the present sample.

These findings suggest that educator perceptions, at least as operationalized by two TELL constructs Community Engagement and Support (CES) and Managing Student Conduct (MSC), matter for low SES student reading and math achievement growth, respectively. The mobility index (MI), a possible proxy measure of homelessness, was shown to be positively and significantly related to low SES student achievement growth in math, in agreement with the findings of Cowen (2017) who analyzed the impact of mobility across Michigan from the 2010-2011 to 2012-2013 school years. The findings of the present study strongly resemble the findings of Cowen (2017), who found that 
homelessness was significantly related, yet "small for math and essentially zero for reading" (p. 39). Furthermore, Hattie (2008) found that student mobility had an effect size of -0.34 .

In considering the finding of the present study that the TELL CES construct was the strongest, indeed the only, predictor of low SES student growth in reading, it is important to note this construct consists of eight survey items and that five of these items $(62.5 \%)$ explicitly use the words "parent(s)/guardian(s)". Evidence exists that parental involvement in the education of their children is aligned to higher academic growth (Hill \& Tyson, 2009; Jeynes, 2007; Zhan \& Sherraden, 2011). Using data from the Education Longitudinal Study of 2002, Benner et al. (2016) found that "moderation analyses revealed that school-based [parental] involvement seemed to be particularly beneficial [in terms of students' grade point averages] for more disadvantaged [low SES students and students with lower prior-achievement] youth" (p. 1053). This findings is consistent with Lam's (2014) theory, in that it demonstrates the importance of educator expectations.

Also worthy of discussion is the finding that the TELL MSC construct was significant and was the strongest predictor of low SES achievement growth in math. Indeed, TELL MSC was one of only two variables entered into the OLS regression model predicting low SES achievement growth in math. The TELL MSC survey items focus on educator perceptions of whether or not students understand behavioral expectations, follow those expectations, and whether teachers in the school feel like other teachers and school administrators understand and support the behavioral expectations of the school. It is interesting to note these findings in light of the body of literature, which spans decades, pertaining to the impact of classroom- and school-based diversity programs on 
academic achievement (Aronson \& Bridgeman, 1979; Aronson \& Patnoe, 1997, 2011; Cohen \& Lotan, 1995; Orfield, 2017; Slavin, 1980). Orfield (2017) remarks on the need for educators to,

$[\mathrm{I}]$ ntentionally cross the lines of social divisions... in order to increase the human capital of schools struggling with divisions.... The reality is that we have become an extremely diverse society with intense separation and inequality without any framework of policy or even a serious ongoing body of research and legal analysis to help us through what is obviously a very difficult transition [of school demographic shifts and resegregation] (pp. 166-167).

The observation that educator perceptions, operationalized by the TELL constructs CES and MSC, are the strongest, arguably the sole, predictors of low SES student achievement growth in the present study and the observation that these perceptions are, in turn, also significantly correlated with the DI and SSH lend credence to consideration of the burgeoning literature on the interrelatedness of socioeconomic inputs, school climate, and academic achievement of low SES students (Berkowitz et al., 2017). According to Berkowitz et al. (2017), there are conflicting frameworks for the directionality of socioeconomic inputs and school climate in terms of which is mediating and which is moderating in their predictability of low SES student growth. For example, in 2002, Bryk and Schneider argued that students of low SES backgrounds would benefit from positive school climates (perhaps such as those with higher perceived parental school-involvement and educator perceptions about student conduct and school wide support for behavioral expectations). Bryk and Schieder (2002), along with other authors, have argued for the primacy of school climate and how the deleterious effects of 
a low socioeconomic background can be moderated by a positive school climate (Brand, Felner, Shim, Seitsinger, \& Dumas, 2003; Schagen \& Hutchinson, 2003). An alternative framework expresses the primacy of SES background to influence positive school climate (McCoy, Roy, \& Sirkman, 2013).

\section{Implications for Policy}

The DI is used to ensure some level of within-school socioeconomic and, ultimately, racial diversity in JCPS - a large, urban public school district with pronounced geographic stratification of race and SES. Frankenberg (2017) found that the use of the DI in JCPS's managed school-choice SAP was, indeed, efficacious in structuring some level of within-school racial diversity; at least, to a greater extent than simulations of SAP's modeled on neighborhood school assignment or a completely choice-based SAP. Worthy of mention here are the findings of Taylor \& Frankenberg (2016) on the relative efficacy of JCPS's SAP to structure racial diversity compared to other districts across the U.S. However, Frankenberg (2017) also found,

Black and White students' exposure becomes less similar [since the Meredith case in 2007], suggesting increasing racial segregation. Latino students become more integrated with White students and less so with Black students... Thus, by 20142015, Latinos were more integrated with White students while Black students were most segregated (p. 236).

The results of the present study extend the findings of Frankenberg (2017) as well as Taylor and Frankenberg (2016) that racial segregation, while low relative to other districts across the U. S. (Orfield, Kucsera, \& Siegel-Hawley, 2012; Taylor \& Frankenberg, 2016), remains extant in JCPS. 
Frankenberg (2017) reported mixed findings with respect to the efficacy of JCPS's SAP in stabilizing economic segregation, yet the present study confirms that some schools continue to serve high concentrations of students from low SES backgrounds. What implications exist from the results of the present study with respect to the current SAP of JCPS? First, the present study provides empirical evidence that the DI is positively and significantly correlated to school-level academic achievement - at least, as operationalized in the present study. Frankenberg (2017) suggests that "understanding the effects of these shifts in [student assignment] policy is important because they could lead to improved student outcomes" (p. 244).

The findings of the present study support assertions from prior research that the ways in which districts assign students to schools, based on socioeconomic and racial composition, can have an impact on student achievement (Caldas \& Bankston, 1996; Lippman, Burns, \& McArther, 1996; Sirin, 2005; Vanderhaar et al., 2004). Lippman et al. (1996) found that student achievement sharply declined when a school's poverty rate rose above $40 \%$ and Vanderhaar et al. (2004) found significant differences between student achievement levels in schools with low-poverty concentrations versus medium and high-poverty concentrations on the Comprehensive Test of Basic Skills (CTBS) Total Battery and the Total Academic Index (TAI). The findings of Caldas and Bankston (1996) demonstrated that minority concentrations in Louisiana schools were negatively related to achievement outcomes even after controlling for individual and school-level SES. Furthermore, there is "strong evidence that segregation by race is usually segregation by poverty as well" (Orfield \& Frankenberg, 2011). 
One thing is certain: JCPS continues to serve a large and diverse metropolitan area and, therefore, maintains the opportunity that many other large metropolitan areas, which are fractured into smaller school districts that serve more homogenous groups of people, have lost through the result of the Court's decision in Milliken v. Bradley (1974). The continued commitment of JCPS to structure within-school diversity remains promising, although there are reasons to suspect an impending demise of that commitment. In the 2017 legislative session in Kentucky, a bill filed by a House representative from Jefferson County would have allowed parents and students to opt out of the SAP in favor of their neighborhood school, effectively ending JCPSs SAP and undoubtedly would have resulted in increased segregation in JCPS. The bill passed the House, but died in the Senate where other education legislation, namely a charter school bill, took priority. Recently, media outlets reported that some residents of a newly constructed neighborhood in one of the most affluent areas of the school district (coincidentally, with a newly constructed elementary school built to serve that neighborhood) strongly opposed the construction of low-income housing within a proposed location inside of that neighborhood (Ryan, 2016; Shafer, 2016). The voices of these and other powerful political actors suggest the desire of at least some affluent residents to live in segregated neighborhoods and, perhaps, send their children to segregated schools. These sentiments reverberate the findings of Saporito and Lareau (1999), who found that White families tend to avoid schools with high concentrations of Black students, even before considering other school factors. Yet other community members continue to support an ideal of an integrated metropolitan area (McCravy, 2016) and, presumably, integrated schools. 
This study also provides a description of one mechanism, utilized by JCPS, in which school districts can help to mitigate "the sorting of students across metropolitan areas that perpetuate patterns of educational inequality in suburban space" (Rhodes \& Warkentien, 2017, p. 169) in light of factors such as disproportionate access to residential choices that increase the likelihood of what Rhodes and Warkentien (2017) call the “package deal”. Indeed, Rhodes and DeLuca (2014) note that families living in poverty tend to decouple choices about residential and school choice by relying on SAP's, such as JCPS's, which might allow poor families access to higher performing schools in spite of having less information about school rankings and choice options. Yet, there is much work to be done in JCPS if access to school choice is to be equitably distributed across families of different socioeconomic/racial backgrounds living within the district, as noted by Frankenberg (2016).

One policy recommendation, based upon the findings of the present study, would be to encourage district leaders to review the diversity guidelines set forth in JCPS's SAP, established using the DI, and to review the commitment of district governance to ensure those guidelines are met - as several schools had DI values well outside of those diversity guidelines in the 2015-2016 school year. Such a renewed commitment might provide the impetus to reduce the number of schools serving high concentrations of students in poverty and to reduce the apparent and growing isolation of Black students in JCPS noted in this study, by Frankenberg (2017), and reported by local media outlets (Otts \& Konz, 2015). Such a trend is seemingly ubiquitous across the U.S., as researchers have found that racial segregation is on the rise as desegregation mandates are ending (Reardon, Grewall, Kalogrides, \& Greenberg, 2012). While 
socioeconomic/racial integration alone cannot buffer low SES students against the realities of the many factors which likely contribute to differential expectations of academic achievement, avoiding high concentrations of students in poverty (Vanderhaar et al., 2006) and minority status (Caldas \& Bankston, 1996) may offer greater opportunities for equitable educational outcomes by providing access to higher performing schools - whatever that means.

Another policy recommendation emerging from the findings of the present study is the need to provide differentiated and equitable supports across schools with varying student needs. Milner (2010), Jones and Nichols (2013), among other authors, argue that educators should act to differentiate supports and that can only begin by refusing to ignore differences that students bring with them to school. As Orfield (2017) notes, $[\mathrm{M}]$ ost teachers... say that they treat all students the same and assume that is the best policy for fairness (Frankenberg, 2012). Research on suburban racial change, which is now massive, found the same kind of denial by educators about the need to do anything specific about race and resegregation (p. 165).

Carmichael-Murphy and Carpenter (2017) found evidence that at least some principals seem to address issues of race from a deficit mindset and conflate issues of race with SES in making sense of Positive Behavioral Interventions and Supports (PBIS) systems implemented in their schools. Furthermore, several JCPS policies, such as schoolfunding policies, are grounded in the notion of equality (such as teacher-funding formulas, which equalize funding for teachers based solely on the number of students attending a school), thereby ignoring the differences students bring to schools and limiting equitable resource distributions across schools. The present study justifies calls 
for a systematic review of how various district and board policies might inhibit the equitable distribution of resources so that schools serving higher concentrations of marginalized students are afforded the tools to address challenges such compositions can present.

JCPS has made remarkable, if only relative, strides ensuring continued efforts to try and mitigate existing neighborhood segregation and provide diverse learning environments in schools. As the present study demonstrates, socioeconomic/racial integration via JCPS's SAP matters for educational outcomes. Yet, there are still marginalized students who remain effectively segregated based on their socioeconomic background and/or racial identity. This segregation, while relatively limited across the district, has consequences for the expectations of students in certain schools. While some parents continue to fight for their rights to choose the best schools for their children, an understandable argument, there is evidence that educational outcomes are linked to myriad life outcomes, including longevity (Hummer \& Hernandez, 2013; Rostron, Boies, $\&$ Arias, 2010). The present study purports that the persistence of structuring any number of schools with high concentrations of marginalized students and a failure to provide equitable educational supports can potentially have devastating effects on those students, from short-term academic achievement to the very expectation of their longevity. The persistence of JCPS to remain committed to diversity is an argument about axioms. This study provides further empirical evidence to inform decisions about whether or not to continue to uphold diversity as a core value so that arguments for structuring within-school diversity are not misconstrued as doing so for the sake of diversity itself. 


\section{Implications for Future Research}

One purpose of this study was to seek a better understanding of the use of competing measures of SES, specifically univariate versus multivariate and individual versus collective measures, as well as measures constructed to include traditional measures of SES and race/ethnicity. Much debate exists among educational researchers on how to best operationalize SES. The present study provides an explicit definition of one collective and multiple-component measure of socioeconomic diversity, the DI, utilized by JCPS to ensure some level of school diversity and compares the strength of the DI in predicting academic achievement to other common measures of SES; in particular, concentrations of FRL participants, concentrations of Minority students, and the interaction between FRL and Minority. The need for such analysis is made explicit by Harwell and LeBeau (2010) among others (APA, 2007; Milner, 2007).

The results of this study suggest that concentrations of poverty predict schoollevel academic achievement better than measures which include information pertaining to concentrations of Minority students in schools. When considering the presupposition that poverty tends to matter more than race in predicting school-level academic achievement, more research would certainly shed light on the matter. Charlotte-Mecklenburg Schools (CMS), for example, plans to implement a managed-choice SAP that is very similar to the SAP of JCPS in the 2017-2018 school year, with one big difference: the collective measure of SES adopted by CMS does not include information about race like the DI does. It would be interesting to compare, for example, the efficacy of the DI in predicting aggregate levels of academic achievement with the metric to be used by CMS. 
However, such comparisons may prove difficult due to the fact that these two school districts operate in different accountability contexts.

The present study adds to the body of literature, suggesting that the ways in which school districts structure socioeconomic/racial diversity might impact other factors that directly or indirectly influence student achievement as well, such as through teacher retention or school climate factors, among others (Berkowitz et al., 2017; Ingersoll, 2003). As noted by Diem and Brooks (2013), "integration was a solution to segregation, but integration does not address quality education" (p. 115). The present study highlights the need for future research to investigate the mechanisms through which SAP's can impact these and other factors related to school-level academic achievement. I join call from Berkowitz et al. (2017) to "establish the nature of impact positive climate has on academic achievement and a multifaceted body of knowledge regarding... [the possibility that] a positive climate can successfully disrupt the associations between low SES and poor academic achievement" (p. 425). Orfield (2017) notes that while funding of diversity programs and research has reduced since the 1980s, many classroom and school techniques were developed to improve racial relations and academic achievement” (p. 166). JCPS does invest in diversity and poverty programs. These programs provide an opportunity for researchers to investigate how such programs might help mitigate potential social divisions and their deleterious effects on academic achievement.

Other implications for future research stem from limitations of the present study. Due to the exploratory nature of this study and the selected methodological approach, one limitation is that arguments of causality cannot be inferred and also, that these results leave much to be learned about; for example, the potential of mediating and/or 
moderating effects among the independent variables and covariates selected for inclusion in the present study. As Berkowitz et al. (2017) note, the expansive yet inconsistent "body of knowledge regarding the interrelations between SES, school climate, and academic achievement... a better understanding of these relationships can help in further explicating the role of school climate and its potential contribution to reducing the achievement gap" (p. 427). Although any extension of the present study to investigate these interrelations should pay careful consideration to the fact that "one of the challenges in fully understanding the relationships among SES, academic achievement, and school climate may be related to the manner in which school climate is defined and measured" (Berkowitz et al., 2017, p. 427). Nonetheless, structural equation modeling (SEM) or classification and regression trees (CART) may prove to be viable methodological approaches in exploring the interrelatedness of these constructs in the present school district and could prove helpful in future policy decisions about how to support high-minority/high-poverty schools.

Another limitation is the problem of generalizability of these findings to other large school districts or across time. As mentioned above, comparisons across district SAP's, accountability contexts and geographic distributions of enclave neighborhoods within different school districts pose challenges to research design. Although the use of geographic information systems (GIS), such as ACS data, may provide an avenue to extend this line of inquiry. Another interesting possibility for future research might be a longitudinal analysis of how changes in socioeconomic/racial diversity arising from shifts in student assignment policies across time has affected school-level academic achievement in JCPS schools. The progressive expansion of the actual range of DI 
values in JCPS since the current SAP was implemented in 2013 may provide a natural experiment in which to test hypotheses about how JCPS's SAP and demographic shifts have affected school-level academic achievement over time.

Another purpose of this study was to inform district SAP's of school districts seeking to maximize both student diversity and student achievement. While the present study does not question the broader importance of diversity in educational contexts, it investigates the potential that students of high SES may have a more immediate impact on academic outcomes of low SES students; specifically, the achievement growth of low SES students. Such an understanding of the relationship between school diversity and academic outcomes may help to guide districts seeking to maximize both student diversity and academic achievement. In addition, such a study of the relationship between peer socioeconomic diversity and academic outcomes might inform our theoretical understanding of such a relationship.

This study sought to inform competing theories of this relationship, in particular those of Lam (2014) and Blau et al. (2001). The present study was unable to provide strong evidence to support either of these competing theories. However, this does not mean that peer socioeconomic diversity does not impact the achievement of low SES students. It is important to keep in mind that while neither the DI nor SSH were found to be significant in predicting low SES student achievement growth, these measures of racial/socioeconomic diversity were significantly correlated with the TELL constructs and the DI was significantly correlated with low SES student achievement growth in both reading and math. It is entirely possible that the lack of evidence is due to factors, such as the methodological approach or the ways in which these conceptions of diversity were 
operationalized, masked the explanatory power of these theories. Furthermore, the way in which achievement growth of low SES students was operationalized may prove to be limiting in exploring the viability of these theoretical frameworks.

One way in which the methodological approach could have been limiting is that the present study fails to account for within-school tracking and instead focusses solely on between school tracking. Hierarchical linear modeling (HLM) might prove fruitful to this end if individual students, categorized by SES, could be nested into classes and schools. While scholars, such as Kozol (1991), have made explicit the savage inequalities between schools, Labaree (2010) and Oakes (2005) have acknowledged and described how schools track students within. Future research and more sophisticated methodological tools may allow for a more complete picture of the effects of peer socioeconomic diversity on the academic achievement of low SES students in JCPS.

There are also possible limitations arising from the ways in which socioeconomic/racial diversity were operationalized in the present study. This study operationalized diversity as disparity and as variety (Harrison \& Klein, 2007) using the DI and a transformation of the DI, school socioeconomic heterogeneity (SSH), respectively. While the DI is a weighted average of the distribution of students' socioeconomic backgrounds (based on neighborhood characteristics), thus accounting for some differences in the distribution of student SES between schools, other differences may have been masked by the DI. For example, it is possible that the set of schools in the sample with DI values near the middle of its theoretical distribution may, in reality, have very different student compositions. Since the DI categorizes student SES into one of three categories one could imagine a school serving equal proportions of low and high 
SES students, another serving equal proportions of low, medium, and high SES students or a school serving only medium SES students. Due to the symmetrical nature of the DI, all three of these cases would have the same DI value, but with very different student populations. Moreover, since the DI is susceptible to this limitation, SSH would therefore also be susceptible to this limitation. It is therefore possible that the ways in which socioeconomic/racial diversity were operationalized herein masked the relationship of socioeconomic diversity and low SES student achievement growth. Future research along this line of inquiry might seek alternative ways to operationalize these conceptions of diversity derived from the theories of Lam (2014) and Blau at al. (2001). It is important to keep in mind that while neither the DI nor SSH were found to be significant in predicting low SES student achievement growth, these measures of racial/socioeconomic diversity were significantly correlated with the TELL constructs and the DI was significantly correlated with low SES student achievement growth in both reading and math. These findings should encourage future research that operationalizes socioeconomic/racial diversity in alternative ways to investigate evidence for the theories of Lam (2014) and Blau et al. (2001).

Finally, it is acknowledged that the way in which low SES student achievement growth scores were aggregated in the present study may have been too crude to observe any potential relationships between socioeconomic/racial diversity and low SES student growth. The use of growth scores provide a distinct advantage over measures of status, such as using the percentage of proficient students (PPS), in that they account for low SES student prior achievement. Ho (2008) makes explicit the limitations of using the percentage of proficient students (PPS) in school accountability systems. First, Ho 
(2008) points to the fact that proficiency cut scores are subjective, and second, that achievement gaps apparent in accountability systems are dependent upon these subjective cut scores. One limitation of the present study was the way low SES student achievement growth was operationalized herein, in that another (arguably subjective) cut score was used - the measure of "typical" yearly growth operationalized by the Kentucky Assessment and Accountability system to classify students based on a normative growth measure and subjective cut-score. The use of such a subjective cut score potentially masks significant yearly achievement gains and, possibly, the relationships between socioeconomic/racial diversity and the achievement growth of low SES students. Future research should consider growth outcomes that are more granular in nature, such that a higher fidelity of actual student growth is accounted for in measuring such an outcome.

\section{Conclusion}

This chapter provided an overview of the study, including a restatement of the study purpose and research questions as well as a review of the methodological approach. Next, two strands of key findings were provided, each situated in related literature. Finally, implications for policy and future research emerging from the present study were discussed. The findings from this study suggest that the ways in which districts group students within schools is important for student achievement. While JCPS expends tremendous resources to ensure some level of within-school socioeconomic and, ultimately, racial diversity, segregation still exists. However, JCPS should be commended on its continued commitment to structuring within-school diversity. Indeed, Frankenberg (2017) claims that, “JCPS may be a 'best case scenario' for student assignment policies after Parents Involved because of its strong policy design and 
desegregation history (Rearson \& Rhodes, 2011; Richards, Stroub, Heilig, \& Volonnino, 2012)" (p. 245).

This study suggests that JCPS maintains the opportunity to mitigate inequities resultant from the challenges of socioeconomic contexts and racial identity many urban public school districts face and provides an analysis which seeks to untangle the intersections between SES and race. These are issues at the forefront of educational equity, steeped in political rhetoric and reflective of deeply seeded historical divisions based on class, race, and the many ways in which they intersect. The present study asserts that the measure by which JCPS operationalizes socioeconomic/racial diversity is significantly and positively correlated to school-level academic achievement and therefore provides the school district with a mechanism through which to control the extent to which marginalized students are further marginalized by the deleterious effects of school segregation by SES and race. If JCPS is to remain a leader in school integration among American school districts in spite of diminishing urgency of the courts to mandate, or even enforce historic mandates of school integration, then it should consider its level of continued commitment to its own diversity guidelines. The argument for diversity in schools is not one that should be misconstrued as doing so for the sake of diversity alone. Indeed, diversity matters in education. 


\section{REFERENCES}

Abbott, M. L., \& McKinney, J. (2012). Understanding and applying research design. Hoboken, NJ: Wiley.

Adler, N., \& Rehkopf, D. (2008). U.S. disparities in health: Descriptions, causes, and mechanisms. Annual Review of Public Health, 29, 235-252.

Adler, N., \& Snibbe, A. (2003). The role of psychosocial processes in explaining the gradient between socioeconomic status and health. Current Directions in Psychological Science, 12, 119-123.

American Psychological Association. (2007). Report of the APA task force on socioeconomic status. Washington, DC: American Psychological Association.

Angrist, J., \& Lang, K. (2004). Does school integration generate peer-effects? Evidence from Boston's Metco program. The American Economic Review, 94(5), 16131634.

Araya, R., Dunstan, F., Playle, R., Thomas, H., Palmer, S., \& Lewis, G. (2006). Perceptions of social capital and the build environment and mental health. Social Science and Medicine, 62, 3072-3083.

Argote, L., \& Ingram, P. (2000). Knowledge transfer: A basis for competitive advantage in firms. Organizational Behavior and Human Decision Processes, 82, 150-169. 
Arcidiacono, P., \& Nicholson, S. (2005). Peer effects in medical school. Journal of Public Economics, 89, 327-350.

Ardasheva, Y., Tretter, T. R., \& Kinny, M. (2012). English language learners and academic achievement: Revisiting the threshold hypothesis. Language Learning, 62(3), 769-812.

Aronson, E., \& Bridgeman, D. (1979). Jigsaw groups and the desegregated classroom: In pursuit of common goals. Personality and Social Psychology Bulletin, 5(4), 438446.

Aronson, E., \& Patnoe, S. (1997). The jigsaw classroom: Building cooperation in the classroom (2nd ed.). New York: Addison Wesley.

Aronson, E., \& Patnoe, S. (2011). Cooperation in the classroom: the jigsaw method (3rd ed.). London: Pinter and Martin.

Austin, J. R. (2003). Transactive memory in organizational groups: The effects of content, consensus, specialization, and accuracy on group performance. Journal of Applied Psychology, 88, 866-878.

Banks, K. (2001). The Effect of School Poverty Concentrations in WCPSS. Research Watch. Evaluation and Research Report No. 01.21.

Battle, J., \& Lewis, M. (2002). The increasing significance of class: The relative effects of race and socioeconomic status on academic achievement. Journal of Poverty, $6(2), 21-35$. 
Benner, A.D., Boyle, A.E., \& Sadler, S. (2016). Parental involvement and adolescents' educational success: The roles of prior achievement and socioeconomic status. Journal of Youth and Adolescence, 45, 1053-1064. doi: 10.1007/s10964-016$0431-4$

Benner, A., \& Wang, Y. (2014). Demographic marginalization, social integration, and adolescence educational success. Journal of Youth and Adolescence, 43, 16111627.

Berkowitz, R., Moore, H., Astor, R. A., \& Benbenishty, R. (2017). A research synthesis of the associations between socioeconomic background, inequality, school climate, and academic achievement. Review of Educational Research, 87(2), 425469. doi: $10.3102 / 0034654316669821$

Betebenner, D. (2009). Norm- and criterion-referenced student growth. Educational Measurement: Issues and Practice, 29(4), 42-51.

Blau, P.M. (1977). Inequality and heterogeneity. New York: Free Press.

Blau, J.R., Lamb, V. L., Stearns, E., \& Pellerin, L. (2001). Cosmopolitan environments and adolescents' gains in social studies. Sociology of Education, 74, 121-138.

Bloom, M. (1999). The performance effect of pay dispersion on individuals and organizations. Academy of Management Journal, 42, 25-40.

Bollen, K., Glanville, J., \& Stecklov, G. (2001). Socioeconomic status and class in studies of fertility and health in developing countries. Annual Review of Sociology, 27, 153-185. 
Bornstein, M., \& Bradley, R. (2003). Socioeconomic status, parenting, and child development (Eds.). Mahwah, NJ: Lawrence Erlbaum.

Brand, S., Felner, R., Shim, M., Seitsinger, A., \& Dumas, T. (2003). Middle school improvement and reform: Development and validation of school-level assessment of climate, cultural pluralism, and school safety. Journal of Educational Psychology, 95, 570-588. doi: 10.1037/0022-0663.95.3.570

Breen, R. (2005). Foundations of class analysis in the Weberian tradition. In E.O. Wright (Eds.), Alternative foundations of class analysis (pp. 41-69). Cambridge, UK: Cambridge University Press.

Brown v. Board of Educ. 347 U.S. 483 (1954).

Bryk, A., \& Schneider, B. (2002). Trust in schools: A core resource for improvement. New York, NY: Russell Sage Foundation.

Burnett, K., \& Farkas, G. (2009). Poverty and family structure effects on children's mathematics achievement: Estimates from random and fixed effects models. The Social Science Journal, 46, 297-318.

Caldas, S.J., \& Bankston, C. (1997). Effect of school population socioeconomic status on individual academic achievement. The Journal of Educational Research, 90(5), 269-277.

Caldwell, G., \& Ginther, D. (1996). Differenees in learning styles of low socioeconomic status for low and high achievers. Education, 117(1), 141-148. 
Carman, K.G., \& Zhang, L. (2012). Classroom peer effects and academic achievement: Evidence from a Chinese middle school. China Economic Review, 23, 223-237.

Carmichael-Murphy, M. F., \& Carpenter, B. W. (2017, April). Stumbling in the dark: Principal sensemaking of PBIS policy and practice in racially diverse schools. Paper presented at the American Education Research Association Annual Meeting, San Antonio, TX.

Chen, X., Chang, L., Liu, H., \& He, Y. (2008). Effects of the peer group on the development of social functioning and academic achievement: A longitudinal study in Chinese children. Child Development, 79(2), 235-251.

Cherng, H.Y., Calarco, J.M., \& Kao, G. (2013). Along for the ride: Best friends' resources and adolescents' college completion. American Educational Research Journal, 50(1), 76-106.

Cohen, E. G., \& Lotan, R. A. (1995). Producing equal-status interaction in the heterogeneous classroom. American Educational Research Journal, 32(1), 99120.

Cook, R. D., \& Weisburg, S. (1982). Residuals and influence in regression. New York: Chapman and Hall.

Costa-Font, J., \& Gil, J. (2004). Social interactions and the contemporaneous determinants of individuals' weight. Applied Economics, 36, 2253-2263.

Cowen, J. M. (2017). Who are the homeless? Student mobility and achievement in Michigan 2010-2013. Educational Researcher, 46(1), 33-43. 
Crotty, M. (1998). The foundations of social research: Meaning and perspective in the research process. Thousand Oaks, CA: Sage.

Cummins, J. (1979). Linguistic interdependence and the educational development of bilingual children. Review of Educational Research, 49, 222-251.

Cummins, J. (2000). Language, power, and pedagogy: Bilingual children in the crossfire. Clevedon, UK: Multilingual Matters.

Darwin, C. (1871). The descent of man and selection in relation to sex. London: J. Murray.

Delpit, L. (2006). Other people's children: Cultural conflict in the classroom. New York: The New Press

Diem, S., \& Brooks, J. S. (2013). "Integration was a solution, but integration does not address quality education": A conversation about school desegregation with Dr. Michael A. Middleton. Teachers College Record, 155, 1-11.

Diem, S., \& Frankenberg, E. (2013). The politics of diversity: Integration in an era of political and legal uncertainty. Teachers College Record, 115, 1-30.

Diemer, M., Mistry, R., Wadsworth, M., Lopez, I., \& Reimers, F. (2013). Best practices in conceptualizing and measuring social class in psychological research. Analysis of Social Issues and Public Policy, 13(1), 77-113.

Engle, P.L., \& Black, M.M. (2008). The effect of poverty on child development and educational outcomes. Annals of the New York Academy of Sciences, 1136, 243256. 
Eshelman, A., \& Rottinghaus, P. (2014). Viewing adolescents career futures through the lens of socioeconomic status and social class. The Career Development Quarterly, 63, 320-332.

Every Student Succeeds Act of 2015, Pub. L. No. 114-195, §2, 129 Stat. 1177 (2015).

Ewijk, R., \& Sleegers, P. (2010). The effect of peer socioeconimc status on student achievement: A meta-analysis. Education Research Review, 5, 134-150.

Field, A. (2013). Discovering statistics using IBM SPSS statistics (4th ed.). Thousand Oaks, CA: Sage.

Finkelstein, S., \& Hambrick, D.C. (1996). Strategic leadership: Top executives and their effects on organizations. Minneapolis, MN: West Educational Publishing.

Fischer, C. (1976). The Urban Experience. New York: Hardcourt Brace Jevanovich.

Frankenberg, E. (2016, November). Examining equity implications of local response to federal limits on diversity: Louisville, Kentucky's integration policy. Paper presented at the Annual Convention of the University Council for Educational Administration, Detroit, MI.

Frankenberg, E. (2017). Assessing segregation under a new generation of controlled choice policies. American Educational Research Journal, 54(1S), pp. 219S-250S. doi: $10.3102 / 0002831216634462$

Gaviria, A., \& Raphael, S. (2001). School-based peer effects and juvenile behavior. Review of Economics and Statistics, 83, 257-268. 
Goldhaber, D., Lavery, L., \& Theobald, R. (2015). Uneven playing field? Assessing the teacher quality gap between advantaged and disadvantaged students. Education Researcher, 44, 293-307.

Guryan, J. (2004). Desegregation and black dropout rates. The American Economic Review, 94(4), 919-943.

Hampton v. Jefferson County Board of Education, 102 F. Supp. 2 d 358 (W.D. Ky. 2000).

Hanushek, E., Kain, J., Markman, J., \& Rivken, S. (2003). Does peer ability affect student achievement? Journal of Applied Econometrics, 18, 527-544.

Hanushek, E., Kain, J., \& Rivkin, S. (2004). Disruption versus Tiebout improvement: The costs and benefits of switching schools. Journal of Public Economics, 88, 1721-1746.

Harrington, A., Marshall, B., \& Müller, H. (2006). Encyclopedia of social theory. New York, NY: Routledge.

Harrison, D.H., \& Klein, K.J. (2007). What's the difference?: Diversity constructs as separation, variety, or disparity in organizations. Academy of Management Review, 32(4), 1199-1228.

Harwell, M., \& LeBeau, B. (2010). Student eligibility for a free lunch as an SES measure in education research. Educational Researcher, 39(2), 120-131.

Harwell, M., Maeda, Y., \& Lee, K. (2004, April). Replicating and extending Whites (1982) Meta-analysis of the relationship between SES and student achievement. 
Paper presented at the annual meeting of the American Education Research Association, San Diego, CA.

Hattie, J. (2008). Visible learning: A synthesis of over 800 meta-analyses relating to achievement. New York, NY: Routledge.

Hauser, R. M., \& Warren, J. R. (1997). Sociological indexes for occupations: A review, update, and critique. Sociological Methodology, 27, 177-298.

Hill, N. E., \& Tyson, D. F. (2009). Parental involvement in middle school: A metaanalytic assessment of the strategies that promote achievement. Developmental Psychology, 45, 740-763. doi: 10.1037/a0015362

Ho, A. D. (2008). The problem with "proficiency": Limitations of statistics and policy under No Child Left Behind. Educational Researcher, 37(6), 351-360.

hooks, b. (1994). Teaching to transgress: Education as the practice of freedom. New York: Routledge.

Hornstra, L., Van der Veen, I., Peetsma, T., \& Volman, M. (2015). Does classroom composition make a difference: Effects on developments in motivation, sense of classroom belonging, and achievement in upper primary school. School Effectiveness and School Improvement, 26(2), 125-152. doi: $10.1080 / 09243453.2014 .887024$

Hummer, R. A., \& Hernandez, E. M. (2013). The effect of educational attainment on adult mortality in the United States. Population Bulletin, 68(1), 2-16. 
Huynh, M., Borrell, L., \& Chambers, E. (2014). Maternal education and excessive gestational weight gain in New York City, 1991-2001: The effect of race/ethnicity and neighborhood socioeconomic status. Maternal Child Health Journal, 18, 139-145.

Ingersoll, R.M. (2003). The teacher shortage: Myth or Reality? Educational Horizons, $81(3), 146-152$.

Isenberg, E., Max, J., Gleason, P., Potamites, L., Santillano, R., \& Hock, H. (2013). Access to effective teaching for disadvantaged students. Washington, DC: National Center for Education Evaluation and Regional Assistance, U.S. Department of Education.

Jackson, S.E., Joshi, A., \& Erhardt, N.L., (2003). Recent research on team and organizational diversity: SWOT analysis and implications. Journal of Management, 29, 801-830.

Jefferson County Public Schools. (2015, December 15). Vision 2020: Excellence with equity. Retrieved January 09, 2016, from https://www.jefferson.kyschools.us/sites/default/files/Vision-2020-Brochure.pdf

Jeynes, W. H. (2007). The relationship between parental involvement and urban secondary school student academic achievement. Urban Education, 42, 82-110. doi: $10.1177 / 0042085906293818$

Johnson, T., Hsiao, W., Jani, A., \& Master, V. (2011). Increased mortality among Hispanic testis cancer patients independent of neighborhood socioeconomic status: A SEER study. Journal of Immigrant Minority Health, 13, 818-824. 
Jones, B., \& Nichols, E. (2013). Cultural competence in America's schools: Leadership, engagement, and understanding. Charlotte, NC: Information Age Publishing. ISBN: 978-1-62396-174-9.

Kang, C. (2007). Academic interactions among classroom peers. Applied Economics, $39,1531-1544$.

Kentucky Legislature. (2017). Legislative Record Online: HB 151 voting summary. Retrieved from http://www.lrc.ky.gov/record/17RS/HB151.htm

Kessler, R., \& Cleary, P. (1980). Social class and psychological distress. American Sociology Review, 45, 463-478.

Kozol, J. (1991). Savage inequalities: Children in America's schools. New York, NY: Broadway Books.

Labaree, D. (2010). Someone Has to Fail: The Zero-Sum Game of Public Schooling (3rd ed.). Cambridge, MA: Harvard University Press.

Ladson-Billings, G. (2001). Crossing over to Canaan: The journey of new teachers in diverse classrooms. San Francisco, CA: Jossey-Bass.

Lam, G. (2014). A theoretical framework for the relationship between socioeconomic status and academic achievement. Education, 134(3), 326-331.

Lau, D.C., \& Murnighan, J.K. (1998). Demographic diversity and faultlines: The compositional dynamics of organizational groups. Academy of Management Review, 23, 325-340. 
Lee, J.C., \& Krugman, J. (2013). Latino school concentration and academic performance among Latino children. Social Science Quarterly, 94(4), 1-30. doi: 10.1111/j.1540-6237.2012.00935.x

Lerner, R. M. (2004). Liberty: Thriving and civic engagement among America's youth. Thousand Oaks, CA: Sage.

Lippman, L., Burns, S., \& McArther, E. (1996). Urban schools: The challenge of location and poverty. Washington, D.C.: U.S. Department of Education, Office of Educational Research and Improvement.

Locke, K.D., \& Horowitz, L.M. (1990). Satisfaction in interpersonal interactions as a function of similarity in level of dysphoria. Journal of Personality and Social Psychology, 58, 823-831.

Lucas, S.R., Beresford, L., Chapa, J., \& Yun, J. (2010). What counts as evidence in educational settings? Rethinking equity, diversity, and reform in the 21st Century. Review of Research in Education, 34, 25-84.

Ludwig, J., Duncan, G., \& Hirschfield, P. (2001). Urban poverty and juvenile crime: evidence from a randomized housing mobility experiment. Quarterly Journal of Economics, 116, 655-679.

Malecki, C., \& Demaray, M. (2006). Social support as a buffer in the relationship between socioeconomic status and academic performance. School Psychology Quarterly, 21(4), 375-395. 
Martens, P., Chateau, D., Burland, E., Finlayson, G., Smith, M., Taylor, C., Brownell, M., Nickel, N., Katz, A., Bolton, J., \& the PATHS Equity Team. (2014). The effect of neighborhood socioeconomic status on education and health outcomes for children living in social housing. American Journal of Public Health, 104(11), 2103-2113.

Mather, T., Banks, E., Joshy, G., Bauman, A., Phongsavan, P., \& Korda, R. (2014). Variation in health inequalities according to measures of socioeconomic status and age. Australian and New Zealand Journal of Public Health, 38(5), 436-440.

Matthews, K., Gallo, L., \& Taylor, S. (2010). Are psychosocial factors mediators of socioeconomic status and health connections? Annals of the New York Academy of Sciences, 1186, 146-173.

McCoy, D. C., Roy, A. L., \& Sirkman, G. M. (2013). Neighborhood crime and school climate as predictors of elementary school academic quality: A cross-lagged panel analysis. American Journal of Community Psychology, 52, 128-140. doi: $10.1007 / \mathrm{s} 10464-013-9583-5$

McCravy, C. (2016). Letter: Norton Commons affordable housing. The Courier Journal. Retrieved from: http://www.courier-journal.com/story/opinion/readers/ 2016/09/25/letter-norton-commons-affordable-housing/91084524/

McKown, C., \& Weinstein, R. (2008). Teacher expectations, classroom contexts, and the achievement gap. Journal of School Psychology, 40, 235-261.

McLeod, J., \& Kessler, R. (1990). Socioeconomic status differences in vulnerability to undesirable life events. Journal of Health and Social Behavior, 31, 162-172. 
Mehana, M., \& Reynolds, A. (2004). School mobility and achievement: A meta-analysis. Children and Youth Services Review, 26(1), 93-119.

Menzer, M., \& Torney-Purta, J. (2012). Individualism and socioeconomic diversity at school as related to perceptions of the frequency of peer aggression in fifteen countries. Journal of Adolescence, 35(5), 1285-1294.

Meredith v. Jefferson County Board of Education et al., 551 U.S. 701 (2007).

Milliken v. Bradley, 418 U.S. 717 (1974).

Milner, H. R. (2007). Race, culture, and researcher positionality: Working through dangers seen, unseen, and unforeseen. Educational Researcher, 36(7), 388-400.

Milner, H. R. (2010). Start where you are but don't stay there: Understanding diversity, opportunity gaps, and teaching in today's classrooms. Cambridge, MA: Harvard Education Press.

Morgan, P. L., Frisco, M. L., Farkas, G., \& Hibel, J. (2010). A propensity score matching analysis of the effects of special education services. The Journal of Special Education, 43(4), 236-254.

Muñoz, M. A., Clavijo, K. G., \& Koven, S. G. (1999). Educational equity in a reform environment: The effect of socio-economic status on student achievement. Paper presented at the Annual Meeting of the University Council for Education Administration, Minneapolis, MN. Retrieved from http://files.eric.ed.gov/fulltext/ED466524.pdf 
New Teacher Center. (2014). TELL Kentucky Student Achievement and Teacher Retention Analysis. Retrieved on: 10/30/15, from: http://www.tellkentucky.org/uploads/File/KY\%20std\%20achieve\%20\%20teach\% 20retent\%20brief_to\%20post.pdf

No Child Left Behind (NCLB) Act of 2001, 20 U.S.C.A. $§ 6301$ et seq. (West 2003).

Noddings, N. (2012). Philosophy of education (3rd ed.). Boulder, CO: Westview Press.

Noguera, P. (2003). City schools and the American dream: Reclaiming the promise of public education. New York: Teachers College Press.

Oakes, J. (2005). Keeping track: How schools structure inequality (2nd ed.). New Haven: CT: Yale University Press.

Oaks, J., \& Rossi, P. (2003). The measurement of SES in health research: Current practice and steps toward a new approach. Social Science and Medicine, 56, 769784.

Orfield, G. (2017). Racial division, research, and building human capital. American Educational Research Journal, 54(1S), 164-167.

Orfield, G., Frankenberg, E., \& Garces, L. (2008). Statement of American social scientists of research on school desegregation to the U.S. Supreme Court in Parents v. Seattle School District and Meredith v. Jefferson County, Urban Review, 40, 96-136. 
Orfield, G., Kucsera, J., \& Siegel-Hawley, G. (2012). E pluribus... separation: Deepening double segregation for more students. Los Angeles, CA: The Civil Rights Project/Projecto Derechos Civiles.

Orfield, G., \& Lee, C. (2005). Why Segregation Matters: Poverty and Educational Inequality. Cambridge, MA: Civil Rights Project, Harvard University.

Otts, C., \& Konz, A. (2015, December 4). Black students increasingly concentrated in some JCPS schools. WDRB. Retrieved from: http://www.wdrb.com/story/ 30672447/sunday-edition-black-students-increasingly-concentrated-in-some-jcpsschools

Parents Involved in Community Schools v. Seattle School District No. 1 et al., 551 U.S. 701 (2007).

Pearce, D. (1980). Breaking down the barriers: New evidence on the impact of metropolitan desegregation on housing patterns. Washington, DC: National Institute of Edcuation.

Peterson, C., Rauscher, G., Johnson, T., Kirschner, C., Barrett, R., Kim, S., Fitzgibbon, M., Joslin, C., \& Davis, F. (2014). The association between neighborhood socioeconomic status and ovarian cancer tumor characteristics. Cancer Causes Control, 25, 633-637.

Pfeffer, J., \& Langton, N. (1993). The effect of wage dispersion on satisfaction, productivity, and working collaboratively: Evidence from college and university faculty. Administrative Science Quarterly, 38, 588-606. 
Phillips, K., Rodosky, R., Muñoz, M., \& Larsen, E. (2009). Integrated schools, integrated futures?: A case study of school desegregation in Jefferson County, Kentucky. In C. E. Smreakar \& E. B. Goldring (Eds.), From the courtroom to the classroom: A shifting landscape of school desegregation (pp. 239-269). Cambridge, MA: Harvard Education Press.

Ream, R. K. (2003). Counterfeit social capital and Mexican-American underachievement. Educational Evaluation and Policy Analysis, 23(3), 237-262.

Reardon, S., Grewall, E., Kalogrides, D., \& Greenberg, E. (2012). Brown fades: The end of court-ordered desegregation and the resegregation of American schools. Journal of Policy Analysis and Management, 31(4), 876-904.

Reardon, S. F., \& Rhodes, L. (2011). The effects of socioeconomic school integration policies on racial school desegregation. In E. Frankenberg \& E. Debray (Eds.), Integrating schools in a changing society (pp. 187-207). Chapel Hill, NC: University of North Carolina Press.

Reynolds, A. J., \& Wolfe, B. (1999). Special education and school achievement: An exploratory analysis with a central-city sample. Educational Evaluation and Policy Analysis, 21(3), 249-69.

Rhodes, A., \& DeLuca, S. (2014). Residential mobility and school choice among poor families. In A. Lareau \& K. Goyette (Eds.), Choosing homes, choosing schools (pp. 137-165). New York, NY: Russell Sage. 
Rhodes, A., \& Warkentien, S. (2017). Unwrapping the suburban "package deal": Race, Class, and School Access. American Educational Research Journal, 54(1), 168189.

Richards, M., Stroub, K., Heilig, J., \& Volonnino, M. (2012). Achieving diversity in the Parents Involved era: Evidence for geographic integration plans in metropolitan school districts. Berkley Journal of African-American Law and Policy, 14, 65-95.

Ross, A. (2016, October 27). JCPS tool checks odds on getting desired school. The Courier Journal. Retrieved from: http://www.courierjournal.com/story/news/education/2016/10/27/jcps-tool-checks-odds-gettingdesired-school/92824466/

Ross, C., \& Mirowsky, J. (2008). Neighborhood socioeconomic status and health: Context or composition. City and Community, 7(2), 163-179.

Rostron, B. L., Boies, J. L., \& Arias, E. (2010). Education reporting and classification on death certificates in the United States. Vital Health Statistics, 2(151), 1-16.

Rumberger, R., \& Larson, K. (1998). Student mobility and the increased risk of high school dropout. American Journal of Education, 72(1), 6-21.

Ryan, J. (2016, September 14). Fight over affordable housing erupts in Norton Commons. WFPL. Retrieved from: http://wfpl.org/fight-over-affordablehousing-erupts-norton-commons/

Saporito, S., \& Lareau, A. (1999). School selection as a process: The multiple dimensions of race in framing educational choice. Social Problems, 46(3), 418-439. 
Sass, T.R., Hannaway, J., Xu, Z., Figlio, D.N., \& Feng, L. (2012). Value added of teachers in high-poverty schools and lower poverty schools. Journal of Urban Economics, 72, 104-122.

Schagen, I., \& Hutchison, D. (2003). Adding value in educational research: The marriage of data and analytical power. British Educational Research Journal, 29, 749-765. doi: 10.1080/0141192032000133659

Schmidt-Wilson, S. (2013). Social class and expectations of rural adolescents: The role of Parent Expectations. The Career Development Quarterly, 61,

Shafer, S. S. (2016, September 25). Affordable housing plans prompts concerns in Norton Commons. The Courier Journal. Retrieved from: http://www.courierjournal.com/story/opinion/readers/2016/09/25/letter-norton-commons-affordablehousing/91084524/

Siegel, P.A., \& Hambrick, D.C., (2005). Pay disparities within top management groups: Evidence of harmful effects on performance in high-technology firms. Organization Science, 16; 259-274.

Siegel-Hawley, G. (2011). Is class working? Socioeconomic student assignment plans in Wake County, North Carolina, and Cambridge, Massachusetts. In E. Frankenberg, \& E. DeBray (Eds.), Integrating schools in a changing society: New policies and legal options for a multiracial generation (pp. 208-222). Chapel Hill, NC: University of North Carolina Press. 
Siegel-Hawley, G., \& Frankenberg, E. (2014). Southern slippage: Growing school segregation in the most desegregated region of the country. Los Angeles, CA: The Civil Rights Project/Proyecto Derechos Civiles.

Simpson, E.H. (1949). Measurement of diversity. Nature, 163, 688. doi: $10.1038 / 163688 \mathrm{a} 0$

Sirin, S. (2005). Socioeconomic status and academic achievement: A meta-analytic review of research. Review of Educational Research, 75(3), 417-453.

Slavin, R. E. (1980). Cooperative learning in teams: State of the art. Educational Psychologist, 15(2), 93-111.

Stevens, J. (1996). Applied Multivariate Statistics for the Social Sciences (3rd ed.). Mahwah, NJ: Lawrence Erlbaum Associates.

Sun, R., \& Van Ryzin, G. (2014). Are performance management practices associated with better outcomes?: Empirical evidence from New York Public Schools. American Review of Public Administration, 44(3), 324-338.

Tam, M.Y.S., \& Bassett, G.W. (2004). Does diversity matter?: Measuring the impact of high school diversity on freshman GPA. The Policy Studies Journal, 32(1), 129143.

Taylor, K., \& Frankenberg, E. (2016, November). Student assignment policies and segregation: A special approach to examining segregation of school catchment areas. Paper presented at the Annual Convention of the University Council for Educational Administration, Detroit, MI. 
Tsui, A.S., Ashford, S.J., St. Clair, L., \& Xin, K.R. (1995). Dealing with discrepant expectations: Response strategies and managerial effectiveness. Academy of Management Journal, 38, 1515-1543.

Tsui, A.S., \& Gutek, B.A. (1999). Demographic differences in organizations: Current research and future directions. Lanham, MD: Lexington Books.

U.S. Census, 2010

Van Dorn, R., Bowen, G., \& Blau, J. (2006). The impact of community diversity and consolidated inequality on dropping out of high school. Family Relations, 55, 105-118.

Vandenberghe, V. (2002). Evaluating the magnitude and the stakes of peer effects analyzing science and math achievement across OECD countries. Applied Economics, 34, 1283-1290.

Vanderhaar, J., Muñoz, M., Rodosky, R. (2006). Leadership as accountability for learning: The effects of school poverty, teacher experience, previous achievement, and principal preparation programs on student achievement. Journal of Personnel Evaluation in Education, 19, 17-33.

Vardardottir, A. (2013). Peer effects and academic achievement: a regression discontinuity approach. Economics of Education Review, 36, 108-121.

White, K. (1982). The relation between socioeconomic status and academic achievement. Psychological Bulletin, 91, 461-481. 
Zhan, M., \& Sherraden, M. (2011). Assets and liabilities, educational expectations, and children's college degree attainment. Children and Youth Services Review, 33, 846-854. doi: 10.1016/j.childyouth.2010.12.006 


\title{
APPENDIX A
}

Geographic Distribution of Socioeconomic Categories by U.S. Census Block Group:

\author{
Jefferson County, Kentucky
}

Three Factor ACS 2009 (Orfield \& Frankenberg, 2011)

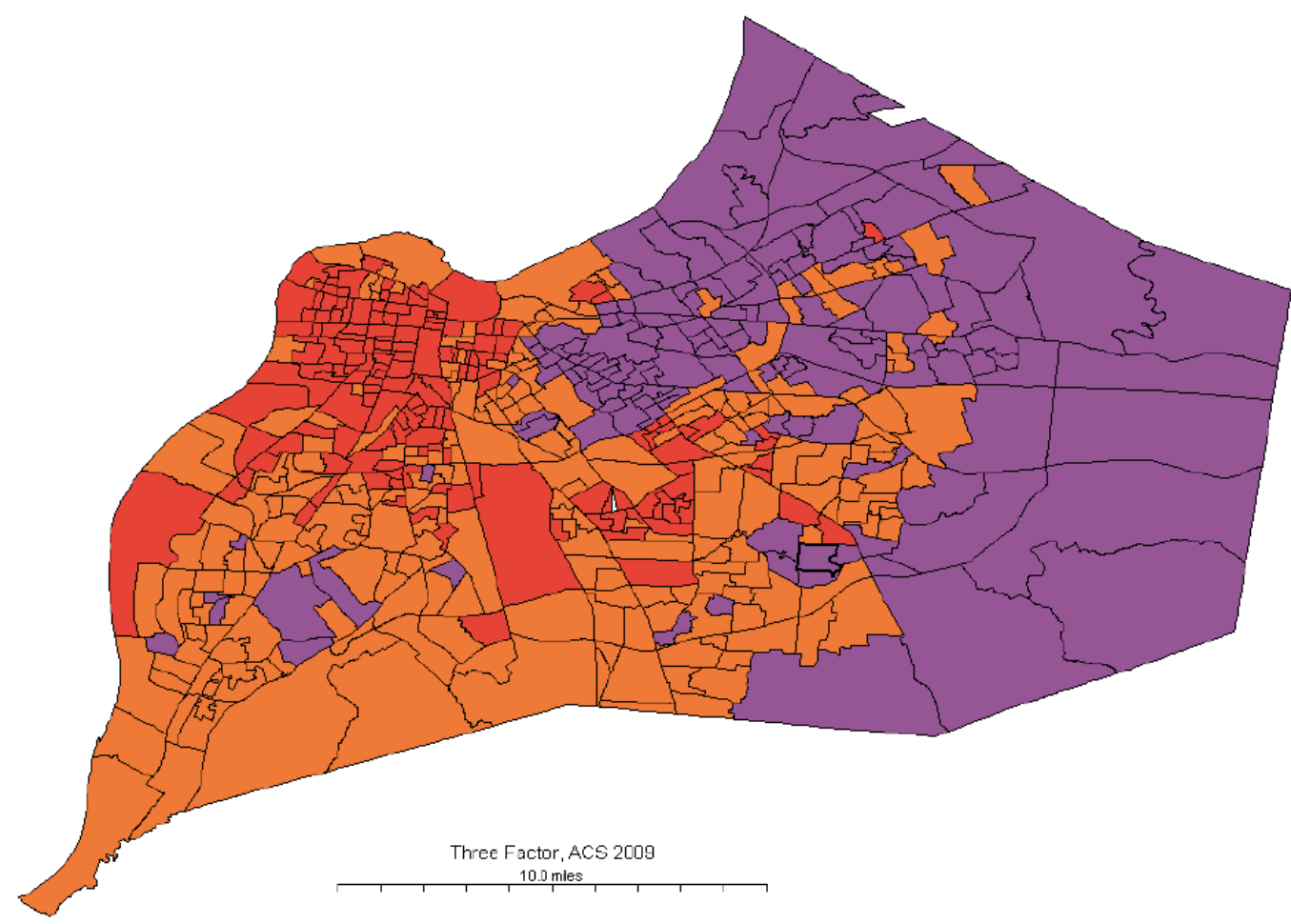

Category 1 (Lowest SES Census Block)

Category 2

Category 3 (Highest SES Census Block) 


\section{APPENDIX B}

\section{RESEARCHER POSITIONALITY}

The purpose of this paper is to provide a vessel through which to document my own reflection, using the framework of Milner (2007) on researching the self, researching the self in relation to others, and shifting from self to system. This reflection was conducted through the lens of my experience as a researcher through my dissertation (currently in progress): Diversity for Diversity's Sake? The Relationship between Diversity and School-Level Academic Achievement (Wisman, 2017). As the title suggests, my dissertation seeks to explore the relationship between a school's diversity operationalized by Jefferson County Public School's (JCPS's) diversity index (DI), in relation to other metrics of socioeconomic diversity analogous to component factors of the DI. My dissertation provides an exquisite context to investigate the interactions between poverty and race, as the DI includes more traditional measures of socioeconomic status (SES), income and education attainment, with race; the call for which is made explicit by the APA Task Force on Socioeconomic Status (APA, 2007). Furthermore, Milner (2007) states, "SES does not necessarily account for all of the inequitable situations in which people find themselves... race, culture, and gender, among other factors, may play central and independent roles in how people live and experience life" (p. 390). Another purpose of my dissertation is to investigate the viability of two competing theories on the relationship between socioeconomic diversity and academic 
achievement (Blau, Lamb, Searns, \& Pellerin, 2001; Lam, 2013) by conceptualizing and operationalizing diversity in different ways (Harrison \& Klein, 2007). The following research questions are posed:

1. To what extent does the diversity index (DI) predict academic achievement, as measured by the percentage of students within a school scoring proficient or higher on state-mandated reading and math tests, while controlling for other school input and process variables?

2. What is the relative efficacy of the DI in predicting academic achievement to analogous student-level components: (a) the proportion of students receiving free or reduced-price lunch (FRL), (b) the proportion of students belonging to a historically marginalized race/ethnicity, and (c) the interaction between FRL and race/ethnicity, while controlling for other school input and process variables?

3. To what extent does the DI significantly predict academic growth among students of low socioeconomic status (SES), while controlling for other school input and process variables?

4. Does school-level socioeconomic heterogeneity significantly improve academic growth among students of lower socioeconomic status (SES), while controlling for other school input and process variables?

The remainder of the present paper is intended to imbue a greater sense of "racial and cultural awareness, consciousness, and positionality" (p. 388) by reflecting on the possibility of what Milner (2007) calls dangers seen, unseen and unforeseen lurking in wait as I make my way through the penultimate task of my doctoral program, the 
demonstration of my scholarly prowess as a researcher of education: my dissertation journey. I begin by providing a reflection centered squarely on myself as a researcher, indeed by researching the self. I then continue by providing some reflections on researching the self in relation to others, namely the participants included in my study. Finally, I shift this reflection from self to system, by considering the nature of race, racism, and culture in the context of my dissertation, JCPS and the broader community served by the school district, the Louisville Metro Area (Louisville, Kentucky).

\section{Researching the Self}

Milner (2007) provides the framework for reflection undertaken herein: by engaging in critical self-reflection centered about a set of seven questions for researchers to raise "awareness and consciousness known (seen), unknown (unseen), and unanticipated (unforeseen) issues, perspectives, epistemologies, and positions" (p. 395). The first two questions posit the need to make explicit one's own racial and cultural heritage and to explore the ways in which one's own racial and cultural backgrounds influence how one experiences the world, what is emphasized in one's research, and how one evaluates and interprets others and their experiences. Furthermore, to explore how one knows. I am privileged. I was born into privilege, the son of a White medical doctor and a highly educated White mother, who has been a registered nurse, turned theologian, turned therapist. I was raised in an American Baptist church and the public schools of West Virginia until, following my parents' divorce where we encountered situational poverty. I found myself spending my early adolescence in the Southern Baptist Church and in the public schools of a very different, cosmopolitan environment: Louisville. Through these institutional, cultural, and social settings I became aware of the fact that 
there was diversity in which people experienced the world and that our experiences and even perceptions of reality are formed by our contexts. Moreover, I came to the understanding that some contexts are not privileged.

I still struggle with my privilege; I struggle to conscientiously reflect on the ways that my own privilege augment my own perceptions of reality. Perhaps this is why I came to immerse myself in the beautiful objectivity (or so I though) and the brilliance of the way in which knowledge is created in science. When I use the word science, I use the term in the objectivist epistemological stance. It was not until I enrolled in my doctoral program that I came to understand the beauty, as well as the axioms of alternative epistemologies. This deeper understanding of my own ontological roots and an appreciation of other epistemologies provides the basis for my reflection on Milner's (2007) remaining questions for researching the self: How do I negotiate and balance my racial and cultural selves in society and in my research? What are and have been the contextual nuances and realities that help shape my racial and cultural ways of knowing? What racialized and cultural experiences have shaped my research designs, practices, approaches, epistemologies and agendas?

Through my undergraduate studies I learned about our common ancestry (that is, the evolution of our species) and learned to appreciate our diversity in light of our unity through our evolutionary heritage. I learned how the scientific method, incomparable in understanding the nature of our world, relative to other ways of knowing, lead to an understanding of an indifference of race. Race is not a biological construct recognized by modern evolutionary biology, in spite of the fact that Darwin himself used the term explicitly in the context of human evolution throughout his writings and its explicit 
application in The Descent of Man and Selection in Relation to Sex (1871). This instilled a notion of colorblindness that dominated my axiomatic purview of the social world for the better part of a decade, well into my twenty's. This notion was not challenged until I was a thirty year-old science teacher of five years, and had recently gained employment as a Biology teacher at a high-minority/high-poverty urban public high school in Louisville. And then more so, when I enrolled in this doctoral program.

This was the first time in which I, as a White man, was in a learning environment in which I was a minority - one of only three White men enrolled in my cohort. It was in the first semester of this program that I gave more than an ancillary reflection of the possibility that my own implicit biases shape the way I live and experience life, and approached my own research. I began to grapple with my own colorblindness and challenged my epistemological roots that stemmed from my training in the hard sciences. I came to understand that while race was not a biological construct it most certainly exists as a sociological construct that has deep-seeded effects on the lived experience of all, but especially in the lives of the poor and marginalized. Indeed, I have come to understand my positionality as one who professes an anti-racist agenda while continuously grappling with my own privilege as a practitioner of education and as a novice researcher of education.

I have alluded to my axiological, ontological, and epistemological roots through my early life experiences and my training in the hard sciences. My awakening to the reality of race and social class and a shifting of my axiomatic drive to advocate, as an ally, for the poor and marginalized, has coincided with a shift in my own ontological and epistemological purview. Throughout the course of my doctoral studies in the social 
sciences, I have gained a larger perspective on the nature of reality and acceptance of other ways of knowing. I have conducted research grounded in the constructivist and interpretivist epistemologies and have gained an appreciation of alternative ways of knowing in light of these perspectives, while also conducting research grounded in the objectivist perspective. My dissertation utilizes a correlational design in order to understand relationships among variables. On the surface, such a post-positivistic methodological approach brings into question the need to spend time considering my own positionality as a researcher. After all, such an approach is firmly grounded in the objective, no? Well, not as much as I had thought: I have been overwhelmed by the realization that even quantitative methods are riddled with subjective decisions.

By virtue of the fact that the schools that comprise the sample in my dissertation contain students of diverse racial, socioeconomic, and cultural backgrounds different from my own, the interpretations of my results may be riddled with dangers seen, unseen, and unforeseen; after all, how does one come to know aside from one's own lived experiences. With respect to the seen, I acknowledge the possibility that others may use the results of my study to base arguments against structuring within-school diversity. I also recognize the possibility that my research may have unseen consequences - in particular for the poor and marginalized students in the district. As an objectivist, I feel as though I should be disinterested in how my results pan out. However, my axiological beliefs and values about the importance of young people to experience diversity are deep and I acknowledge the potential of my implicit biases to augment my interpretations of the results. 


\section{Researching the Self in Relation to Others}

As noted above, the cultural, racial, and historical backgrounds of my participants are myriad, as my study sample includes nearly all of the A1 schools in JCPS $(\mathrm{N}=130)$. My study categorizes students into groups based on their own and their neighborhoods' socioeconomic and racial demographics. The nature of the variables operationalized in my study create categories by which to group certain types of people as well as their level of academic achievement. In doing so, I recognize that individuals which make up the schools in my study are necessarily reduced in the complexity of their own cultural, racial, social, and educational realities. As a product of JCPS, I recognize that some proportion of the students in some of the schools in my study are likely to have had similar experiences to my own, but I also acknowledge the vast diversity in the lived experiences of my participants. The school district is a very different place than it was when I attended primary and secondary school in JCPS. I acknowledge that many of the students in this district identify from myriad racial, cultural, and national origins that are quite disparate from my own and about which I know very little. Nonetheless, I am attempting to negotiate and balance my own interests and research agenda with those of my participants through the axiological foundation of my study, which is about equity in educational outcomes.

When considering the questions posed by Milner (2007) in researching the self in relation to others, I am prompted to reflect on the beliefs of my participants about race and culture. As I ponder this proposition, I draw heavily from my readings of hooks (1994), Jones and Nichols (2013), Kozol (1991), Milner (2010), Noddings (2012), and Noguera (2003), among others. I draw from the axioms of Critical Theory and from 
Critical Race Theory in particular. I acknowledge the marginalization of many of the participants in my study and the tensions inherent in my own and in their convictions and beliefs about race and culture. Given the size of schools in my sample, there is no way I can know all of the beliefs on race and culture of the students they serve, but my knowledge is informed by reading many scholarly works that have shaped the axioms of social justice to which I now hold dear. Yet, while I have worked very closely with many students in my time as a teacher and now as a consultant in several high-minority/highpoverty schools across the district, I acknowledge that my knowledge and understanding about the beliefs of all students is broken and incomplete, at best. I can only approach my understandings of the whole picture through generalizations about the marginalization of minority and poor students. In other words, I don't know.

I acknowledge my privilege as a researcher; when I consider how I negotiate and balance my own interests and research agendas with those of my participants, I try to keep, at the forefront of my mind, the need to be an ally to the marginalized. Indeed, the axiological foundation of my study is about equity in education, in particular, as it pertains to student assignment. I have come to understand that disparities exist within the school district within which I am deeply immersed and I'm sure that conflict exists between my own axiological foundations and those of my participants: again, I cannot know. I can hope that the results of my dissertation can be used to help to mitigate the disparities of the situations in which the marginalized experience life. I can also take great care in thinking through the meaning of my results and in constructing the discussion. Here, I believe I can use my axioms to frame the interpretation of my results. Indeed, I do not think it possible to make meaning of any analysis without grounding it in 
one's axioms, in addition to the literature base. I can only be cognizant of the fact that the interests of my participants may be quite divergent from my own. This I have learned from Milner (2007, 2013) and Crotty (1998).

On political nuances that may have shaped the realities and ways of knowing imbued in my participants, I reflect heavily on the political landscape of America over the past year as well as on the political landscape of the present school system. My participants construct their realities through their experiences, not only those in their day to day exchanges with others, but in their perceptions of themselves framed by the realities of the political systems in which they are immersed. I like to believe that I am an ally, and that I understand how the deafening proclamations of our current president and his supporters influence the perceptions about how society values the beliefs and values of my participants - especially the marginalized. I cannot know this, of course. But I like to think that there is some level of consistency between my own axioms about the importance of structuring diversity in schools and their axioms about it. I do have anecdotes to support the contrary, however. For example, when I see Black preachers from churches and other faith-based organizations that are located in the West End of Louisville advocating for Charter schools, I question the consistency between my own axioms and the axioms of many of my participants and their families and communities. Why should they have any reason to believe that structuring school diversity is a good thing when they see blatant inequities in the schools that they or their children attend in a school district that has received national acclaim for its level of integration through busing? When it is often their own middle and high school children who are disproportionately affected by busing. 


\section{Shifting from Self to System}

Historically, Louisville has been seen as a bastion of racial integration in its schools and has been lauded, nationally, for its commitment to structuring within school diversity. Yet, the reality of de facto racial and socioeconomic segregation persists in the larger community. The cultural, racial, and historical landscape of JCPS students in Louisville is complicated, but is not too different from many large, urban public school systems that desegregated in the American south in the 1960s and 1970s. Since the 1930s, more White and affluent families have dispersed from Louisville's West and South Ends and migrated to the East End; leaving the western portions of the city with higher concentrations of people living in poverty and of minority status. In addition, the South End of the city, once a stronghold for middle class White families is now one of the most socioeconomically and racially diverse regions in the city. While noting these general trends, it should also be noted that across the city enclave neighborhoods have emerged in which the socioeconomic and racial diversity of a neighborhood is low, creating a mosaic of socioeconomic and racial enclaves with poorer and browner people tending to live in the west and southwest portions of the city while more affluent and White people live in the eastern portions of the city. Louisville is a diverse community, with pockets of isolation within. This has isolated people of different racial, cultural, and SES in the community; and while the school system attempts to structure racial diversity within schools, in spite of recent challenges in the courts, including the United States Supreme Court (Meredith v. Jefferson County Board of Education et al., 2007), challenges abound. 
A major challenge can be seen in an apparent temporal shift in the political will of powerful actors who influence JCPS from one that allegedly values diversity to one that perhaps does not. For example, my dissertation begins with a recent statement from a school board member who professed her personal belief that school diversity is no longer as important to the community as it once was. Furthermore, a recently proposed bill in the State House attempted to disintegrate JCPS's student assignment plan in favor of neighborhood schools; a proposal which most certainly would have resegregated schools, due in part to explicitly-racist historical housing policies that have shaped the current geographic distribution of demographic groups in Louisville. As demographic shifts continue to play out across America and in Louisville, another challenge for JCPS is how to best serve students whose families have immigrated from all across the globe. It brings the entire meaning of the word diversity back into consideration and further exacerbates unseen and unforeseen consequences of policies and practices to educate all students in.

While the district professes its commitment to diversity, they say "the differences of each are assets of the whole" (JCPS, 2015, p. 2), I have come to understand that the students who are marginalized (either by race/ethnicity, SES, or their intersection) bear the brunt of the tracking system that is pervasive in JCPS. The school district expends tremendous resources to structure school diversity while simultaneously providing families with some degree of school choice; yet student assignment is ultimately decided by the district. When one examines the disparities between schools, in terms of school input/process variables and academic outcomes, it becomes apparent that there is a 
relationship between inequities structured through the student assignment plan (SAP) and inequities in educational outcomes for marginalized students and families.

A point of reflection for which I would be remiss if I did not mention, is the inconsistencies in the level of cultural competency of educators that I have personally witnessed in the many schools that I serve, and is supported through other data, such as disproportionate representation of minority groups among students who receive disciplinary suspensions. These inconsistencies pose barriers that are both seen and unseen in my own interactions with students and educators in these schools. I often worry about the barriers to learning and thriving (see Lerner, 2004) that are inherent in differential levels of cultural competency among educators in the school system in which I work and conduct research. A danger perhaps unforeseen by many is the lack of safe spaces for marginalized students to engage in Positive Youth Development (Lerner, 2004).

A final thought on my reflection in shifting from the self to the system is not an insignificant one. When I reflect on this shift, it has become apparent that it is very difficult to separate myself from the system in which I work and conduct research, JCPS. I am a product of JCPS and my children are students in JCPS. I have worked as an educator and as a consultant in this district for nearly a decade. I am entrenched in this system. Although I know that my purview brought about by my experiences working in the district have been shifting, especially in light of my doctoral studies, I must make explicit to myself and any other readers of this reflection, that my immersion in this system is, on one hand, beneficial as a researcher. I have institutional knowledge that allows me to navigate the system in order to work, conduct research, and to better serve 
my own children than would likely be possible if I did not have this institutional knowledge. For example, I have contacts with people who work in JCPS's Office of Data Management. These contacts certainly made me feel at ease in openly communicating with research technicians to more quickly procure the data necessary to conduct my research. I recognize that such a relationship might be seen by some as providing the opportunity for dangers seen, unseen, and possibly unforeseen. To this concern, I must profess the resolve in the systems and structures in place within JCPS. For example, at one point in the data collection process I was told that I could not have aggregated data from 10 elementary schools because there were less than 10 low SES students attending each of those schools. While I did not hesitate to ask for an exception, one was not granted. A solution was found that satisfied my data needs, but never were any protocol intended to protect the anonymity of students ever broken. I only wonder if my entrenchment in JCPS and knowing people in the Office of Data Management affected my comfort in asking for an exception. I recognize the possibility of dangers unseen and unforeseen that may arise from my own immersion in the system in which I conduct research. For example, it is possible that my lived experiences have biased my own purview of the system such that my own axiological, ontological, and epistemological foundations prevent me from seeing dangers that may arise from my work, research, and as a community stakeholder in JCPS.

In concluding this reflective exercise, I feel as though a consideration of the reflective questions of Milner (2007), while they may have not provided absolute clarity, have at least forced me to consider the possible dangers: seen, unseen, and unforeseen that lie, or indeed may be hiding, in wait. This exercise has, at the very least, piqued my 
sensitivities to the importance of considering my own positionality as I inch ever closer to the end of my dissertation journey. Especially now, in a time when I am writing to report the results of my analysis and am pondering the implications, indeed the meaning, left to be made from my analysis. I have made explicit the fact that much regarding the racial and cultural axioms of my participants is unknown. I will depend upon the literature base, of those mentioned herein and others, as a lens through which to interpret the meaning of my results and to consider the possible implications - especially to the poor and marginalized, to whom I have explicitly expressed my intentionality as an ally and advocate for equity in their education. 


\section{CURRICULUM VITAE}

NAME: $\quad$ Richard Aaron Wisman

ADDRESS: 6606 Morocco Dr.

Louisville, KY 40214

DOB: $\quad$ Morgantown, West Virginia - June 7, 1981

EDUCATION

\& TRAINING:
B.S. Biology

University of Louisville

1999-2009

M.A., Teaching

University of the Cumberlands

2010-2012

Ed.D., Educational Leadership and Organizational Development University of Louisville

2014-2017

AWARDS: David L. Clark Graduate Student Research Seminar in Educational Administration \& Policy

2017

PROFESSIONAL ORGANIZATIONS: American Educational Research Association

\section{PUBLICATIONS:}

\section{NATIONAL MEETING PRESENTATIONS}

Wisman, R. A., Carmichael-Murphy, M. F., Davis, C. C., \& Ingle, W. K. (November, 2017). Uplifting voices: Black student unions, positive youth development, and equity. A paper presented at the Annual Convention of the University Council for educational Administration, Denver, Colorado.

Ingle, W. K., \& Wisman, R. A. (November, 2016). Revisiting and extending the work of Cowen and Fowles: A historical analysis of Kentucky teacher contracts. . A paper presented at the Annual Convention of the University Council for Educational Administration, Detroit, Michigan. 
Wisman, R. A., Muñoz, M. A., \& Stevens, P. T. (November, 2016). Evaluating the efficacy of tier 2 mathematic interventions at a high-minority/high-poverty allboys middle school. A paper presented at the Annual Convention of the Consortium for Research on Educational Assessment and Teaching Effectiveness, Louisville, Kentucky.

Davis, C. C., Ellison, J., Kissling, R., \& Wisman, R. A. (November, 2015). Understanding the experiences of principals in persistently low achieving schools: A phenomenology. A paper presented at the Annual Convention of the University Council for Education Administration, San Diego, California.

\section{REFEREED JOURNALS}

Ingle, W. K., \& Wisman, R. A. (in press). Extending the work of Cowen and Fowles: A historical analysis of Kentucky teacher contracts. Educational Policy. 